\title{
Examining the Efficacy of a 1-Session Brief Behavioral Activation Intervention with University Students with Mild to Moderate Depressive Symptoms
}

D. Lee McCluskey

Follow this and additional works at: https://researchrepository.wvu.edu/etd

\section{Recommended Citation}

McCluskey, D. Lee, "Examining the Efficacy of a 1-Session Brief Behavioral Activation Intervention with University Students with Mild to Moderate Depressive Symptoms" (2017). Graduate Theses, Dissertations, and Problem Reports. 6192.

https://researchrepository.wvu.edu/etd/6192

This Dissertation is protected by copyright and/or related rights. It has been brought to you by the The Research Repository @ WVU with permission from the rights-holder(s). You are free to use this Dissertation in any way that is permitted by the copyright and related rights legislation that applies to your use. For other uses you must obtain permission from the rights-holder(s) directly, unless additional rights are indicated by a Creative Commons license in the record and/ or on the work itself. This Dissertation has been accepted for inclusion in WVU Graduate Theses, Dissertations, and Problem Reports collection by an authorized administrator of The Research Repository @ WVU.

For more information, please contact researchrepository@mail.wvu.edu. 
Examining the Efficacy of a 1-Session Brief Behavioral Activation Intervention with University Students with Mild to Moderate Depressive Symptoms

D. Lee McCluskey M.S.

Dissertation submitted to the Eberly College of Arts and Sciences at West Virginia University in partial fulfillment of the requirements for the degree of

Doctor of Philosophy in

Clinical Psychology

\author{
Natalie Shook, Ph.D., Chair \\ Daniel McNeil, Ph.D. \\ Amy Fiske, Ph.D. \\ Aaron Metzger, Ph.D. \\ Julie Brefczynski-Louis, Ph.D.
}

Department of Psychology

West Virginia University

Morgantown, WV

2017

Keywords: Depression, Mindfulness, Behavior Therapy, Behavioral Activation Copyright 2017 D. Lee McCluskey 


\begin{abstract}
Examining the Efficacy of a 1-Session Brief Behavioral Activation Intervention with University Students with Mild to Moderate Depressive Symptoms

D. Lee McCluskey

Early intervention may increase the likelihood that students with depressive symptoms complete degree requirements and reduce the likelihood of negative outcomes associated with depression in adults. The goal of this study was to assess the efficacy of a 1-session version of Brief Behavioral Activation Treatment for Depression-Revised (BATD-R; Lejuez, Hopko, Acierno, Daughters, \& Pagoto, 2011) with university students with mildto-moderate depressive symptoms. Participants $(N=39)$ were randomly assigned to either a clinical or a control group. Participants completed measures of depression, negativity bias, mindfulness, and experiential avoidance at pre-intervention, two-week follow-up, and one-month follow-up. Both ITT and study completer analyses were conducted. There was a significant main effect of session, such that depression scores decreased from Session 1 to Session 2 and increased from Session 2 to Session 3. Depression scores at Session 3 were significantly lower than scores at Session 1. No significant differences were identified for condition at any time, suggesting that factors other than the intervention were causing the changes in depression scores. Implications for theory and practice are discussed.
\end{abstract}




\section{Acknowledgments}

I would like to express my gratitude for Natalie Shook, Ph.D., my mentor and dissertation chair, without whom this study would not have been possible. I am deeply indebted to Dr. Shook for the work that she has done to foster my growth throughout my graduate school career, and across the design and execution of this study. I would also like to acknowledge Daniel W. McNeil, Ph.D., who has provided indispensable guidance to me throughout my academic journey. Dr. McNeil spent considerable time training and supervising study therapists, for the clinical component of this study and I am truly indebted to him as well. I would also like to thank Rebecca Gilley, B. S.; Cameron Ford, M. S., Cierra Brooks Edwards, M.S., Britany Liebsack, M. S.; Richard Cui, M. S., and Daniel Stephenson, M. S., for their work on this project. 


\section{Table of Contents}

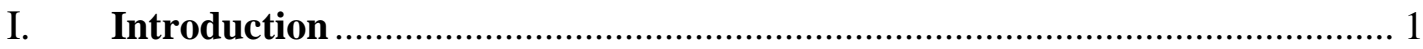

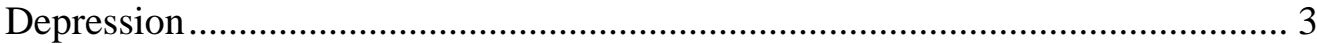

Depression among University Students ................................................. 6

Depression Treatment and University StudentsError! Bookmark not defined. Cognitive Therapy ............................................................................ 9

Interpersonal Psychotherapy ....................................................... 10

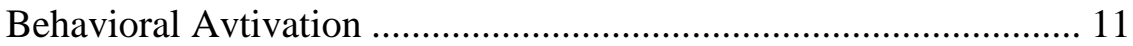

Brief Behavioral Activation for Depression....................12

Constructs Associated with Depression.............................17

Negative Cognitive Biases and Depression.....................18

Experiential Avoidance and Depression......................22

Mindfulness and Depression................................24

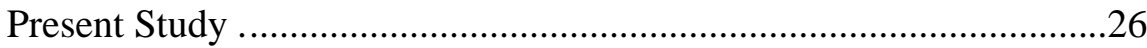

Hypotheses ........................................................................... 27

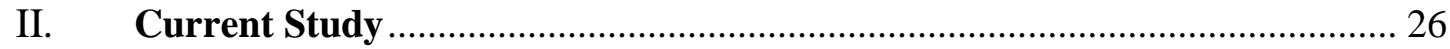

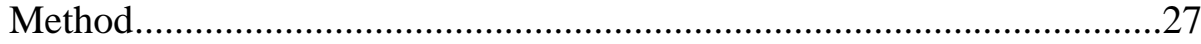

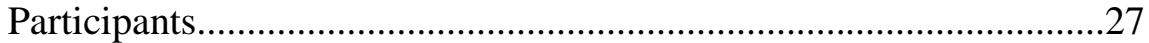

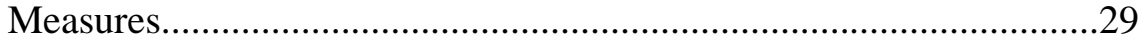

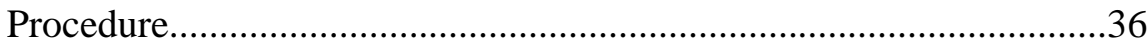

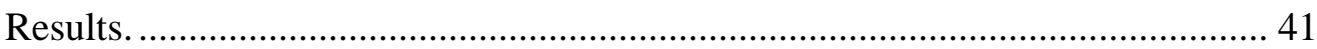

Preleminary Analyses ...................................................................... 41

Intervention Adherence and Study Completion........................................42

Intervention Efficay Analyses................................................................ 43

Secondary Outcome Variable Analyses................................................... 46

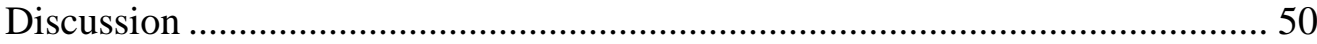

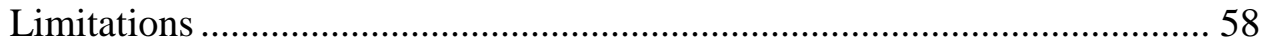

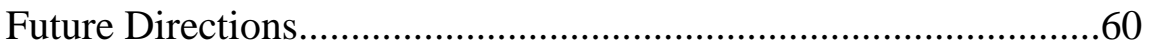

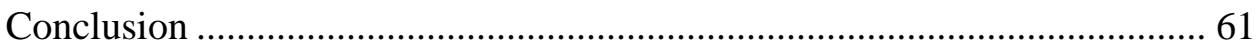

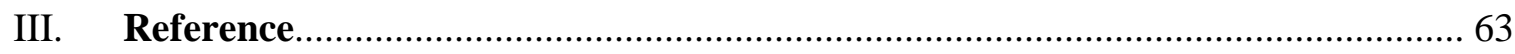

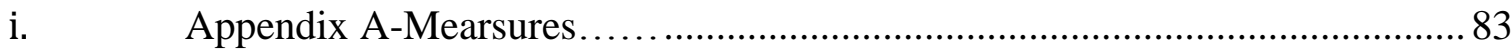

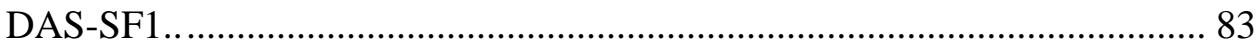

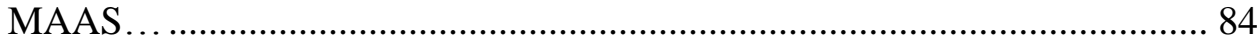

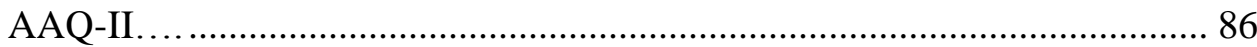

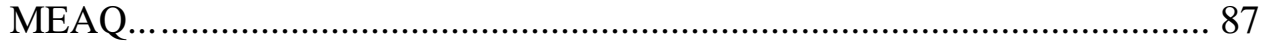

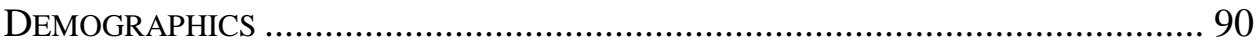

ii. Appendix B- BATD-R Modified Protocol for BATD treatment of Moderately Depressed College Students.................................................93

iii. Tables and Figures................................................................... 126 
Examining the Efficacy of a 1-Session Brief Behavioral Activation Intervention with University

\section{Students with Mild to Moderate Depressive Symptoms}

Depression affects approximately $6.7 \%$ of the adult population in the United States, making depression the leading cause of disability for Americans aged 15-44 years. Among university students, the prevalence for depression is much higher and has increased significantly over the past two decades, with current rates of depression between $15 \%$ and $20 \%$ (American College Health Association, 2007; Benton, Robertson, Tseng, Newton, \& Benton, 2003; Gallagher, 2007; Gawrysiak, Nicholas, \& Hopko, 2009; Voelker, 2003). Further, in 2014, the National Survey of College Counseling Centers reported a 58\% increase in students presenting with clinical levels of depression over the past five years (Gallagher, 2014).

Because depressed individuals tend to lose interest in, and motivation for, engaging in important and enjoyable activity, depression can affect the productivity of university students. In fact, the findings of the 2011 American College Health Association-National College Health Assessment indicated that $30.3 \%$ of American college students reported feeling "so depressed that it was difficult to function" (p. 13) at some time within the previous 12 months (American College Health Association, 2012). Depression that individuals experience while university students may affect not only their academic performance and ability to complete degree requirements, but may also affect their lives for years to come. Lower educational attainment is associated with higher levels of depression and lower earning capacity in adulthood (Bruce, Takeuchi, \& Leaf, 1991; Eisenberg, Golberstein, \& Hunt, 2009; Everson, Maty, Lynch, \& Kaplan, 2002; Hysenbegasi, Hass, \& Rowland, 2005; Roberts, Stevenson, \& Breslow, 1981; Stansfeld, \& Marmot, 1992). 
Early intervention might decrease the likelihood that university students who experience depressive symptoms withdraw from their university prior to completing degree requirements. It may also decrease the impact of other threats to health and productivity associated with depression as adults, such as increased risk of suicide, increased risk for heart attack, and an estimated 70 billion dollars per year lost due to costs associated with depression (Greenberg, Stiglin, Finkelstein, \& Berndt, 1993; National Institutes of Mental Health, 1999; Young, Rygh, Weinberger, \& Beck, 2007). However, evidence for the efficacy of treatments which directly address depressive symptoms in university students is sparse. Therefore, little is known about which interventions work within this population. However, evidence suggests that very brief interventions are necessary with this population, as the average number of sessions attended by students in college counseling centers is 3.3 (Draper, Jennings, Baron, Erdur, \& Shankar, 2002). The purpose of this project was to test the efficacy of a one-session modification of Brief Behavioral Activation Treatment for Depression-Revised (BATD-R; Lejuez, Hopko, Acierno, Daughters, \& Pagoto, 2011; Lejuez, Hopko, \& Hopko, 2001) with university students who selfreported mild to moderate depressive symptoms. Also, negative cognitive biases, mindfulness levels, and experiential avoidance were examined as secondary outcome variables due to their relations with depression (Hayes et al., 2004; Gotlib, Krasnoperova, Yue, \& Joormann, 2004; McDermut, Haaga \& Bilek, 1997; Rinck \& Becker, 2005). It was hypothesized that greater reductions in depression scores would be observed in university students with mild to moderate scores on the Beck Depression Inventory-II (BDI-II; Beck, Steer, \& Brown, 1996) at two-weeks and one-month following a one-session intervention based on BATD-R compared to a no treatment control group. It was also hypothesized that greater reductions in negativity bias and experiential avoidance, as well as greater increases in mindfulness level, would be observed at 
two-weeks and one-month in the same university student sample following the same one-session intervention based on BATD-R compared to a no treatment control group.

\section{Depression}

Depression is a mood disorder characterized by symptoms that include, but are not limited to, sadness, hopelessness, and feelings of guilt, worthlessness, or helplessness. Symptoms also may include loss of interest or pleasure in activities, decreased energy, restlessness or irritability, changes in appetite or weight, sleep related problems, and thoughts of death and/or suicide (National Institutes of Mental Health, 2015). Several factors are proposed to play a role in the etiology and maintenance of depression. For instance, cognitive behavioral theories of depression suggest that biases toward responding to negative stimuli (Beck, 1987; Eiszenman, et al., 2003; Gotlib, Krasnoperova, Yue, \& Joormann, 2004; McDermut, Haaga \& Bilek, 1997; Rinck \& Becker, 2005) and the tendency to avoid unwanted experiences (i.e., experiential avoidance) underlie depression (Hayes et al, 2004; Hayes, Wilson, Gifford, Follette, \& Strosahl, 1996; Lejuez, Hopko, \& Hopko, 2001). More recently, the role of mindfulness has been highlighted as a trait that may buffer against depression (Paul, Stanton, Greeson, Smoski, \& Wang, 2012) and a practice that is efficacious in reducing symptoms of depression and relapse of depressive symptoms (see Goyal et al., 2010, for review).

Cognitive biases toward negative stimuli (i.e., negativity biases and dysfunctional attitudes) have previously been shown to influence the etiology and maintenance of depression (Beck, 2002; Gotlib et al., 2004; Williams, Matthews, \& Macleod, 1996). Beck (1987) asserted that individuals with depression experiences a type of selective focusing where the positive aspects of an individual's experiences are excluded. This bias appears to be more at the level of interpretation than observation, but a prolonged negativity bias is characteristic of the disordered 
cognitive processes found in depressed individuals (Beck, 1987). There is considerable evidence supporting this assertion (e.g., Eiszenman, et al., 2003; Gotlib, Krasnoperova, Yue, \& Joormann, 2004; McDermut, Haaga \& Bilek, 1997; Rinck \& Becker, 2005; Shook Fazio \& Vasey, 2007).

Along with negative cognitive biases, experiential avoidance, or the unwillingness to remain in contact with an unwanted private experience such as a painful emotion or negative cognition, is also associated with depression (Georgio et al., 2010; Forman et al., 2007; Mould et al., 2007). Experiential avoidance may play a role in the development and maintenance of depression by expanding the range of situations that are perceived to be aversive (Hayes et al., 2004). For example, an individual may experience depressive symptoms such as decreased pleasure in activities, behavioral predispositions toward inactivity, and feelings of guilt. The individual may have thoughts such as, "I feel so guilty about my poor performance on that test" or "It feels bad when I have to get out of bed and go to class." The individual experiences psychological pain while thinking about the experience as well as the pain caused by the acute experience. However, as time goes by and the pain caused by the acute experience subsides, the individual begins to target the negatively evaluated thoughts and feelings about the experience as the focus of avoidance. Further, the individual might begin to make active attempts to avoid these thoughts and feelings (Hayes et al., 2004), which may result in thoughts of suicide, or engaging in some other avoidance behavior (i.e., not going to class to avoid thinking of the test, refusing to get out of bed, or excessive alcohol use). As depression worsens, the reinforcement for important and previously enjoyable activities decreases due to continued avoidance of said activities (Bruce, Takeuchi, \& Leaf, 1991; Hysenbegasi, Hass, \& Rowland, 2005).

Mindfulness may play a substantial role in reducing depressive symptomatology and preventing relapse. Trait mindfulness may provide a buffer against the development of 
depressive symptoms and lead to improved treatment outcomes through reducing depressive cognitions. Hofman, Sawyer, Witt, and Oh (2010) conducted a meta-analysis of mindfulnessbased treatments for depression and anxiety. Overall, mindfulness-based treatments were efficacious in reducing symptoms of depression, with a large effect size (Hedges' $\mathrm{g}=0.95$ ). These findings suggest that greater levels of mindfulness might have an inverse relation with depressive symptoms. Mindfulness may be particularly useful in reducing relapse of depressive symptoms. Teasdale and colleagues (2000) evaluated a mindfulness-based treatment for depression as a relapse prevention program for individuals who experienced recurrent depressive episodes. A group of currently recovered recurrently depressed patients $(N=145)$ were randomly assigned to either continue with treatment as usual (TAU) or to receive a mindfulness-based intervention in addition to TAU. The mindfulness-based intervention significantly reduced risk of relapse for individuals with 3 or more previous major depressive episodes which comprised 77\% of the total sample. Paul, Stanton, Greeson, Smoski, and Wang (2012) found that trait mindfulness might reduce vulnerability to depression by buffering against rumination and negative bias, and by reducing automatic emotional responding, as well. Further, Frewen, Lundberg, MacKinley, and Wrath (2011) found that trait mindfulness was negatively associated with both frequency and difficulty letting go of depressive cognitions.

Overall, depression is a multi-faceted disorder, characterized by distinct behavioral, emotional, and cognitive patterns. Growing evidence has linked depression to mindfulness, negativity bias, and experiential avoidance. Although depression affects individuals across the life span, one group that has received relatively little attention is university students and the impact that depression may have on academic success, as well as future career, social, and health outcomes. 


\section{Depression among University Students}

In 2015 , roughly $13 \%$ of college students reported being diagnosed with or treated for depression in the past 12 months (American College Health Association, 2015). Further, 50\% reported feeling that things were hopeless within the last 12 months, and $64 \%$ of students who were no longer attending college left for a mental health related reason (American College Health Association, 2015; National Alliance on Mental Illness, 2012). Although many factors (e.g., under-preparation for the required academic work; financial pressures; competing claims of family and jobs) influence attrition, it is possible that the significant deleterious effects that depression has on academic performance are, in part, responsible for many of these dropouts (Hysenbegasi, Hass, \& Rowland, 2005; Symonds, Schwartz, \& Ferguson, 2011).

Hysenbegasi and colleagues (2005) found that depression resulted in lower academic performance, decreased opportunities for learning, decreased ability to demonstrate learning (i.e., being able to absorb and retain information), and may have negatively affected college students' future career paths. On average, depressed university students present with grades that are half a letter grade lower than their non-depressed peers (Hysenbegasi, Hass, \& Rowland, 2005). Eisenberg, Golberstein, and Hunt (2009) found that depression was not only a significant predictor of lower GPA, but also the likelihood of leaving the university prior to degree completion. While controlling for socioeconomic status, gender, race, GPA at admission, GPA for previous semesters, and admission test scores, each point increase on depression scores was associated with a $0.31 \%$ increase in the probability of leaving the university prior to degree completion. These negative academic outcomes in turn might worsen the student's depression, as considerable evidence supports higher depression rates for individuals with lower educational attainment (Bruce, Takeuchi, \& Leaf, 1991; Everson, Maty, Lynch, \& Kaplan, 2002; Roberts, 
Stevenson, \& Breslow, 1981; Stansfeld, \& Marmot, 1992). Furthermore, the lower academic performance may lead to future economic difficulties as well (United States Census Bureau, 2014).

The 2014 Current Population Survey (CPS) reported a 14.8\% poverty rate for the United States, and of those individuals living in poverty, only $5 \%$ had a bachelor's degree or more, compared to roughly $10 \%$ who completed some college but did not complete their degrees (United States Census Bureau, 2014). Individuals who do not complete their degrees are twice as likely to live in poverty. Further, individuals who completed a bachelor's degree earned approximately $40 \%$ more per week than individuals who completed only high school or some college (United States Department of Labor, 2014). These numbers are important when discussing depression because approximately $12 \%$ of 18-39 year olds below the poverty level also experience depression. For individuals aged 40-59 years, this number jumps to roughly $22 \%$, making these individuals more vulnerable to the previously discussed problems related to health and productivity associated with depression (Pratt \& Brody, 2008).

Indeed, there are health and social benefits to educational attainment. Cohn and Geske (1992) found that individuals with higher education levels experienced lower mortality rates in their respective age groups and that parents' educational attainment was positively correlated with better overall health in their children, when controlling for income (Porter, 2002; Cohn \& Geske, 1992). Individuals who complete post-secondary education tend to be less likely to rely on public assistance or to be arrested for criminal activity (Watts, 2001). They also provide more tax revenue, are more likely to vote in elections, donate blood, and are more active in their communities (Baum \& Payea, 2005; Dee, 2003; Watts, 2001). Depression makes all of these benefits less likely because of its association with lower educational attainment (Bruce, 
Takeuchi, \& Leaf, 1991; Everson, Maty, Lynch, \& Kaplan, 2002; Roberts, Stevenson, \& Breslow, 1981; Stansfeld, \& Marmot, 1992).

Early intervention for depressive symptoms may increase students' chances to remain in university and possibly reap some of these benefits. That is, there may be a reduced likelihood that the student, with age, will experience further negative effects of depression on health such as increased risk for heart attack, and frequent complications in stroke, diabetes, and cancer (National Institutes of Mental Health, 1999; Young, Rygh, Weinberger, \& Beck, 2007). Furthermore, early intervention and reduced depressive symptoms may also prove to benefit society, as the individual is likely to engage in civic and community activities, as well as being more likely to help support social and community programs through the tax revenue that they provide (Baum \& Payea, 2005; Dee, 2003; Watts, 2001). Together, these findings suggest that reducing depression symptoms in university students may provide benefits to the individual and to society. As such, it is imperative to develop and disseminate efficacious treatments for depressive symptoms within the university student population.

\section{Depression Treatment with University Students}

Currently, antidepressant medications are the most commonly used treatment for depression (Pratt et al., 2011). In fact, from 2005 to 2008 antidepressants were the most frequently prescribed drugs used by persons aged 18-44 years (Pratt et al., 2011). The 2011 National Survey of College Counseling Centers reported that $26 \%$ of the students seen in college counseling centers were on psychiatric medications. This number increased from 9\% in 1994 to $17 \%$ in 2000 to $20 \%$ in 2003 (Gallagher, 2014). Generally, antidepressant medications significantly reduce the symptoms associated with depression for as long as the individual 
continues to take the medication (American Psychiatric Association, 2000). However, there are a number of drawbacks to the use of antidepressants.

First, antidepressant medications have many side effects including, but not limited to, anxiety, agitation, interference with sexual function, gastrointestinal disturbances, weight gain, and insomnia (Dobson et al., 2008; Ferguson, 2001). Second, there is little evidence that antidepressant medications affect the cognitive, emotional, and behavioral mechanisms associated with depression, and therefore, many individuals are encouraged to continue taking medication indefinitely to reduce the likelihood of having their depressive symptoms return (Hollon et al., 2002). Additionally, a financial burden accompanies antidepressant medication. Although less expensive than psychotherapy during the acute phase of treatment (i.e., when the individual is actively attending psychotherapy sessions), antidepressant medication is considerably more expensive than psychotherapy, because the individual must continue taking (and purchasing) the medication indefinitely (Antonuccio, Thomas, \& Danton, 1997; Dobson et al., 2008). Thus, alternative treatments should be encouraged or used in conjunction with antidepressants, as antidepressant medications may not be the most practical or efficacious treatments for long-term reduction of depressive symptoms.

A variety of psychotherapy models are efficacious in the treatment of depression, such as Cognitive Therapy (Beck, Rush, Shaw, \& Emory, 1979), Interpersonal Therapy (Klerman, Weissman, Rounsaville, \& Chevron, 1984), and Behavioral Activation (Martell, Addis, \& Jacobson, 2001). With each form of psychotherapy, depression is conceptualized differently. Thus, the treatment protocols vary substantially.

Cognitive Therapy. During Cognitive Therapy (CT), depressed individuals are conceptualized as having depressive underlying schemata, structures that guide cognitive 
processes, which lead to cognitive distortions. These cognitive distortions tend to center on being helpless, hopeless, and without worth as individuals. The therapist then utilizes prescriptive methods to help the individual to gain objectivity to refute these cognitive distortions. The premise of the treatment model is that once an individual can recognize the irrationality of their cognitive distortions, then their depressive symptoms will dissipate through the changing of their underlying schemata (Beck, 1970). CT for depression is typically delivered over 8 to 16 sessions (Society of Clinical Psychology, 2015a).

Interpersonal Therapy for Depression. Within this model, depression is conceptualized as a response to difficulties and conflicts that an individual is experiencing within their personal relationships (e.g., conflict with another person, life changes that affect how the individual feels about themselves and others, grief and loss, or difficulty in beginning or maintaining relationships). The therapist focuses on helping the individual improve problems associated with their interpersonal relationships, as well as other interpersonal circumstances, that may be related to their depression (Society of Clinical Psychology, 2015b). There are four potential areas on which the therapist may focus: interpersonal role transition, interpersonal role disputes, grief, or interpersonal sensitivity. Across these foci, the therapist works to help the individual accept whatever changes they are experiencing and to make whatever changes are necessary to embrace their current circumstances. As change occurs in interpersonal therapy, it is assumed that progress in interpersonal resolution is followed by progress in symptom reduction and vice versa. Therefore, as interpersonal problems are resolved, depressive symptoms will be reduced, and as depressive symptoms are reduced, interpersonal problems will improve (Klerman, Weissman, Rounsaville, \& Chevron, 1984). Interpersonal Psychotherapy for Depression is typically delivered over 12-16 sessions (Society of Clinical Psychology, 2015b). 
Behavioral Activation. Lewinsohn's (1974) conceptualization of depression asserts that depression is characterized primarily by a low rate of positive reinforcement. This model emphasized environmental events that lead to losses of available reinforcers (e.g., the loss of a job, resources, or relationship, and deficits on the necessary social skills to regain reinforcement once it had been lost). A behavioral activation treatment model for depression was developed based on this conceptualization (Lewinsohn, 1974), which centered on identifying and scheduling pleasurable activities with the belief that engaging in these activities would increase positive reinforcement for depressed individuals (Kanter, Busch, Weeks, \& Landis, 2008; Kanter, Puspitasari, Santos, \& Nagy, 2012; Lewinsohn, Biglan, \& Zeiss, 1976). These activities are viewed as particularly important when the individual is faced with depressive symptoms that would typically lead to avoidance behaviors (Ferster, 1973).

Contemporary Behavioral Activation (Martell, Addis, \& Jacobson, 2001) utilizes a functional contextualistic perspective (Hayes, Strosahl, \& Wilson, 1999) to conceptualize how depression affects the individual. Functional Contextualism is a philosophy of science where depressive behavior is viewed in context and utilizes James' (1907) Pragmatic Truth Criterion as a basis for the etiology of depression. The Pragmatic Truth Criterion asserts that the truth in anything exists in how well it functions in a particular capacity (James, 1907). For example, reduced engagement in important activities that are aversive, such as paying bills, enables the individual to avoid immediate discomfort, and therefore can be perceived as valid by the individual, and provide negative reinforcement through escape. The therapist aids the individual in scheduling and completing activities, provides skills training, contingency management, and allows for some focus on cognitive variables (e.g., rumination). Behavioral Activation typically occurs over 20-24 sessions (Hopko, Lejuez, Ruggiero, \& Eifert 2003a; Kanter et al., 2010). 
Summary. All of these treatments have received empirical support for their efficacy in randomized controlled trials (Dimidjian, et al. 2006; Kovacs, Rush, Beck, \& Hollon, 1981; Weissman, Klerman, Paykel, Prusoff, \& Hanson, 1974). However, the evidence of efficacious treatments for depressive symptoms with university students is very sparse, and much of it was conducted over two decades ago (Hodgson, 1981; Hogg \& Deffenbacker, 1988; Pace \& Dixon, 1993; Shaw, 1977; Taylor \& Marshall, 1977). Still, most of the evidence indicates that 6-8 sessions of cognitive, behavioral, or interpersonal treatments are efficacious with depressed university students. A practical problem with these studies is that the number of sessions utilized exceeds the number typically allotted to students by university counseling centers (Lee, 2005). Draper and colleagues (2002) surveyed 42 university members of the Research Consortium of Counseling and Psychological Services in Higher Education and found that the average number of sessions attended by students at university counseling centers was $3.3(S D=2.4)$. As such, college students may not receive the full benefit of these treatment protocols. Thus, a very brief intervention is necessary to make a substantial impact on university students experiencing depressive symptoms. Because of its brevity, as well as its ease of dissemination and implementation, Brief Behavioral Activation Treatment for Depression may show particular promise with university students.

\section{Brief Behavioral Activation Treatment for Depression}

Brief Behavioral Activation Treatment for Depression (BATD; Lejuez, Hopko, \& Hopko, 2001) is a brief, manualized, evidence based behavioral treatment for depression. The original treatment manual contained 12 sessions, but the authors recently updated the manual and reduced the total number of sessions to 10 (BATD-R; Lejuez, Hopko, Acierno, Daughters, \& Pagoto, 2011). Although influenced by Functional Contextualism, BATD and BATD-R draw heavily 
from Hernstein's Matching Law (1970) as a means of conceptualizing the mechanisms of depression. Hernstein asserted that the proportion of reinforcers received for one behavior relative to another behavior is equal to the number of times that an individual engages in the first behavior relative to the second behavior (Hernstein, 1970). Thus, depression arises from the individual receiving greater reinforcement for depressive behaviors (e.g., talking about depressed feelings, not engaging in activities, over-eating or under-eating) and less reinforcement for nondepressive behaviors (e.g., engaging in activities, self-care behavior, exercise). BATD is intended to systematically change the ratio of reinforcement for depressive to non-depressive behaviors by having individuals schedule and engage in values-based activities, thus putting the individual in contact with greater opportunity for reinforcement of non-depressed behavior (Kanter et al., 2010).

BATD-R (Lejuez, Hopko, Acierno, Daughters, \& Pagoto, 2011), the most recently updated manualized form of this treatment model, consists of 10 sessions. During session one, the therapist discusses the behavioral conceptualization of the etiology and maintenance of depressive symptoms with the individual receiving services. A daily monitoring form is introduced, and for homework, the individual is asked to track their activity and rate that activity on importance and the amount of enjoyment received by engaging in said activity. The first session ends with a discussion of the importance of the structure of the treatment.

During session two, the therapist and the individual review the individual's daily monitoring forms for the previous week and troubleshoot any difficulties that the individual may have had tracking activities. They then review the treatment rationale and complete a life areas, values, and activities inventory. This inventory covers five areas: Relationships, education/career, recreation/interests, mind/body/spirituality, and daily responsibilities. The 
individual is then asked to identify particular values within each one of these areas and to list several measurable activities related to each value. Thus, the activities arise from the individual's own values.

The individual's daily monitoring forms for the previous week are reviewed at the start of session three, and the life areas, values, and activities inventory is reviewed and edited. The individual is then asked to rank fifteen of the activities from their inventory from 1 "easiest to accomplish" to 15 "hardest to accomplish." The individual is asked to not complete any of the activities this week but to simply rank them and continue tracking daily activities for the week.

For session four, the individual's daily monitoring forms for the previous week are reviewed at the start of the session and the therapist discusses with the individual how engaging in these activities will help the individual to move toward their own values. The therapist encourages the individual to schedule only a few activities at first, approximately 1-3 that are ranked low and will be easy to achieve. For example, an individual might wish to go for a walk at 6 p.m. on Tuesday, August $8^{\text {th; }}$, they would then write this activity into their daily monitoring form for that day and at that time. Scheduling is done each week in sessions following session four. The individual continues to review daily monitoring forms and scheduling activities with the therapist in each of the remaining sessions.

In session five, behavioral contracts are introduced, where the individual is asked to make contracts with significant people in their lives for support in treatment and in recovering from depression. These contracts are reviewed in session six. During session seven, the life areas, values, and activities inventory is, once again, reviewed and edited. During session eight, the activity selection and ranking form is reviewed and edited. The contracts are reviewed and edited in session nine, and in session ten, the earlier daily monitoring forms are reviewed in order to 
examine what progress has been made since treatment began. Suggestions are made about what to do in case symptoms return. Upon completion of session ten, the individual has completed the manualized model of treatment and if needed, the therapist and client can continue with treatment or make the decision to terminate.

A growing body of research supports the efficacy of BATD in treating depressive symptoms (Freij \& Masri, 2008; Hopko et al., 2005; Hopko et al., 2011; Hopko, Lejuez, LePage, Hopko, \& McNeil, 2003.; Ryba, Lejuez, \& Hopko, 2014; Hopko et al., 2013; Snarski et al., 2011). Fewer studies have assessed the efficacy of BATD-R, as it was only released in 2011. However, the revised manual and modified versions of BATD-R have been shown to significantly reduce depression in inner-city illicit drug users with elevated depressive symptoms (Daughters et al., 2008), smokers with elevated depressive symptoms (MacPherson et al., 2010), and moderately depressed university students (Gawrysiak et al., 2009).

Although briefer than many other manualized treatments for depression, BATD-R still requires 10 sessions in order to adhere to the treatment protocol. This number exceeds the average number of university counseling center sessions completed by students (i.e., 3-4 sessions; Baron, Erdur, \& Shankar, 2002). As such, treatment attrition may be a concern (Lee, 2005). Thus, an even briefer intervention might be necessary within this population. There is evidence that suggests that the number of BATD-R sessions could be reduced further and maintain treatment efficacy.

Some evidence indicates that the benefits of BATD are achieved before the fourth session. Hopko, Robertson, and Carvalho (2009) conducted a study of sudden gains, i.e., reduction in depression scores of at least seven points on the Beck Depression Inventory-II (BDIII; Beck, Steer, \& Brown, 1996) between sessions, among 26 cancer patients who met criteria for 
major depressive disorder (Hopko et al., 2005; Hopko et al., 2008). Half of the participants received a purely behavioral 9-session intervention based on the BATD protocol, and the other half received 9-sessions of a treatment that used BATD as its foundation, but included other CBT interventions. Both treatments were efficacious in reducing depression symptoms. However, the largest reductions in BDI-II scores typically occurred prior to session 4. Similarly, Ryba, Lejuez, and Hopko (2014) found a 45\% decrease in depression scores from baseline to prior to beginning to engage in structured activities in session 4 in a group of 23 participants from a clinical trial of BATD with depressed breast cancer patients (Hopko et al., 2011). These findings align with earlier evidence that $60 \%$ to $70 \%$ of symptom improvement in depressed patients occur within the first 4 weeks of cognitive-behavioral therapy (Ilardi \& Craighead, 1994).

There is some evidence that a single session of BATD may benefit university students with moderate depression (Beck Depression Inventory-II $\geq 14$; BDI-II; Beck, Steer, \& Brown, 1996). Gawrysiak, Nicholas, and Hopko (2009) conducted a small $(N=30)$ randomized control trial utilizing a 1-session modified version of BATD with university students presenting with moderate depression symptoms. Participants were introductory psychology students who were randomly assigned to a BATD group or a no-treatment control group. Relative to the notreatment control group $(n=16)$, the BATD group $(n=14)$ showed significantly greater reductions in depression after one session at two-week follow-up. A large effect size was reported for the efficacy of the intervention $(d=1.61)$.

Although the findings from the Gawrysiak et al. (2009) study are promising, there were some limitations to the study. First, while adequately powered, the size of the sample utilized for this study was quite small, thus possibly affecting generalizability and external validity by increasing the likelihood that the sample is not representative of the overall population. Second, 
the study only reported follow-up data for two weeks following the intervention, thus limiting knowledge of treatment effects following the two weeks of activity scheduling and engagement. Third, participants on antidepressant medication or who had received psychotherapy in the last two years were excluded from the study, thus possibly increasing the likelihood of positive treatment results due to including less treatment resistant participants and also reducing external validity as these types of cases are often seen in the community.

Overall, these findings support the position that a much briefer version of BATD might be efficacious at significantly reducing symptoms of depression. However, only Gawrysiak, Nicholas, and Hopko (2009) have examined a 1-session version of BATD within a university student population. Also, no studies have examined other variables that are associated with depression and may change due to BATD. To better understand the variables that predict positive treatment outcomes and optimize therapeutic change, it is crucial that we examine variables associated with positive change and recovery from depression, as well as how their presence or absence may affect the efficacy of psychotherapy protocols (Kazdin, 2007; Keitner, Ryan, Miller, \& Norman, 1992).

\section{Constructs Associated with Depression}

According to the findings of Hopko and colleagues (2009) and Ryba and colleagues (2014), much of the positive outcomes of BATD occur prior to the process of scheduling and participating in enjoyable and important activities. This suggests that variables other than increased reinforcement for the activation of behavior and reduced reinforcement for depressive behavior may be important when examining the efficacy of BATD. Ryba and colleagues (2014) suggested that these improvements result from psychoeducation, developing a therapeutic alliance, environmental modification (i.e., reducing reinforcement for depressed behavior), and 
conducting a structured assessment of the individual's personal values, which occur in the first two sessions of BATD. However, it is possible that other factors are also important when examining these changes. Three potential variables informed by the existing depression literature are negative cognitive biases, mindfulness, and experiential avoidance.

Negative Cognitive Biases and Depression. Negative cognitive biases occur when an individual is predisposed to give greater attention to negative objects, events, or information than to positive objects, events, or information (Shook, Fazio, \& Vasey, 2007). Cognitive behavioral theories of depression assert that depressed individuals possess biases, often referred to as dysfunctional attitudes or negative cognitive style, that play a substantial role in the etiology and maintenance of depression (Abramson, Metalsky, \& Alloy, 1989; Beck, 1987). Abramson, Metalsky, and Alloy (1989) asserted that depressed individuals tend to attribute negative life events to unspecific causes. For example, an individual might attribute the loss of a job to a particular cause that is likely to affect many outcomes (i.e., I'm just stupid), rather than a specific cause such as the company was downsizing. Beck (1987) asserted that depressed individuals exhibit selective focusing on the negative aspects of their experiences while excluding the positive aspects of their experiences. Along with theoretical evidence, the empirical support for the role of negatively biased cognitions in depression is considerable (e.g., Eiszenman, et al., 2003; Gotlib, Krasnoperova, Yue, \& Joormann, 2004; McDermut, Haaga \& Bilek, 1997; Rinck \& Becker, 2005; Shook Fazio \& Vasey, 2007).

Shook, Fazio, and Vasey (2007) examined whether the extent to which individuals exhibit a learning bias in attitude formation is related to negative cognitive style and symptoms of depression in a non-clinical analog sample $(N=53)$ of university students. Learning bias was measured by BeanFest (Fazio, Eiser, \& Shook, 2004), a computer game set in an imaginary 
universe of beans where half of the beans were "good" (i.e., increase the player's points by 10 if selected) and half were "bad" (i.e., decrease the player's points by 10 if selected). To win the game, players were required to learn which beans were good and which beans were bad.

Learning was assessed in a test phase following the game, where how well the individual learned the valence of each bean was assessed. During the test phase, individual beans were presented and participants categorized them according to whether they were good or bad beans. No feedback was provided during the test phase, and no points were received. If participants correctly identify bad beans from the game better than good beans, this demonstrated negative bias in learning, indicating that the individual tended to learn negative novel stimuli better than positive novel stimuli. Shook and colleagues (2007) found that higher depression scores on the BDI-II were associated with a greater learning bias, suggesting that individuals who showed greater levels of depressive symptoms also showed reduced ability to learn positive information.

McDermut, Haaga, and Bilek (1997) studied differences in negative biases among depressed $(n=24)$, dysphoric $(n=21)$, and non-depressed $(n=34)$ adults. Participants were asked to give either a positive or negative attribution for six recent events (e.g., briefly describe a positive or a negative event that occurred to you during the last year, name the major cause of the event, and indicate why you believed the stated cause to be the primary cause of the event) and to provide a justification for the attribution. Depressed individuals showed greater negative bias, determined by the presence of one of the following: Arbitrary inference (deciding the cause of an event based on contradictory or irrelevant information), overgeneralization (forming a rule based on a single event and applying this rule to future events even if they are unrelated), or selective abstraction (interpreting an incident based on one detail, while ignoring more significant and important information), than the non-depressed group when justifying negative-event 
attributions, and showed less bias than the non-depressed group when justifying positive-event attributions. Dysphoric individuals scored between the two other groups for both negative and positive attributions. These results suggest that depressed individuals possessed an attributional bias toward negative events and their causes.

Depressed individuals may also possess biases to visual stimuli related to sadness and loss. Eiszenman and colleagues (2003) utilized a naturalistic visual scanning approach to assess selective attention in individuals with major depressive disorder. Participants $(N=17)$ were asked to scan and re-scan images with different themes (i.e., neutral stimuli, stimuli related to sadness and loss, stimuli related to anxiety and threat, and stimuli relating to social contact and interpersonal attachment). An eye-tracking system was utilized to monitor the total fixation time and the average duration that an individual spent looking at images with a particular theme. Depressed individuals spent significantly more time looking at images with dysphoric themes related to sadness and loss than individuals in the control group. The average time spent looking at images with neutral, social, and threatening themes were similar for both groups. In a different attentional study, Gotlib, Krasnoperova, Yue, and Joormann (2004) utilized a pictorial version of the dot-probe task (Bradley et al., 1997) and a set of 120 photographs of faces of people expressing different emotions. They found that depressed individuals $(n=19)$ exhibited specific biases toward photographs related to sadness when compared to individuals diagnosed with generalized anxiety disorder $(n=18)$ or a non-clinical control group ( $n=16$; Gotlib et al., 2004). These results suggest that depressed individuals possess an attentional bias toward dysphoric visual stimuli.

Similarly, Rinck and Becker (2005) systematically examined attention in 117 women (35 with social phobia, 27 with major depression, and 55 non-clinical controls). Participants 
completed a test of visual attention to words instead of images. The social phobia group and the depression group both exhibited attentional biases for words related to their respective disorders (i.e., exhausted, dejected, and indifferent for depression; and embarrassment, criticized, and unwanted for social phobia). Visual attention was measured by a visual search task, where participants were presented with a disorder related target word, then searched for said word hidden in a matrix of distractor words distributed across a computer screen. All distractor words were from a single set (i.e., depression-related, neutral, positive, or social phobia-related words); however, the distracter words were not related to the same disorder as the target word. Participants were to press a specific key indicating when they had found the target word. Reading times for the target word, reaction times (i.e., how long it took to find in the matrix), and mistakes were recorded by the computer. Depressed individuals exhibited significantly higher amounts of interference from depression-related distractors, than the other two groups, suggesting the presence of an attentional bias toward depression related words.

These results suggest that negativity biases affect depressed individuals across multiple domains. Negative biases make it more likely that the depressed individual will view the world from a place of sadness, helplessness, and eventually hopelessness. The individual's experience is thereby shaped by these negative ways of interacting with the world. However, it is possible that through beginning to understand how behavior affects emotion, developing a values-based way to change behavior, and beginning to attend to activity level through the early sessions of BATD that the individual might come to challenge these biases without realizing it. Jacobson and colleagues (1996) found that behavioral activation was as effective as cognitive therapy at altering dysfunctional attributional style, and that changes in negative cognitive style were more 
likely to be followed by decreased depression in BA than in CT. Thus, negativity bias was reduced in behavioral activation along with depression.

Experiential Avoidance and Depression. Experiential avoidance is both theoretically and statistically related to depression (Hayes et al, 2004; Hayes, Wilson, Gifford, Follette, \& Strosahl, 1996; Lejuez, Hopko, \& Hopko, 2001). Experiential avoidance can be defined as the internal or external behavior that occurs when an individual is unwilling to experience being in contact with a private experience (e.g., thoughts, emotions, bodily sensations) and attempts to control these experiences by changing them or the context in which they occur (Hayes, Wilson, Gifford, Follette, \& Strosahl, 1996). Depression, posttraumatic stress disorder, obsessivecompulsive disorder, panic disorder, borderline personality disorder, substance misuse, and suicide are associated with frequent attempts to suppress or avoid unwanted thoughts and feelings (Giorgio et al, 2010; Hayes et al., 1996; Iverson, Follette, Pistorello, \& Fruzzetti, 2012; Kashdan \& Kane, 2011; Levin, Lillis, Seeley, Hayes, Pistorello, \& Biglan, 2012). Evidence suggests that attempts to suppress, avoid, and control unwanted thoughts and feelings may play a larger role in the development and maintenance of psychological distress than do the actual unwanted experiences (Hayes et al., 2004; Sloan, 2004; Gold \& Wegner, 1995).

In the short term, experiential avoidance is effective. Initially, it reduces the thought or feeling that the individual is attempting to avoid. For example, if one distracts oneself from a very sad thought, or attempts are made to suppress that thought, there is usually a brief reduction in the thought's frequency (Hayes et al., 2004). This period of time is short lived, however, and some studies have shown that the thought will often return stronger and with greater frequency (Gold \& Wegner, 1995). This process places the avoided experience into a self-amplifying loop, as the individual repeats the process of attempting to avoid the experience (Gold \& Wegner, 
1995). The more the individual attempts to avoid the uncomfortable experience, the stronger their discomfort becomes (Hayes et al., 2004). For example, the more a depressed individual attempts to avoid feelings of sadness, the sadder his or her feelings become.

Rumination in particular has been highlighted as a means of experiential avoidance. Giorgio and colleagues (2010) had 138 undergraduate students complete self-report measures of experiential avoidance, worry, and depression; a significant relation between rumination in depression and experiential avoidance was found (i.e., individuals with higher levels of rumination also reported higher levels of experiential avoidance). Similarly, Cribb, Moulds, and Carter (2006) found that rumination, depression, and experiential avoidance all correlated significantly with one another, even when controlling for anxiety. Bjornsson and colleagues (2010) conducted two studies to further examine the effects of experiential avoidance and rumination on depression in a college population. They found that experiential avoidance was only associated with depression when high levels of rumination were present. Meaning that when individuals with depression experience high levels of rumination that they will in turn wish to avoid any unwanted thoughts or emotions. Taken together, these finding suggest that there is a significant relation between experiential avoidance and depression.

BATD-R asks the individual to pay attention to what they are doing rather than how they are feeling and to engage in activities based on their values rather than avoiding important or enjoyable activities. Thus individuals may experience a reduction in experiential avoidance throughout the treatment process. It is possible that this occurs because the individual is continually placing themselves in situations that they would typically avoid, through attending sessions and tracking and scheduling activities. Thus, BATD-R may reduce experiential avoidance. 
Mindfulness and Depression. Mindfulness is a practice that originated in Buddhism and has been called "the heart" of Buddhist meditation (Kabat-Zinn, 2003; Thera, 1962). KabotZinn (2003) defined mindfulness as "the awareness that emerges through paying attention on purpose, in the present moment, and non-judgmentally to the unfolding of experience moment by moment" (p. 145). Mindfulness has been shown to provide a variety of health benefits, including lower levels of depression and reductions in levels of negativity bias (Brown, Ryan, \& Creswell, 2007; Kiken \& Shook, 2011, 2012).

Brown and Ryan (2003) found negative correlations between trait mindfulness and depression, anxiety, hostility, impulsivity, and self-consciousness. They also found that higher levels of mindfulness were positively correlated with feelings of autonomy, competence, and well-being. Raes, Dewulf, Van Heeringen, and Williams (2009) found that trait mindfulness was significantly negatively correlated with Cognitive Reactivity, the degree to which mild dysphoria activates patterns of negative cognitions, which has shown to be a key causal risk factor for recurrence of depressive symptoms (Lau, Segal, \& Williams, 2004). Paul, Stanton, Greeson, Smoski, and Wang (2012) found that trait mindfulness might reduce vulnerability to depression by buffering against rumination and negative bias, and by reducing automatic emotional responding.

Additionally, multiple treatment models have been developed that utilize mindfulness interventions to address depression as well as other disorders, and a growing amount of evidence for these treatments is being established (see, Hayes, Masuda, Bissett, Luoma, \& Guerrero, 2004, for review). Hofman, Sawyer, Witt, and Oh (2010) conducted a meta-analysis of mindfulnessbased treatments for depression and anxiety. They found that, across 39 studies, the effect size for depressive symptom reduction in individuals who did not meet criteria for a depressive 
disorder was moderate (Hedges' $\mathrm{g}=0.59$ ); however, for individuals who met criteria for a depressive disorder, the effect size was large (Hedges' $g=0.95$ ). These findings suggest that increased levels of mindfulness might have an inverse relation with depressive symptoms.

These findings demonstrate the inverse relation between mindfulness, at both a state and trait level, and depressive symptoms. BATD may affect mindfulness. It is possible that the increased focus on what the individual is doing in the present moment in BATD-R is accompanied by an increased awareness of the present moment. For example, as the individual begins attending to tracking activities, learning and clarifying values (i.e., through the life areas, values, and activities inventory), and scheduling values-based important and enjoyable activities, that the individual's overall level of mindfulness is increased through increased attention to the present moment. Therefore, it is possible that BATD-R increases mindfulness without providing specific training in mindfulness skills.

\section{Summary}

Depression in university students is a serious problem affecting not only students' mental health, but also academic performance and completion of degree requirements. These effects may influence students' lives for years to come by lowering earning capacity in adulthood and increasing risk of heart attack and/or other health related problems (Bruce, Takeuchi, \& Leaf, 1991; Hysenbegasi, Hass, \& Rowland, 2005; National Institutes of Mental Health, 1999). Early intervention may increase the likelihood that students with depressive symptoms complete degree requirements, and reduce the likelihood of negative outcomes associated with depression in adulthood. Because the average number of sessions attended by students at university counseling centers was $3.3(S D=2.4$; Draper et al., 2002), a very brief intervention is necessary to make a substantial impact on university students experiencing depressive symptoms. 
Gawrysiak, Nicholas, and Hopko (2009) demonstrated that a single session of BATD was sufficient to significantly reduce mild to moderate depressive symptoms in university students. However, there were several limitations to this study, and no other studies have replicated these findings. It is also unknown whether other variables related to depression (i.e., negative cognitive bias, mindfulness, experiential avoidance) are affected by BATD. It is of great importance that we examine the presence or absence of particular variables that may affect the efficacy of the protocol for depression; as understanding the variables associated with positive change and recovery from depression will allow us to better predict positive treatment outcomes and optimize therapeutic change (Kazdin, 2007; Keitner, Ryan, Miller, \& Norman, 1992).

\section{Present Study}

The purpose of this study was to replicate and extend the findings of Gawrysiak Nicholas, and Hopko (2009) by testing the efficacy of a modified version of their 1-session intervention in reducing self-reported depressive symptoms in a sample of university students. The goal was to address three of the limitations related to the original study. Specifically, this study added a second follow-up session at one month, in order to provide evidence for continued intervention effects following the two-week activity scheduling period. Further, Gawrysiak et al. limited external validity by excluding individuals who were currently on antidepressant medication or had engaged in psychotherapy within the past 2 years. In order to increase external validity in the current study, only individuals who had not been stabilized on their antidepressant medication for 8 weeks or longer and who were enrolled in psychotherapy when they began the study were excluded. While adequately powered, the size of the sample utilized in Gawrysiak et al. was quite small $(N=30)$, thus possibly affecting generalizability and external validity by increasing the likelihood that the sample is not representative of the overall population. To 
control for this possibility, the sample size for the current study was increased $(N=39)$, but more importantly a sample from a different student body, one who had similar levels of depression to those in the previous study, but were not actively seeking treatment through their participation in the current study, thereby increasing generalizability. It was hypothesized that greater reductions in depression scores would be observed in university students with mild to moderate scores on the Beck Depression Inventory-II (BDI-II; Beck, Steer, \& Brown, 1996) at two-weeks and onemonth following a one-session intervention based on BATD-R compared to a no treatment control group.

A secondary aim of this study was to examine whether the one-session intervention would change scores in negative cognitive bias, mindfulness, and experiential avoidance. Examining these variables is important if we are to understand the relations between depression, these variables, and therapeutic change within BATD. This knowledge may improve our ability to help patients address these variables through values-based activities within the protocol, and through addressing these variables, improve overall treatment efficacy (Kazdin, 2007; Keitner, Ryan, Miller, \& Norman, 1992). It was hypothesized that greater reductions in negativity bias and experiential avoidance, as well as greater increases in mindfulness level, would be observed at two-weeks and one-month in the same university student sample following the same onesession intervention based on BATD-R compared to a no treatment control group.

\section{Method}

\section{Participants}

Using the West Virginia University Department of Psychology SONA Systems Website and flyers posted around the various university campuses, 1574 undergraduate students were recruited and completed prescreening measures online. Individuals were excluded from 
participating if they were under 18, not fluent in English, did not meet depression score criteria, or had significant histories of suicidal thoughts, psychosis, substance abuse, or bipolar disorder. Also, individuals taking antidepressant medication were required to be stabilized for a period of 8 weeks prior to beginning the study. A review of the literature determined that these were common exclusion criteria across studies utilizing BATD and BATD-R. Of the 1574 individuals who were prescreened, $93.5 \%$ were over 18 years old; $73.7 \%$ were female; $79.4 \%$ identified as Caucasian, 6.3\% identified as African American, 3.0\% identified as Asian, 3.1\% identified as Hispanic, and .3\% identified as other. Additionally, $1.8 \%$ reported a history of psychosis, $2.7 \%$ reported a history of bipolar disorder, $3.4 \%$ reported a history of substance abuse, and $29 \%$ reported having previously sought mental health services.

There were 350 individuals who met the inclusion/exclusion criteria and had Beck Depression Inventory-II (BDI-II; Beck, Steer, \& Brown, 1996) scores suggesting the presence of mild to moderate depressive symptoms (i.e., scores from 13 to 28). Of the 350 eligible students, $100 \%$ were over 18 years old, $81.7 \%$ were female, $85.1 \%$ identified as Caucasian, $4.3 \%$ identified as African American, 4.3\% identified as Asian, 2.3\% identified as Hispanic, and .3\% identified as other). All of these individuals were emailed and invited to participate in the study.

Based on a power analysis using G*Power (Faul, Erdfelder, Buchner, \& Lang, 2009) for repeated measures analyses of variance (ANOVA) with a within-between subjects interaction, a total of 36 participants were necessary to detect a moderate effect size with specifying parameters (power $=.95, a=.05$, and moderate effect size $F=0.25$ ). Of the 350 individuals who were invited to participate, thirty-nine students responded to the invitation and participated in the main study $\left(M_{\text {age }}=19.56\right.$ years, $S D=1.35$, range $=18$ to $23 ; 79.5 \%$ female; $82.1 \%$ identified as Caucasian, $7.7 \%$ identified as African American, 5.1\% identified as Asian, 2.6\% identified as 
Hispanic, and $2.6 \%$ identified as other).

A series of chi-square tests were utilized to compare the 39 individuals who elected to participate in the study and the 311 individuals who did not respond to the email invitation across demographic variables. Overall, there were no significant differences in demographics between the two groups (see Table 1). Similarly, a series of independent samples $t$-tests were utilized to compare the 39 individuals who elected to participate in the study and the 311 individuals who did not respond to the email invitation across all prescreening measures. Overall, there were no significant differences in scores for any of these variables between the two groups (see Table 2).

The SONA website was used to invite the majority of participants to take part in the study $(n=36)$. However, three participants were recruited by flyer and invited to participate by email. Participants were randomized into a clinical $(n=21)$ or control $(n=18)$ group using a computer-based random number generator. One clinical group participant was excluded from analyses due to signs that he or she was not following directions and responding indiscriminately to items (i.e., giving a single response for an entire measure across multiple measures) during the assessment portion of Session 1 . Thus, the final sample size was $38\left(M_{\mathrm{age}}=19.61\right.$ years, $S D=$ 1.35, range $=18$ to $23 ; 78.9 \%$ female; $81.6 \%$ Caucasian, $7.9 \%$ African American, $5.3 \%$ Asian, $2.6 \%$ Hispanic, and $2.6 \%$ other). Independent samples $t$-tests and chi-square tests suggested that the clinical and control groups did not differ at Session 1 on any of the outcome or demographic variables (see Tables 3 and 4).

\section{Measures}

Beck Depression Inventory-II (BDI-II; Beck, Steer, \& Brown, 1996). The BDI-II is a two-factor 21-item self-report measure of depression. The Cognitive-Affective factor measures the elements of depression that relate to thoughts and emotion (e.g., "I feel utterly worthless."), 
whereas the Somatic factor measures the levels of bodily sensations (e.g., "I am so restless or agitated that it's hard to stay still") associated with depression. Items are scored on a 4-point scale ranging from $0-3$ representing either the frequency or severity of depressive symptoms. The 21 items are summed to give a single score. Total scores range from 0-63 with a score of 0-13 indicating minimal depression, 14-19 indicating mild depression, 20-28 indicating moderate depression, and 29-63 indicating the presence of severe depression. The BDI-II matches the criteria for depression in the DSM-IV. The BDI-II has shown high internal consistency in a sample of primary care medical patients $(\alpha=.94$; Arnau, Meagher, Norris, \& Bramson, 2001), and medium to high internal consistency across multiple samples of English speaking students with alphas ranging between .86 (Shean \& Baldwin, 2008) and .93 (Beck et al., 1996; see Wang \& Gorenstein, 2013, for review).

Dysfunctional Attitudes Scale - Short Form 1 (DAS - SF1; Beevers, Strong, Meyer, Pilkonis, \& Miller, 2007). The DAS - SF1 is a 9-item self-report measure that assesses negative dysfunctional attitudes. Individuals rate how they feel generally about themselves or their world (e.g., "If I fail at my work, then I am a failure as a person."). The DAS is scored on a 7-point scale with responses ranging from 1 ("Totally Agree") to 7 ("Totally Disagree"). Because of the scaling, with lower scores indicating a greater presence of dysfunctional attitudes, items are reverse coded and then summed. Items are scored so that higher scores indicate the presence of greater dysfunctional attitudes. The DAS-SF1 has shown good internal consistency $(\alpha=.84)$ in a sample of depressed adults (Beevers, Strong, Meyer, Pilkonis, \& Miller, 2007), and evidence for convergent validity has been found in depressed adult populations between the DAS-SF1 and The Dysfunctional Attitudes Scale-short form A ( $r=.92$; Weissman, 1979) and the Cognitive Bias Questionnaire ( $r=.53$; Krantz \& Hammen, 1979). 
BeanFest (Fazio et al., 2004). The BeanFest paradigm was utilized as an objective measure of negativity bias. BeanFest is a computer game set in an imaginary universe of beans where half of the beans were "good" (i.e., increase the player's points by 10 if selected) and half were "bad"' (i.e., decrease the player's points by 10, if selected). To win the game, players were asked to learn which beans were good and which beans were bad. The only way to assess the valence of the beans was by their appearance, which only varied by shape (circular, oval, or oblong) and number of speckles (1-10). There were 100 possible shape-speckle combinations; 36 beans were presented during the game taken from six regions of the bean matrix (see Fazio et al., 2004, for details). The valence of the beans varied across shape and number; however, a positive bean would always be positive and a negative bean would always be negative. This was to prevent participants from being able to simply learn a single rule for the valence of each bean (e.g., oblong beans are positive) and to show that outcomes were solely based on learning the valence of a particular bean (Kiken \& Shook, 2011; 2012).

During the game, participants were presented with a single bean and asked decide whether to select the bean. The participant's total points were adjusted according to the bean's point value (i.e., 10 or -10 ) if the participant selected the bean. If the participant did not select the bean, there was no change in the participant's total points. Participants were given 50 points at the beginning of the game. If a participant reached 100 points, the game had been won, and reaching zero points would have lost the game. In either case, a new game began at that time and the participant was given 50 points. Although the participant's success determined the number of games, all participants completed 108 trials. For the current study, a full-feedback version of BeanFest was used, meaning that participants, at the end of the trial, were informed of the bean's value whether or not they selected the bean. Thus, all participants received the same information 
about the valence of both positive and negative beans. After the full feedback game, a test phase assessed participants" accuracy in classifying the beans as "good" or "bad." Participants were presented with the same beans that were utilized in the game, but in random order, as well as 64 novel beans that were not presented during the game as a means to test for generalization; they were asked to identify the valence of each bean. During the test phase, there was no point value assigned to any bean, and participants did not receive feedback (Kiken \& Shook, 2011; 2012).

To assess negative biases in learning, an index of learning bias was created by subtracting the proportion of correctly learned positive game beans from the proportion of correctly learned negative game beans. A positive difference indicated the presence of a negative bias in learning. If a bias was not present, then equal learning of positive and negative beans resulted in a difference of zero. The proportions of positive and negative beans learned correctly were then examined separately to examine whether a particular learning bias was due to the greater learning of one valence or to the poorer learning of the other valence in game beans. For example, individuals with higher depression scores may simply learn negative information better than positive information, or they may simply have difficulties learning positive information (Fazio et al., 2004).

To assess for a negative overall generalization bias, positive responses to novel beans were coded as -1 and negative responses were coded as +1 . Responses to the 64 novel beans were then averaged, which represented overall generalization of bean valence. If the outcome was positive, this represented greater negativity bias through the generalization of negative attitudes, and negative numbers represented greater positivity bias through the generalization of positive attitudes. A mean around zero represented no presence of bias, due to the number of novel beans classified as positive and negative being relatively equal (Fazio et al., 2004). 
Mindful Attention Awareness Scale (MAAS; Brown \& Ryan, 2003). The MAAS is a 15-item self-report measure of trait mindfulness. Participants reported the extent to which they regularly experienced each item (e.g., "I find it difficult to stay focused on what's happening in the present") on a scale from 1 ("almost always") to 6 ("almost never"). Averaging the 15 items created a composite score. Higher scores reflected higher trait mindfulness. Brown and Ryan (2003) found the MAAS to have good internal consistency $(\alpha=.82)$. MacKillop and Anderson (2007) also found the MAAS to have good internal consistency $(\alpha=.89)$, and conducted a confirmatory factor analysis which supported the proposed one factor structure of the MAAS $(\mathrm{RMR}=0.08 ; \mathrm{CFI}=0.91 ; \mathrm{RMSEA}=0.07 ; \mathrm{CI}=0.07-0.08)$.

Acceptance and Action Questionnaire-II (AAQ-II; Bond et al., 2011). The AAQ-II is a 7-item self-report measure of experiential avoidance and psychological inflexibility $(\alpha=.84)$. Individuals rated each item (e.g., "Emotions cause problems in my life.") on a scale from 1 ("never true") to 7 ("always true"). Summing the 7 items created a composite score, such that greater scores represent higher levels of experiential avoidance. The AAQ-II provided evidence for test retest reliability at 3 months $(r=.81)$ and at 12 months $(r=.79)$. When compared to the 16-Item AAQ-I (Hayes et al., 2004), the AAQ-II appeared to be measuring the same construct ( $r$ $=.97$; Bond et al., 2011). The AAQ-II was utilized as a prescreening measure but was not utilized in the final study in an effort to reduce participant time completing pre-intervention assessment as similar information could be obtained from the Multidimensional Experiential Avoidance Questionnaire.

\section{Multidimensional Experiential Avoidance Questionnaire (MEAQ; Gamez,}

Chmielewski, Kotov, Ruggero, \& Watson, 2011). The MEAQ is a 62-item self-report measure of different dimensions of experiential avoidance: Behavioral Avoidance $(\alpha=.90)$, Repression and 
Denial $(\alpha=.89)$, Distraction and Suppression $(\alpha=.86)$, Distress Aversion $(\alpha=.89)$,

Procrastination $(\alpha=.88)$, and Distress Endurance $(\alpha=.82)$. Individuals rated each item (e.g., " If I could magically remove all of my painful memories, I would.") on a scale from 1 ("strongly agree") to 6 ("strongly disagree"). Overall the MEAQ had high internal consistency with alphas ranging from .91 to .92 (Gamez et al., 2011). Reverse scoring necessary items before summing the scores for items within each dimension createed a composite score. Greater scores indicated higher levels of experiential avoidance.

Beck Anxiety Inventory (BAI; Beck, Epstein, Brown, \& Steer, 1988). The BAI is a 21item self-report inventory where individuals were asked to rate their experiences of symptoms related to anxiety (e.g., terrified, hands trembling) on a scale from 0 (not experiencing a symptom at all) to 3 (being severely bothered by a particular symptom). The BAI had high internal consistency $(\alpha=.92)$ and has shown high test-retest reliability $(r(81)=.75)$ over a 1 week period (Beck et al., 1988). A reliability generalization study (Ayala, Vonderharr-Carson, and Kim, 2005) found mean alpha ranges for the BAI from .88 to .92 , and mean test-retest reliability coefficients from .46 to .83 across various populations. Summing the 21 items of the BAI created a composite score, and larger scores indicated the presence of more severe anxiety. Because of the strong relation between depression and anxiety, the BAI was included as a covariate to test for effects on depression while controlling for anxiety.

\section{Attitudes Toward Seeking Professional Psychological Help- Short Form (ATSPPH-} SF; Fischer \& Farina, 1995). The ATSPPH-SF is a 10-item self-report measure used to assess participants' attitudes toward seeking psychological help (e.g., Considering the time and expense involved in psychotherapy, it would have doubtful value for a person like me). The ATSPPH-SF was developed using Fischer and Turner's (1970) original 29-item Attitudes Toward Seeking 
Professional Psychological Help measure. The ATSPPH-SF yielded an alpha of .84 and 1-month test-retest reliability of .80. Individuals were asked to rate their attitudes toward seeking psychological help from 1 (disagree) to 4 (agree). A composite score was created by reverse scoring necessary items and summing items, such that higher scores indicated more positive attitudes towards seeking professional psychological help.

Multidimensional Scale of Perceived Social Support (MSPSS; Zimet, Dahlem, Zimet, \& Farley, 1988). The MSPSS (Zimet et al., 1988) is a 12-item self-report scale that measures perceived support from three domains: friends, family, and a romantic partner (e.g., I can count on my friends when things go wrong). Individuals were asked to rate their level of agreement on a 7-point Likert-type scale, ranging from "very strongly disagree" to "very strongly agree" with higher scores suggesting greater levels of perceived social support. Adequate psychometric properties have been found across multiple studies in both the United States and in Europe (Kazarian \& McCabe, 1991; Zimet et al., 1988, 1990). Canty-Mitchell and Zimet (2000) reported internal reliability estimates of .93 for the total score and alphas ranging from .89 to .91 for the subscales. A composite score was created by summing items; higher scores indicated greater perceived social support.

Demographics. Individuals were asked to provide information on race, gender, age, employment history, GPA, educational attainment, and household income, as well as medical and mental health history. Because of the elements of mindfulness that exist within these practices, additional items were included to gather information regarding history of meditation, yoga, tai chi, or martial arts. Tai chi was not reported because it had never been practiced by any respondent. The demographics questionnaire also included questions regarding exclusion criteria: Being under 18 years old, not fluent in English, not meeting depression score criteria, 
history of suicidal thoughts, psychosis, substance abuse, bipolar disorder, currently participating in psychotherapy, or use of any medication for depression or anxiety for less than 8 weeks.

\section{Procedure}

The study was advertised via the WVU Department of Psychology's SONA website and flyers posted on campus. Participants completed an online prescreening survey. After reading and agreeing to an online consent form, participants completed the following measures in the stated order: Beck Depression Inventory-II minus the suicide item (BDI-II; Beck, Steer, \& Brown, 1996); Mindfulness Attention Awareness Scale (MAAS; Brown \& Ryan, 2003); Multidimensional Scale of Perceived Social Support (MSPSS; Zimet, Dahlem, Zimet, \& Farley, 1988); the Attitudes Toward Seeking Professional Psychological Help-Short Form (ATSPP-SF; Fischer \& Farina, 1995); Dysfunctional Attitudes Scale - Short Form 1 (DAS - SF1; Beevers, Strong, Meyer, Pilkonis, \& Miller, 2007); Beck Anxiety Inventory (BAI; Beck, Epstein, Brown, and Steer, 1988); Acceptance and Action Questionnaire-II (AAQ-II; Bond, Hayes, Baer, Carpenter, Guenole, Orcutt, Waltz, \& Zettle, 2011); and the Multidimensional Experiential Avoidance Questionnaire (MEAQ; Gamez, Chmielewski, Kotov, Ruggero, \& Watson, 2011); as well as demographics and health history questions. (See Appendix A for all measures except BDI-II and BAI due to copyright protection). Pre-screened individuals recruited by SONA $(n=$ 1,551) were given 1 hour of extra credit; those recruited by flyer $(n=23)$ were entered into a drawing to receive a $\$ 50$ gift card to compensate their time. All participants with BDI-II scores ranging from 13 to 28 were emailed to inform them of their eligibility to participate in the main study, given a description of the study, including number of sessions and incentives, and asked to reply if interested. If participants did not respond to the first email, a second email invitation was sent two weeks later. 
Participants were randomly assigned to either a clinical or control group. For participants in the clinical group, the main study consisted of an approximately one-hour pre-intervention assessment session and a 90-minute BATD-R based intervention session with assigned homework, a two-week follow-up session to assess progress, and a second follow-up session to assess progress at 1-month. For participants in the control group, the main study consisted of an approximately one-hour assessment session, a two-week follow-up assessment session, and a second follow-up assessment session at 1-month. All sessions were held inside the Quin Curtis Center (QCC), which is a psychological service, training, and research center housed inside the WVU Department of Psychology. The QCC is specifically well suited for research projects which aim to gain information that will contribute to the further understanding of how specific interventions might benefit university student populations. Each of the QCC's five therapy/testing rooms, is outfitted with a computer, two-way mirror, and video equipment for recording sessions for supervision purposes and fidelity checks. Computers are secure and are not connected to the internet.

Upon arrival to the QCC, participants were given a description of the study, asked to complete an informed consent form, and consent to be videotaped. Participants were randomly assigned to either the clinical or control group. All participants were then asked to complete BeanFest (BeanFest; Fazio et al., 2004) and a modified version of the prescreening survey. The only differences in the survey were that more demographic questions were added, the AAQ-II was removed to reduce survey length and because the MEAQ measures a similar construct, the order in measures were presented (see below for order of measures presented), and the suicidality item (item-9) of the BDI-II was included. Researchers were asked to contact one of two previously agreed upon licensed psychologists who were either supervising or familiar with 
the study, to assess suicide risk, if suicidality was indicated by a participant before the participant completed the session. Measures were presented in the following order: Beanfest (Fazio et al., 2004); the Attitudes Toward Seeking Professional Psychological Help-Short Form (ATSPP-SF; Fischer \& Farina, 1995); Beck Anxiety Inventory (BAI; Beck, Epstein, Brown, and Steer, 1988); Beck Depression Inventory-II (BDI-II; Beck, Steer, \& Brown, 1996); Dysfunctional Attitudes Scale - Short Form 1 (DAS - SF1; Beevers, Strong, Meyer, Pilkonis, \& Miller, 2007); Mindfulness Attention Awareness Scale (MAAS; Brown \& Ryan, 2003); the Multidimensional Experiential Avoidance Questionnaire (MEAQ; Gamez, Chmielewski, Kotov, Ruggero, \& Watson, 2011); and the Multidimensional Scale of Perceived Social Support (MSPSS; Zimet, Dahlem, Zimet, \& Farley, 1988), as well as demographics and health history questions. Upon completion of the initial assessment, participants in the clinical group then received the 90minute BATD-R intervention. Those in the control group were thanked, compensated for their time, and encouraged to return in two weeks for a follow-up appointment with the same researcher. Clinical group participants recruited through SONA received two hours of extra credit, control group participants recruited through SONA had the option of receiving one and one half hours, and both clinical and control group participants recruited through campus flyers received $\$ 10$ cash.

Study therapists, a team of 6 clinical psychology doctoral students ( 2 female; 4 male), administered the intervention. All therapists had been previously trained in behaviorally oriented interventions and also received training and supervision in this BATD-R based intervention throughout the data collection portion of the study. All therapists were co-therapists for at least two intervention sessions with an advanced graduate student who had completed extensive training and supervision in BATD-R as a therapist in a previous study utilizing the full 10- 
session protocol of BATD-R. These sessions were completed before study therapists were assigned their first sessions to complete alone with a participant. All intervention sessions were videotaped and reviewed randomly during weekly group supervision meetings. Study therapists were supervised by a licensed psychologist who worked with the treatment developers for the first clinical trial of BATD (Lejuez, Hopko, LePage, Hopko, \& McNeil, 2003).

The treatment protocol (see Appendix B) was based on the protocol utilized in Gawrysiak, Nicholas, and Hopko (2009). However, the protocol was slightly modified to reflect updates, based on BATD-R (Lejuez et al., 2011). These changes were intended to streamline the process of converting participant's values into observable and quantifiable activities. For example, a participant may value being a loving husband and may have a plethora of ideas about what a loving husband does, but may not have the skills necessary to put those activities into action. In the original manual, participants were only asked to mark yes or no regarding whether they completed an activity or not. In the modified manual, participants were asked to track all of their daily activities and to mark intervention oriented activities as they were completed. These activities were scheduled into the behavioral checkout sheets during the intervention. The updated behavioral checkout sheets also asked participants to track non-scheduled activities enabling clinicians to examine overall activity level rather than simply whether or not the participant completed scheduled activities. These changes enabled the individual to work with the therapist to develop and schedule specific activities at specific times. Given these changes, a section on the rationale for activity tracking was also added to the manual, which incorporated changes taken from the BATD-R protocol.

During the intervention session, the therapist discussed the behavioral conceptualization of the etiology and maintenance of depressive symptoms with the participant. A daily monitoring 
form was introduced (behavioral checkout sheets), and the participant was asked to track their activity and rate that activity on importance and the amount of enjoyment received by engaging in said activity for the two weeks between the intervention and the two-week follow-up session. A life areas, values, and activities inventory was completed by the participant with the help of the therapist. The participant and the therapist then added specific activities based on the inventory to the participant's daily activity forms at scheduled times. Participants were asked to complete these activities over the interim between the intervention and two-week follow-up session. The intervention session ended with a discussion of the importance of how the intervention is structured (Lejuez, Hopko, Acierno, Daughters, \& Pagoto, 2011). Participants were then thanked, compensated for their time, and encouraged to return in two weeks for a follow-up appointment with the same researcher. Participants recruited through SONA received either two hours of extra credit, and participants recruited through campus flyers received $\$ 10$ cash.

Approximately two weeks after the initial assessment, all participants were asked to return to the QCC to complete a second assessment, which consisted of the same measures as the initial assessment. Participants in the clinical group were also asked to return their behavioral checklist forms. After completing the measures, participants were thanked, compensated for their time, and encouraged to return in two weeks for a follow-up appointment with the same researcher. Participants recruited through SONA received either one hour of extra credit or $\$ 10$ cash, and participants recruited through campus flyers received \$10 cash.

Approximately one month after the initial assessment, all participants returned to the QCC to complete a third assessment, which consisted of the same measures as the initial assessment. After completing the measures, participants were thanked, and compensated for their 
time. Participants recruited through SONA received either two hours of extra credit or $\$ 15$ cash, and participants recruited through campus flyers received $\$ 15$ cash.

\section{Results}

\section{Preliminary Analyses}

All variables were examined for normality, univariate outliers, and multivariate outliers. Several problems with skewness were identified. The MAAS scores at Sessions 1 (skewness $=$ $1.04 ; S E=.38), 2($ skewness $=1.07 ; S E=.38)$, and $3($ skewness $=.91 ; S E=.38)$ were not normally distributed and positively skewed. The MEAQ scores at Session 1 were not normally distributed and negatively skewed (skewness $=-.89 ; S E=.38$ ). The BDI-II scores at Session 2 (skewness $=.59 ; S E=.38)$ and $3($ skewness $=1.16 ; S E=.38)$ were not normally distributed and positively skewed. The ATSPP-SF scores at Session 1 (skewness $=-.37 ; S E=.38)$ were not normally distributed and negatively skewed. The MSPS scores at Sessions 1 (skewness = -.75; $S E=.38), 2$ (skewness $=-1.04 ; S E=.38)$, and 3 (skewness $=-.79 ; S E=.38$ ) were not normally distributed and negatively skewed. The MAAS and BDI-II scores were corrected with a square root transformation, because they were positively skewed. The MEAQ, MSPS, and ATSPP-SF scores were negatively skewed and had to be inverted before being logarithmically transformed. However, MSPS scores for Session 2 were still non-normal after this transformation (skewness = -1.41; $S E=.38)$. Means, standard deviations, bivariate correlations, and Cronbach's alphas for all self-report measures for each session are presented in (Table 6).

All proposed secondary outcome variables correlated significantly with BDI-II scores at both Sessions 1 and 3, but did not significantly correlate at Session 2. For Session 1, BDI-II scores correlated significantly with DAS-SF scores $(r=.500 ; p<.05)$, MAAS scores $(r=-.650$; $p<.05)$, and MEAQ scores $(r=.580 ; p<.05)$. No significant correlations were present for 
Session 2. For Session 3, BDI-II scores correlated significantly with DAS-SF scores $(r=.396 ; p$ $<.05)$, MAAS scores $(r=-.487 ; p<.05)$, and MEAQ scores $(r=.332 ; p<.05)$.

The Beck Anxiety Inventory (BAI; Beck, Epstein, Brown, \& Steer, 1988), Multidimensional Scale of Perceived Social Support (MSPSS; Zimet, Dahlem, Zimet, \& Farley, 1988), the Attitudes Toward Seeking Professional Psychological Help-Short Form (ATSPP;

Fischer \& Farina, 1995) and demographic variables; were examined as potential covariates. The correlations between the potential covariates and the outcome variables (i.e., BDI-II, negative cognitive bias, mindfulness, and experiential avoidance) are all reported in Table 5. As the BAI correlated significantly with the BDI-II, analyses examining changes in BDI-II across sessions were conducted with and without the BAI; all other previously mentioned potential covariates were examined as well; however, only ANCOVAs where covariates affected change in the original analyses were reported.

Some activities, such as meditation, yoga, Tai Chi, prayer, and martial arts, are often associated with mindfulness (Baer et al., 2008; Mills \& Allen, 2000; Shelov, Suchday, \& Friedberg, 2009; Trousselard et al., 2010). Tai Chi was removed from these analyses because no participants reported having practiced this activity. To determine whether individuals who practiced, or had practiced these activities, showed significantly different baseline mindfulness scores than others in the sample, a series of independent samples $t$-tests were conducted. Overall, individuals who engaged in these activities were no more mindful at baseline than individuals without said histories (see Table 8).

\section{Intervention Adherence and Study Completion}

Patient adherence to activity tracking was measured using the behavioral checkout sheets that were returned to the therapist at Session 2. Of the 21 participants in the clinical group, 12 
$(57.14 \%)$ individuals provided this information as requested. However, three participants completed all tracking forms without marking completion of scheduled activities. Thus, these data can only be used to assess activity tracking and not for completion of scheduled activities. Because of this, any inferences about adherence to the intervention are limited.

To examine completion of scheduled activities, an adherence score was calculated by dividing the number of scheduled activities completed by the number of activities that were scheduled. For the nine individuals $(42.86 \%)$ who provided this data, participants scheduled an average of 20 activities over the interim between Sessions 1 and 2. Participants completed an average of $16.22(S D=9.27)$ of the scheduled activities, resulting in an adherence score of $82 \%$.

There was an overall attrition rate of $38.50 \%(n=8)$ in the clinical condition and $38.90 \%$ attrition $(n=7)$ in the control condition. That is, of the 21 clinical participants, 16 completed Session 2 and 13 completed Session 3. Of the 18 control participants, 17 completed Session 2 and 11 completed Session 3. Importantly, attrition did not differ between groups $(p=.96)$. After imputing the series mean to account for the missing BDI-II item 9, for the sake of comparison, treatment completers and non-completers did not differ on any demographic or outcome variable at pre-screening (see Tables 9 and 10). In accordance with the Consolidated Standards of Reporting Trials (CONSORT, 2010), Figure 1 contains a flow diagram of the study's randomization and attrition process. Figure 2 illustrates attrition and BDI-II scores across sessions for clinical and control participants who completed Sessions 1, 2, or 3.

\section{Intervention Efficacy Analyses}

The analyses to determine the efficacy of the intervention involved two approaches. First, an intent-to-treat (ITT) approach was utilized to control for attrition bias. Thus, all participants who were randomized for participation in the study were included in the main analyses. This was 
completed using carry forward endpoint analyses where data from the last session attended were carried forward to future incomplete sessions $(n=15)$. Second, a "study completer" or "perprotocol" approach was used to test for the effect of the intervention on individuals who completed all three sessions $(n=24)$.

Intent-to-Treat. Data for the Beck Depression Inventory-II were analyzed using a 3 (session: pre-intervention, two-week follow-up, and one-month follow-up) X 2 (condition: clinical or control) mixed-design ANOVA. Session number was a within-subjects factor, and condition was a between-subjects factor. Mauchly's test suggested that the assumption of sphericity had not been violated $(\chi 2(2)=83.39, \mathrm{p}<.001)$. There was a main effect of session $\left(F(2,72)=232.04, p<.001, \eta \mathrm{p}^{2}=.86\right)$, such that BDI-II scores decreased from Session $1(M=$ 20.08, $S D=7.67)$ to Session $2(M=5.39, S D=4.56 ; p<001)$ and increased from Session 2 to Session $3(M=12.24, S D=9.00 ; p<001)$. BDI-II scores at Session 3 were significantly lower than scores at Session $1(p<001)$. Neither the main effect of condition $(F(1,36)=1.87, p=.18$, $\left.\eta p^{2}=.26\right)$ nor the interaction between session and condition were significant $(F(2,72)=.90, p=$ $\left..41, \eta p^{2}=.024\right)$.

Study Completer. Again, a 3 (session: pre-intervention, two-week follow-up, and one month follow-up) X 2 (condition: clinical or control) mixed-design ANOVA was conducted, but only participants who completed all three sessions were included in the analyses. Mauchly's test suggested that the assumption of sphericity had been violated $\left(\chi^{2}(2)=2.09, p=.35\right)$, so results were interpreted using the Greenhouse-Geisser (1959) interpretation. There was a significant main effect of session $\left(F(1.8,42)=51.05, \mathrm{p}<.001, \eta \mathrm{p}^{2}=.71\right)$, such that BDI-II scores decreased from Session $1(M=18.70, S D=6.43)$ to Session $2(M=4.04, S D=3.69 p<.001)$ and increased from Session 2 to Session $3(M=14.04, S D=9.66 ; p<.001)$. BDI-II scores at 
Session 3 were were significantly lower than scores at Session $1(p<01)$. The main effect of condition $\left(F(1,21)=1.45, p=.24, \eta p^{2}=.07\right)$ was not significant. However, there was a significant interaction between session and condition, $F(1.8,42)=3.84, p<.001, \eta p^{2}=.16$ (see Figure 3).

The interaction was decomposed with simple effects analyses. There were no significant differences in BDI-II scores between conditions at any session (Session $1 p=.77$, Session $2 p=$ .24 , and Session $3 p=.07)$. Both the clinical $\left(F(2,20)=42.09, p<.001, \eta p^{2}=.81\right)$ and control groups $\left(F(2,20)=30.73, p<.001, \eta p^{2}=.75\right)$ showed significant changes in BDI-II scores across sessions. For the clinical condition, BDI-II scores decreased from Session 1 to Session 2 $(p<.001)$ and increased from Session 2 to Session $3(p=.003)$. However, BDI-II scores at Session 3 were still lower than scores at Session $1(p=.001)$. For the control condition, BDI-II scores decreased from Session 1 to Session $2(p<.001)$ and increased from Session 2 to Session $3(p<.001)$. But, BDI-II scores at Session 3 did not significantly differ from scores at Session 1 $(p=.845)$. That is, BDI scores returned to pre-assessment levels for participants in the control group, but not for the clinical group.

\section{Covariate Analyses}

As the BAI correlated significantly with the BDI-II, both ITT and "study completer analyses" examining changes in BDI-II across sessions were conducted with BAI as a covariate.

Intent-to-Treat. Data for the Beck Depression Inventory-II were analyzed using a 3 (session: pre-intervention, two-week follow-up, and one-month follow-up) X 2 (condition: clinical or control) mixed-design ANCOVA with BAI added as a covariate. Mauchly's test suggested that the assumption of sphericity had not been violated $(\chi 2(2)=76.28, \mathrm{p}<.001)$. There was a main effect of session $\left(F(2,70)=38.89, p<.001, \eta p^{2}=.52\right)$, such that BDI-II 
scores decreased from Session $1(M=20.08, S D=7.68)$ to Session $2(M=5.39, S D=.4 .56 ; p<$ $.001)$ and increased from Session 2 to Session $3(M=14.61, S D=9.00 ; p<.001)$. BDI-II scores at Session 3 were significantly less than scores at Session $1(p<.001)$. The main effect of condition was not significant $\left(F(1,35)=1.19, p=.28, \eta p^{2}=.03\right)$. The interaction between session and condition was not significant $\left(F(2,70)=.42, p=.53, \eta p^{2}=.01\right)$.

Study Completer. Data for the Beck Depression Inventory-II were analyzed using a 3 (session: pre-intervention, two-week follow-up, and one-month follow-up) X 2 (condition: clinical or control) mixed-design ANCOVA with BAI added as a covariate, but only for individuals who completed all three assessment sessions. Mauchly's test suggested that the assumption of sphericity had not been violated $(\chi 2(2)=41.53, p<.001)$. There was a main effect of session $\left(F(2,40)=21.76, p<.001, \eta p^{2}=.52\right)$, such that BDI-II scores decreased from Session $1(M=18.69, S D=6.43)$ to Session $2(M=4.04, S D=3.69 ; p<.001)$ and increased from Session 2 to Session $3(M=14.04, S D=9.66 ; p<.001)$. BDI-II scores at Session 3 were significantly lower than scores at Session $1(p=.012)$. The main effect of condition was not significant $\left(F(1,20)=.18, p=.67, \eta p^{2}=.01\right)$. When BAI was added as a covariate, the previously identified interaction between session and condition became non-significant $(F(2,40)$ $\left.=1.55, p=.23, \eta p^{2}=.07\right)$.

\section{Secondary Outcome Variable Analyses}

To determine whether experiential avoidance, negative cognitive bias, and mindfulness changed due to the intervention, a series of 3 (session: pre-intervention, two-week follow-up, and one month follow-up) X 2 (condition: clinical or control) mixed-design ANOVAs were conducted. Specifically, ITT and "study completer" data for negative cognitive bias as assessed by BeanFest and the Dysfunctional Attitudes Scale - Short Form 1, mindfulness as assessed by 
the Mindful Attention Awareness Scale, and experiential avoidance as assessed by the Multidimensional Experiential Avoidance Questionnaire were analyzed separately.

\section{Negative Cognitive Bias}

Intent-to-Treat. Data for changes in mean index of the learning bias (i.e., proportion of negative beans correctly classified minus the proportion of positive beans correctly classified) in BeanFest were analyzed using a 3 (session: pre-intervention, two-week follow-up, and onemonth follow-up) X 2 (condition: clinical or control) mixed-design ANOVA. Mauchly's test suggested that the assumption of sphericity had not been violated $(\chi 2(2)=20.38, p<.01)$. There was no significant main effect of session $(F(2,74)=1.9, p=.15, \eta p 2=.05)$. The main effect of condition was not significant $(F(1,37)=2.45, p=.13, \eta p 2=.06)$. The interaction between session and condition was not significant $(F(2,74)=.04, p=.90, \eta p 2<.01)$.

Data for changes in the generalization bias to neutral stimuli in BeanFest (i.e., negativity bias through the generalization of negative attitudes) were analyzed using a 3 (session: preintervention, two-week follow-up, and one-month follow-up) X 2 (condition: clinical or control) mixed-design ANOVA. Mauchly's test suggested that the assumption of sphericity had not been violated $(\chi 2(2)=8.6, \mathrm{p}<.05)$. There was no significant main effect of session $(F(2,74)=.57, p$

$=.57, \eta p 2=.02)$. The main effect of condition was not significant $(F(1,37)=.18, p=.73, \eta p 2$ $=.15)$. The interaction between session and condition was not significant $(F(2,74)=.54, p=$ $.59, \eta p 2=.01)$

Data for DAS - SF1 were analyzed using a 3 (session: pre-intervention, two-week follow-up, and one-month follow-up) X 2 (condition: clinical or control) mixed-design ANOVA. Mauchly's test suggested that the assumption of sphericity had been violated $(\chi 2(2)=5.23, \mathrm{p}=$ $.07)$, so results were interpreted using the Greenhouse-Geisser (1959) interpretation. There was 
no significant main effect of session $(F(2,72)=2.62, p=.08, \eta p 2=.07)$. The main effect of condition was not significant $(F(1,36)=.48, p=.49, \eta p 2=.01)$. The interaction between session and condition was not significant $(F(2,72)=.07, p=.91, \eta p 2<.01)$.

Study Completer. Data for changes in mean index of learning bias in BeanFest were analyzed using a 3 (session: pre-intervention, two-week follow-up, and one-month follow-up) X 2 (condition: clinical or control) mixed-design ANOVA, but only for participants who completed all three sessions. Mauchly's test suggested that the assumption of sphericity had not been violated $(\chi 2(2)=8.13, \mathrm{p}<.05)$. There was no significant main effect of session $(F(2,44)=.96, p$ $=.39, \eta p 2=.04)$. The main effect of condition was not significant $(F(1,22)=1.44, p=.24, \eta p$ $2=.06)$. The interaction between session and condition was not significant $(F(2,44)=.58, p=$ $.56, \eta p 2=.03)$.

Data for changes in the generalization bias to neutral stimuli in BeanFest were analyzed using a 3 (session: pre-intervention, two-week follow-up, and one-month follow-up) X 2 (condition: clinical or control) mixed-design ANOVA. Mauchly's test suggested that the assumption of sphericity had been violated $(\chi 2(2)=1.15, p=.56)$, so results were interpreted using the Greenhouse-Geisser (1959) interpretation. There was no significant main effect of session $(F(1.9,44)=.20, p=.82, \eta p 2=.01)$. The main effect of condition was not significant $(F(1,22)=.03, p=.87, \eta p 2=.001)$. The interaction between session and condition was not significant $(F(1.9,44)=1.9, p=.16, \eta p 2=.08)$.

Data for the DAS - SF1 were analyzed using a 3 (session: pre-intervention, two-week follow-up, and one-month follow-up) X 2 (condition: clinical or control) mixed-design ANOVA. Mauchly's test suggested that the assumption of sphericity had been violated $(\chi 2(2)=2.36, \mathrm{p}=$ .31), so results were interpreted using the Greenhouse-Geisser (1959) interpretation. There was 
no significant main effect of session $(F(1.8,42)=2.72, p=.08, \eta p 2=.07)$. The main effect of condition was not significant $(F(1,21)=6.20, p=.44, \eta p 2=.03)$. The interaction between session and condition was not significant $(F(1.8,42)=10.34, p=.24, \eta p 2=.07)$.

\section{Experiential Avoidance}

Intent-to-Treat. Data for changes in MEAQ scores were analyzed using a 3 (session: pre-intervention, two-week follow-up, and one-month follow-up) X 2 (condition: clinical or control) mixed-design ANOVA. Mauchly's test suggested that the assumption of sphericity had not been violated $(\chi 2(2)=6.0, \mathrm{p}<.05)$. There was no significant main effect of session $(F(2,72)$ $=.2 .76 p=.07, \eta p 2=.02)$. The main effect of condition was not significant $(F(1,36)=.004, p$ $=.95, \eta p 2<.001)$. The interaction between session and condition was not significant $(F(2,72)$ $=1.51 p=.23, \eta p 2=.04)$.

Study Completer. Data for changes in MEAQ scores were analyzed using a 3 (session: pre-intervention, two-week follow-up, and one-month follow-up) X 2 (condition: clinical or control) mixed-design ANOVA, but only for participants who completed all three sessions. Mauchly's test suggested that the assumption of sphericity had not been violated $(\chi 2(2)=7.84$, $p$ $<.05)$. There was a significant main effect of session $(F(2,42)=8.17, p<.01, \eta p 2=.28)$, such that MEAQ scores did significantly not change from Session $1(M=219.70, S D=20.60)$ to Session $2(M=213.13, S D=28.67 ; p=.13)$, but decreased significantly from Session 2 to Session $3(M=205.56, S D=21.30 ; p=.04)$. MEAQ scores at Session 3 were significantly lower than at Session $1(p<.01)$. The main effect of condition was not significant $(F(1,21)=.60, p=$ $.45, \eta p 2=.03)$. The interaction between session and condition was not significant $(F(2,42)=$ $.41, p=.67, \eta p 2=.02)$.

\section{Mindfulness}


Intent-to-Treat. Data for changes in MAAS scores were analyzed using a 3 (session: pre-intervention, two-week follow-up, and one-month follow-up) X 2 (condition: clinical or control) mixed-design ANOVA. Mauchly's test suggested that the assumption of sphericity had not been violated $(\chi 2(2)=8.9, \mathrm{p}<.05)$. There was no significant main effect of session $(F(2,72)$ $=2.43 p=.10, \eta p 2=.06)$. The main effect of condition was not significant $(F(1,37)=.26 p=$ $.61, \eta p 2=.01)$. The interaction between session and condition was not significant $(F(2,72)=$ $.33, p=.72, \eta p 2=.01)$.

Study Completer. Data for changes in MAAS scores were analyzed using a 3 (session: pre-intervention, two-week follow-up, and one-month follow-up) X 2 (condition: clinical or control) mixed-design ANOVA, but only for participants who completed all three sessions. Mauchly's test suggested that the assumption of sphericity had been violated $(\chi 2(2)=3.52, \mathrm{p}=$ .17), so results were interpreted using the Greenhouse-Geisser (1959) interpretation. There was no significant main effect of session $(F(1.7,42)=2.63, p=.09, \eta p 2=.02)$. The main effect of condition was not significant $(F(1,21)=.01, p=.94, \eta p 2<.01)$. The interaction between session and condition was not significant $(F(1.7,42)=.17, p=.82, \eta p 2=.01)$.

\section{Discussion}

The purpose of this study was to replicate and extend the findings of Gawrysiak Nicholas, and Hopko (2009) by testing the efficacy of a modified version of their 1-session intervention in reducing self-reported depressive symptoms in a sample of university students with mild to moderate depression. The current study extended this work by adding an additional follow-up session at 1-month post intervention. Two other limitations of the previous study were addressed by the current study. First, Gawrysiak and colleagues (2009) limited external validity by excluding individuals who were currently on antidepressant medication or had engaged in 
psychotherapy within the past 2 years. In order to increase external validity in the current study, only individuals who had not been stabilized on their antidepressant medication for 8 weeks or longer and who were enrolled in psychotherapy when they began the study were excluded. Second, while adequately powered, the size of the sample utilized for this study was quite small $(N=30)$, thus possibly affecting generalizability and external validity by increasing the likelihood that the sample is not representative of the overall population. The current study sought to address this possibility, and to account for its own slightly larger sample $(N=39)$ by drawing from a different population of students than the previous study (i.e., students seeking treatment for depression), thus increasing generalizability.

The central hypothesis was that reductions in depression scores would be observed across time points in a sample of undergraduate students presenting with mild to moderate depression scores who had completed a 1-session intervention based on BATD-R compared to a no treatment control group of undergraduate students presenting with mild to moderate depression scores. This hypothesis was not supported by ITT or "study completer" analyses. That is, the two groups did not significantly differ in their depression scores at any of the sessions. Both groups' depression scores significantly improved between Sessions 1 and 2, and scores increased from Sessions 2 and 3. Interestingly, control group participant scores at Session 3 returned to baseline, whereas for clinical group participants, the increase in depression scores from Session 2 to Session 3 did not return to baseline. Rather, they maintained a $44.35 \%$ improvement from intervention to Session 3. Although an interesting finding, this change cannot be attributed to the intervention as the clinical and control groups did not significantly differ in their depression scores at Session $3(p=.07)$. This lack of differences between groups may be due to type II error, given the relatively small sample size $(N=39)$ and the attrition rate $(38.50 \%)$. With a 
larger sample size and/or lower attrition rate, a significant difference between groups may have been detected.

Further, the findings of the current study should be interpreted with great caution. For Session 2 in the current study the BDI-II was found to have very low internal consistency reliability ( $\alpha=.54$ ). This finding was specific to Session 2 as Sessions 1 and 3 were found to have alphas at .77 and .86, respectively. This indicated that at Session 2, in these data, that the questions on the BDI-II did not seem to be measuring the same construct as items did not correlate significantly. This issue could have resulted from a limited sample size due to attrition or a limited range of scores reported as BDI-II scores were very low for both conditions at Session 2. If a measure with higher internal constancy was being utilized at Session 2, then it is possible that the current study would have replicated the previous study.

Thus, the current study did not replicate the findings of Gawrysiak Nicholas, and Hopko (2009) as the previous study found statistically different outcomes for their clinical and control groups at two-week follow-up. One issue that may have affected our inability to replicate their findings has to do with the purpose for which participants were informed that they were recruited for the study. The original study reported that "Potential participants read an online study description that outlined the purpose of the study as an examination of the effectiveness of brief therapy for depression for those individuals who might currently be depressed and in need of assistance" (Gawrysiak et al., 2009; p. 469). It is possible that the individuals from the first study improved more in relation to the control group because all participants in that study felt as if they might currently be depressed and in need of assistance. The current study's intention to draw its sample from a student population not directly seeking treatment may have limited our treatment effect. 
Gawrysiak and colleagues (2009) reported that their recruitment methods were designed with attracting participants who were motivated to change (i.e., reduce their symptoms of depression). It is possible that this motivation had an effect on the previous study's control group and that the current study's lack of focus on motivation to change caused researchers to recruit students who, while having similar depression scores at baseline, with the original study reporting $(M=20.4, S D=5.6)$ very similar BDI-II scores to the current study ( $M=19.56, S D=$ 8.23; $p=.63$ ), were not feeling negative enough to be seeking treatment at the time of their participation. Thus increasing the likelihood of greater attrition and lower internal consistency reliability on the BDI-II due to reduced sample size.

Although intended to simplify certain processes within the intervention, it is possible that the modifications, based on BATD-R, that were made to the original Gawrysiak Nicholas, and Hopko (2009) manual led to the lack of treatment effects in the current study. This difference in outcomes might also be due to the different approach to activity tracking that was introduced in BATD-R and was the largest departure made from the original manual to the current protocol. The type of tracking required for successful implementation of the new protocol is considerably more involved than the tracking that occurred in the original study. This might have increased attrition as tracking activities in this manner for 14 days requires a great deal larger personal commitment than the commitment made by participants in the previous study. Thereby, limiting statistical power to detect what might have been meaningful differences between groups.

The current study utilized 6 rather than two therapists. While extensive efforts were made to reduce variability in treatment delivery by therapists in the current study, the two therapists in the previous study were likely more standardized as increasing the number of therapists increases variability in the delivery of the intervention. It is also possible that this variability could affect 
attrition rates as more individuals are required to interact with participants and therefore more likely to become involved with conflict. It is also possible that, in such a small sample, that particular therapist qualities might have affected outcomes (e.g. likability, perceived earnestness, perceived level of interest in participant). Additionally, it is possible that the lack of significantly different findings between groups in the current study in relation to findings from the Gawrysiak Nicholas, and Hopko (2009) study are related to the differing demands of two sessions and two weeks of participation, when compared to three sessions and one month of participation. It is possible that this difference also led to attrition; as a considerably greater amount of effort was required to complete the current study. Thus, possibly leading to greater attrition and lower internal consistency reliability on the BDI-II at session two due to reduced sample size and a reduced range of scores.

As both groups improved between Sessions 1 and 2, other factors related to participating in a research project focusing on depression and mood improvement may have affected participants. First participants may have been affected by social desirability bias. Social desirability bias (Cronbach, 1950) is a type of response bias that occurs when participants feel that responding in a particular way will be viewed favorably by others. It can occur when participants over-report behavior that they feel is desirable such as mood improvement or underreporting behavior that they feel is undesirable behavior, such as depressive behavior because they are aware that the study is examining an intervention for depression (see, Nederhof, 1985, for review). It is also possible that individuals with mild to moderate depression scores from our sample may feel that they are getting better simply because they are doing something (i.e., participating in a research study) related to mood improvement and reducing depression. It is also possible that their overall reinforcement for non depressive behavior is increased simply by 
their participation, and that by participating, their behavior has become activated in this regard.

The change that occurred between Sessions 1 and 2 could also be due to it being a specific time in the semester in relation to project deadlines, exams etc. Participants tend to seek extra credit points when they feel that they are needed (e.g. directly following a grade that they are unhappy with) it is possible that for those individuals in our sample for whom this is the case that they presented with mild to moderate depression scores, but that their feelings were due to being unhappy with their academic achievement at Session 1, and that by Session 2 they had returned to their regular level of happiness. This might explain their return to higher levels of depression by Session 3 as deadlines for assignments and new exams begin to approach.

Furthermore, from examining the ANCOVA analysis. We found that the group by session interaction that occurred in the study completer analysis for BDI-II scores was made nonsignificant when controlling for BAI. The correlation between BDI-II and BAI scores is widely known (See Beck, Steer, Ball, \& Ranieri, 1996), and there is a great deal of evidence supporting comorbidity between depressive and anxiety related disorders (Alloy, Kelly, Mineka, \& Clements, 1990; Brown, Chorpita, \& Barlow, 1998; Gorman, 1996; Maier \& Falkai, 1999). Thus, it is possible that the high level of overlap between depressive and anxious symptomatology may account for the interaction becoming non-significant when controlling for BAI. However, the main effect for session remained significant, such that the unknown variables that caused BDI-II scores to decrease for all participants from Session 1 to Session 2 and increase from Session 2 to Session 3 continued to do so while controlling for the influence of BAI scores, suggesting that these unknown variables were affecting depression independent of anxiety. 
A secondary aim of this study was to examine whether the one-session BATD intervention affected negative cognitive bias, mindfulness, and experiential avoidance. It is possible that through beginning to understand how behavior affects emotion, developing a values-based way to change behavior, and beginning to attend to activity level through the early sessions of BATD-R that the individual might come to challenge cognitive biases without realizing it. Jacobson and colleagues (1996) found that behavioral activation was as effective as cognitive therapy at altering dysfunctional attributional style, and that changes in negative cognitive style were more likely to be followed by decreased depression in BA than in CT. Thus, negativity bias was reduced in behavioral activation along with depression. Further, BATD-R asks the individual to pay attention to what they are doing rather than how they are feeling and to engage in activities based on their values rather than avoiding important or enjoyable activities. Thus individuals may experience a reduction in experiential avoidance throughout the treatment process. It is possible that the increased focus on what the individual is doing in the present moment in BATD-R is accompanied by an increased awareness of the present moment. For example, as the individual begins attending to tracking activities, learning and clarifying values (i.e., through the life areas, values, and activities inventory), and scheduling values-based important and enjoyable activities, that the individual's overall level of mindfulness is increased through increased attention to the present moment. Therefore, it is possible that BATD-R increases mindfulness without providing specific training in mindfulness skills.

Because of these possibilities, it was hypothesized that negative cognitive bias would decrease, experiential avoidance would decrease, and mindfulness would increase after the 1session intervention. These hypotheses were not supported by the data, as no significant group by session interactions for any of the outcome variables were found. Further, factors that possibly 
led to the non-significant intervention findings such as differences in motivation for change, social desirability bias, and time during the semester may have influenced the non significant findings for these variables as well. This could be due to the fact that the changes that were seen are due to factors other than the BATD-R based intervention. It follows that if the intervention were the cause of the changes in BDI-II outcomes that were observed in the current study, then it is also possible that the second hypothesis might have been supported. If that were not the case, then it is possible that BATD does not affect these variables, but instead, as Ryba, Lejuez, and Hopko (2014) suggest, affects only ratio of reinforcement for depressive and non-depressive behavior, through values based scheduling of important and enjoyable activities as well as common factors related to therapeutic change such as empathy and therapeutic alliance. It is also possible that due to the limited sample size that smaller effect sizes could not be captured so a larger RCT with a large sample might find differing results than those reported by the current study.

It may be possible that the lack of significant change across these measures is due to the specific measures utilized in this study and not related to the affects of the intervention on the specified constructs. Thus, had other measures been utilized such as the Dot-Probe Task (MacLeod, Mathews \& Tata, 1986) for negativity bias, the Acceptance and Action Questionnaire-II (Bond et al., 2011) for experiential avoidance, or the Five Facet Mindfulness Questionnaire (Baer et al., 2008) for mindfulness then the current study might have had different results.

There was a significant main effect of session for the MEAQ in the completer analysis, such that MEAQ scores did not change from Session 1 to Session 2, but decreased significantly from Session 2 to Session 3. This could be related to the amount of commitment that is required 
to participate in a study over a 1-month period in relation to those individuals who leave prior to completing the study. This would explain the decrease in avoidance that is seen for study completers between Sessions 2 and 3 as the individual is required to muster the effort required to persevere to the end of the study. It could also be related to social desirability bias as by the time a participant is assessed at session 3 they have already completed this measure a number of times and likely have some idea of what they believe the researcher would want them to report.

As this study failed to replicate the findings of Gawrysiak and colleagues (2009) two important implications for practice and theory should be noted. First, it is important to note that of the two randomized controlled trials that examined a one session BATD based intervention for moderately depressed university students, one study found significant change when comparing a clinical group to a no treatment control group and one study did not. Suggesting that clinicians might want to be cautious while implementing this intervention as a stand alone treatment until more evidence of its efficacy can be gathered. Second, it may indicate that these interventions are only efficacious in specific populations, such as moderately depressed university students who are motivated for treatment, but not for mild to moderately depressed university student's whose primary reason for participating in the research study is to receive extra credit or monetary compensation.

\section{Limitations}

Several limitations should be mentioned regarding the present study. First, because of the small, but adequately powered, sample size and attrition rate, it is possible that Type-II error was present when examining outcome data. Increasing sample size is one of the strategies that have been suggested for increasing statistical power when dealing with this issue in reporting RCT outcomes (Heritier., Gebski, \& Keech, 2003). The overall attrition rate for the present study was 
$38.5 \%$, not unlike attrition rates seen in outpatient community mental health clinics, which often range from 20-60\% (Simons, Levine, Lustman, \& Murphy, 1984). It was better than other treatment outcome studies which often report attrition rates between 40-60\% (Chambless \& Ollendick, 2001). Still, the attrition rate may have affected the results. Greater attention to motivation for change in advertising and prescreening, such as seeking participants who report feeling the need to address their mood and /or depressive symptoms, might improve attrition rates. Second, it is possible that social desirability bias or repeated administration of measures influenced the results of the present study. Future studies might control for this by explaining to participants in the instructions prior to the different assessment sessions that it is imperative that they be truthful in their responding, and that it is better that we receive reliable information than information that participants think we want to hear. Third, for Session 2 in the current study the BDI-II is had very low internal consistency reliability $(\alpha=.54)$. This finding was specific to Session 2 as Sessions 1 and 3 had alphas at .77 and .86, respectively. This means that at Session 2 , in these data that the questions on the BDI-II did not seem to be measuring the same construct as items were not correlating significantly. If multiple measures were utilized for the main outcome variable, it would allow researchers to more effectively compare change across time points, future studies should take this into consideration. Fourth, direct observation of scheduled activities was not possible. Therefore, it is uncertain whether individuals actually increased their engagement in important and enjoyable activities. New methods of recording activity involvement such as electronic devices (e.g., Fitbit) might be useful in recording some of these data, as would be reports from other individuals who are present when the participant is engaging in scheduled activities. Fifth, students in the study were not administered a structured clinical interview to determine whether they actually met diagnostic criteria for major depression. 
Therefore, it is uncertain whether the results of this study would generalize to individuals who meet criteria for MDD. Similarly, the current sample was fairly homogenous with most participants being Caucasian (81.6\%) and female (78.9\%) which limits the generalizability of these findings to more diverse populations. Future research should attempt to extend these findings with more diverse samples.

\section{Future Directions}

The current study sought to provide support for a one-session intervention for depression in university students (Gawrysiak Nicholas, \& Hopko, 2009) and extend the evidence for significant changes in BDI-II scores from 2-weeks to one-month post intervention in university students with mild to moderate BDI-II scores. However, the current study failed to replicate the findings of Gawrysiak and colleagues (2009). While this failure to replicate is important, these findings are limited to the samples utilized. Currently, the two efficacy trials utilizing a onesession BATD intervention only examined its usefulness with university students with mild to moderate depression scores on the BDI-II. Future, research should compare the efficacy of the one session intervention to the full BATD-R protocol within this same population, and in other populations such as individuals who have been formally diagnosed with Major Depressive Disorder by means of a structured clinical interview.

Further, depressive disorders are the most common mental health difficulties within the general public. They affect roughly $10.3 \%$ of the population of adults in the United States each year (Kessler et al., 1994). Consequently, this one-session BATD-R based intervention should be examined with other participant populations, such as individuals who are experiencing transitions other than than those that are school related. For example, individuals in the military who have to move frequently may be particularly affected by this intervention as they have many 
other transition oriented activities that they must engage in and a 1 session intervention may provide much needed benefit in a very short amount of time. However, due to the findings of the current study, outcomes should be monitored closely and appropriate adjustments made when needed in order to bring about positive outcomes.

Lastly, it is of great importance that we continue to examine the presence or absence of particular variables that may affect the efficacy of treatments for depression; as understanding the variables associated with positive change and recovery from depression, will allow us to better predict positive treatment outcomes and optimize therapeutic change (Kazdin, 2007; Keitner, Ryan, Miller, \& Norman, 1992).

\section{Conclusions}

Depression affects approximately $6.7 \%$ of the adult population in the United States, making depression the leading cause of disability for Americans aged 15-44 years. Among university students, the prevalence for depression is much higher and has increased significantly over the past two decades, with current rates of depression between $15 \%$ and $20 \%$ (American College Health Association, 2007; Benton, Robertson, Tseng, Newton, \& Benton, 2003; Gallagher, 2007; Gawrysiak, Nicholas, \& Hopko, 2009; Voelker, 2003). Nonetheless, the evidence supporting the treatment of depression with this population is sparse. The current study failed to replicate the findings of a previous study examining the efficacy of a one-session intervention (Gawrysiak, Nicholas, \& Hopko, 2009) for reducing depressive symptoms in university students with mild to moderate depression. Due to these inconsistent findings, more outcome research is needed to examine the efficacy of this one session BATD-R based intervention. However, more research is needed before any conclusions can be made regarding the efficacy of a 1-session BATD based intervention. With such small samples, the risk of both 
Type I and Type II error are increased greatly, and future studies need to include larger, and more diverse samples. Future studies should also control for problems related to measurement by using multiple measures and methodologies for determining treatment outcomes. Great care should be taken in future studies to control for social desirability as well as other types of biased responding. At this time, regarding the present study, as well as the study conducted by Gawrysiak and colleagues (2009) conclusions cannot be definitive given the small sample sizes for each study, and more research is needed before assertions regarding the efficacy of a 1session BATD based intervention can be made.

In order to reduce the public health threat associated with depression and because of time constraints in many people's schedules, more studies are needed to test the overall efficacy of this one-session intervention in traditional behavioral health clinics, primary care facilities, and other healthcare settings where individuals might present with depressive symptoms. 


\section{Reference}

Alloy, L. B., Kelly, K. A., Mineka, S., \& Clements, C. M. (1990). Comorbidity in anxiety and depressive disorders: A helplessness/hopelessness perspective. In J. D. Maser, \& C. R. Cloninger (Eds.), Comorbidity of Anxiety and Mood Disorders. Washington, D.C.: American Psychiatric Press.

American College Health Association. (2007). The American College Health Association National College Health Assessment (ACHANCHA) Spring 2006 reference group data report (abridged). Journal of American College Health, 53, 195-206.

American College Health Association. (2012). The American College Health Association National College Health Assessment (ACHANCHA) Fall 2011 reference group data report. Retrieved from http://www.acha-ncha.org/docs/ACHA-NCHAII_ReferenceGroup_ExecutiveSummary_Fall2011.pdf

American Psychiatric Association. (2000). Practice guidelines for the treatment of patients with major depressive disorder (revision). American Journal of Psychiatry, 157, 1-45.

Arch, J. J., \& Craske, M. G. (2006). Mechanisms of mindfulness: Emotion regulation following a focused breathing induction. Behavior Research and Therapy, 44, 1849-1858. doi:10.1016/j.brat.2005.12.007

Baer, R. A., Smith, G. T., Lykins, E., Button, D., Krietemeyer, J., Sauer, S., Walsh, E., Duggan, D., \& Williams, J.M.G., (2008). Construct validity of the Five Facet Mindfulness Questionnaire in meditating and nonmeditating samples. Assessment, 15, 329-342. doi: $10.1177 / 1073191107313003$

Baum, S. Payea, K. (2005).Education pays 2004: The benefits of higher education for individuals and society: Trends in higher education series (College Board Report 5664) 
Beck, A. T. (1970). Cognitive therapy: Nature and relation to behavior therapy. Behavior Therapy, 1, 184-200. doi: 10.1016/S0005-7894(70)80030-2

Beck, A. T. (1987). Cognitive models of depression. Clinical Advances in Cognitive Psychotherapy: Theory and application, 14, 29-61.

Beck, A. T., Steer, R. A., Ball, R., \& Ranieri, W. F. (1996). Comparison of Beck Depression Inventories-IA and-II in psychiatric outpatients. Journal of personality assessment, 67(3), 588-597.

Benton, S. A., Robertson, J. M., Tseng, W., Newton, F. B., \& Benton, S. L. (2003). Changes in counseling center client problems across 13 years. Professional Psychology: Research and Practice, 34, $66-72$.

doi:10.1037/0735-7028.34.1.66

Bjornsson, A., Carey, G., Hauser, M., Karris, A., Kaufmann, V., Sheets, E., \& Craighead, W. E. (2010). The effects of experiential avoidance and rumination on depression among college students. International Journal of Cognitive Therapy, 3, 389-401. doi: 10.1521/ijct.2010.3.4.389

Borkovec, T.D., Alcaine, O., \& Behar, E. (2004). Avoidance theory of worry and generalized anxiety disorder. In R.G. Heimberg, C.L. Turk, \& D.S. Mennin (Eds.), Generalized anxiety disorder: Advances in research and practice. New York: Guilford Press.

Bradley, B. P., Mogg, K., \& Lee, S. C. (1997). Attentional biases for negative information in induced and naturally occurring dysphoria. Behaviour Research and Therapy, 35, 911927. doi:10.1016/S0005- 7967(97)00053-3

Brown, K. W., \& Ryan, R. M. (2003). The benefits of being present: Mindfulness and its role in psychological well-being. Journal of Personality and Social Psychology, 84, 822-848. 
doi: $10.1037 / 0022-3514.84 .4 .822$

Brown, K.W., Ryan, R.M., \& Creswell, J.D. (2007). Mindfulness: Theoretical foundations and evidence for its salutary effects. Psychological Inquiry, 18, 211-237. doi: $10.1080 / 10478400701598298$

Brown, T. A., Campbell, L. A., Lehman, C. L., Grisham, J. R., \& Mancill, R. B. (2001). Current and lifetime comorbidity of the DSM-IV anxiety and mood disorders in a large clinical sample. Journal of Abnormal Psychology, 110, 585-595. doi:10.1037/0021843X.110.4.585

Brown, T. A., Chorpita, B. F., \& Barlow, D. H. (1998). Structural relationships among dimensions of the DSM-IV anxiety and mood disorders and dimensions of negative affect, positive affect, and autonomic arousal. Journal of Abnormal Psychology, 107(2), $179-192$.

doi.org/10.1037//0021-843x.107.2.179

Bruce, M. L., Takeuchi, D. T., \& Leaf, P. J. (1991). Poverty and psychiatric status: longitudinal evidence from the New Haven Epidemiologic Catchment Area Study. Archives of General Psychiatry, 48, 470-474. doi:10.1001/archpsyc.1991.01810290082015

Cohn, E., \& Geske, T. G. (1992). Private nonmonetary returns to investment in higher education. In The economics of American higher education (pp. 173-195). Springer, Netherlands. doi: 10.1007/978-94-011-2950-3_7

Cribb, G., Moulds, M. L., \& Carter, S. (2006). Rumination and experiential avoidance in depression. Behaviour Change, 23, 165-176.

doi:10.1375/bech.23.3.165 
Cronbach, L. J. (1950). Further evidence on response sets and test design. Educational and Psychological Measurement, 10(1), 3-31.

Daughters, S., Braun, A., Sargeant, M., Reynolds, E., Hopko, D., Blanco, C., \& Lejuez, C. W. (2008). Effectiveness of a brief behavioral treatment for inner-city illicit drug users with elevated depressive symptoms: The life enhancement treatment for substance use (LETS Act!). Journal of Clinical Psychiatry, 69, 122-129.

doi:10.4088/JCP.v69n0116

Dee, T. S. (2004). Are there civic returns to education?. Journal of Public Economics, 88, 16971720. doi: $10.1016 /$ j.jpubeco.2003.11.002

Draper, M. R., Jennings, J., Baron, A., Erdur, O., \& Shankar, L. (2002). Time-Limited Counseling Outcome in a Nationwide College Counseling Center Sample. Journal of College Counseling, 5, 26-38.

doi: 10.1002/j.2161-1882.2002.tb00204.x

Dimidjian, S., Hollon, S. D., Dobson, K. S., Schmaling, K. B., Kohlenberg, R. J., Addis, M. E., ... \& Jacobson, N. S. (2006). Randomized trial of behavioral activation, cognitive therapy, and antidepressant medication in the acute treatment of adults with major depression. Journal of Consulting and Clinical Psychology, 74, 658.

doi: 10.1037/0022-006X.74.4.658

Dobson, K. S., Hollon, S. D., Dimidjian, S., Schmaling, K. B., Kohlenberg, R. J., Gallop, R. J., ... \& Jacobson, N. S. (2008). Randomized trial of behavioral activation, cognitive therapy, and antidepressant medication in the prevention of relapse and recurrence in major depression. Journal of Consulting and Clinical Psychology, 76, 468-477.

doi: 10.1037/0022-006X.76.3.468 
Faul, F., Erdfelder, E., Buchner, A., \& Lang, A. G. (2009). Statistical power analyses using G*Power 3.1: Tests for correlation and regression analyses. Behavior Research Methods, $41,1149-1160$.

doi: 10.3758/BRM.41.4.1149

Ferguson, J. M. (2001). SSRI Antidepressant Medications: Adverse Effects and Tolerability. Primary Care Companion to the Journal of Clinical Psychiatry, 3, 22-27. doi: 10.4088/PCC.v03n0105

Frewen, P., Lundberg, E., MacKinley, J., \& Wrath, A. (2011). Assessment of response to mindfulness meditation: meditation breath attention scores in association with subjective measures of state and trait mindfulness and difficulty letting go of depressive cognition. Mindfulness, 2(4), 254-269.

Gorman, J. M. (1996). Comorbid depression and anxiety spectrum disorders. Depression and Anxiety, 4(4), 160-168.

doi: 10.1002/(sici)1520-6394(1996)4:4<160::aid-da2>3.0.co;2-j

Goyal, M., Singh, S., Sibinga, E. M., Gould, N. F., Rowland-Seymour, A., Sharma, R., ... \& Ranasinghe, P. D. (2014). Meditation programs for psychological stress and well-being: a systematic review and meta-analysis. JAMA internal medicine, 174(3), 357-368. doi:/10.1001/jamainternmed.2013.13018

Eisenberg, D., Golberstein, E., \& Hunt, J. B. (2009). Mental health and academic success in college. The BE Journal of Economic Analysis \& Policy,9, 622-635.

doi: $10.2202 / 1935-1682.2191$ 
Eizenman, M., Lawrence, H. Y., Grupp, L., Eizenman, E., Ellenbogen, M., Gemar, M., \& Levitan, R. D. (2003). A naturalistic visual scanning approach to assess selective attention in major depressive disorder. Psychiatry Research,118, 117-128. doi: 10.1016/S0165-1781(03)00068-4

Everson, S. A., Maty, S. C., Lynch, J. W., \& Kaplan, G. A. (2002). Epidemiologic evidence for the relation between socioeconomic status and depression, obesity, and diabetes. Journal of Psychosomatic Research, 53, 891-895.

doi: 10.1016/S0022-3999(02)00303-3

Fazio, R. H., Eiser, J. R., \& Shook, N. J. (2004). Attitude formation through exploration: Valence asymmetries. Journal of Personality and Social Psychology, 87, 293-311 doi:10.1037/0022-3514.87.3.293

Ferster, C. B. (1973). A functional analysis of depression. American Psychologist, 28, 857-870. doi: $10.1037 / \mathrm{h} 0035605$

Freij, K., \& Masri, N. (2008). The brief behavioral activation treatment for depression: A psychiatric pilot study. Nordic Psychology, 60, 129-140. doi: 10.1027/19012276.60.2.129

Forman, E. M., Herbert, J. D., Moitra, E., Yeomans, P. D., \& Geller, P. A. (2007). A randomized controlled effectiveness trial of acceptance and commitment therapy and cognitive therapy for anxiety and depression. Behavior Modification, 31(6), 772-799.

Gallagher, R. P. (2007). National Survey of Counseling Center Directors (2007). Washington, DC: International Association of Counseling Services. Retrieved from http://www.Iacsinc.org/ 
Gallagher, R. P. (2014). National Survey of Counseling Center Directors (2014). Washington, DC: International Association of Counseling Services. Retrieved from http://www.Iacsinc.org/

Gawrysiak, M., Nicholas, C., \& Hopko, D. R. (2009). Behavioral activation for moderately depressed university students: Randomized controlled trial. Journal of Counseling Psychology, 56, 468-479. doi: 10.1037/a0016383

Giorgio, J. M., Sanflippo, J., Kleiman, E., Reilly, D., Bender, R. E., Wagner, C. A., ... \& Alloy, L. B. (2010). An experiential avoidance conceptualization of depressive rumination: Three tests of the model. Behaviour Research and Therapy, 48, 1021-1031. doi: 10.1016/j.brat.2010.07.004

Gold, D. B., \& Wegner, D. M. (1995). Origins of ruminative thought: Trauma, incompleteness, nondisclosure, and suppression. Journal of Applied Social Psychology, 25, 1245-1261. doi: 10.1111/j.1559-1816.1995.tb02617.x

Gotlib, I. H., Krasnoperova, E., Yue, D. N., \& Joormann, J. (2004). Attentional biases for negative interpersonal stimuli in clinical depression. Journal of Abnormal Psychology, 113(1), 127-138. doi: 10.1037/0021-843X.113.1.121

Greenberg, P. E., Stiglin, L. E., Finkelstein, S. N., \& Berndt, E. R. (1993). Depression: a neglected major illness. Journal of Clinical Psychiatry, 54, 419-424. doi:/10.1016/s0006-3223(03)00273-7

Gupta, S. K. (2011). Intention-to-treat concept: a review. Perspectives in Clinical Research, 2(3), 109-112. doi:/10.4103/2229-3485.83221 
Hamdan-Mansour, A. M., Puskar, K., \& Bandak, A. G. (2009). Effectiveness of cognitivebehavioral therapy on depressive symptomatology, stress and coping strategies among Jordanian university students. Issues in Mental Health Nursing, 30, 188-196.

doi: $10.1080 / 01612840802694577$

Hayes, S. C., Masuda, A., Bissett, R., Luoma, J., \& Guerrero, L. F. (2004). DBT, FAP, and ACT: How empirically oriented are the new behavior therapy technologies? Behavior Therapy, 35, 35-54. doi: 10.1016/S0005-7894(04)80003-0

Hayes, S. C., Strosahl, K., Wilson, K. G., Bissett, R. T., Pistorello, J., ... \& Mccurry, S. (2004). Measuring experiential avoidance: A preliminary test of a working model. The Psychological Record, 54, 553-578.

Hayes, S. C., Wilson, K. G., Gifford, E. V., Follette, V. M., \& Strosahl, K. (1996). Experiential avoidance and behavioral disorders: a functional dimensional approach to diagnosis and treatment. Journal of Consulting and Clinical Psychology, 64, 1152-1185.

doi: 10.1037/0022-006X.64.6.1152

Hayward, M. D., Hummer, R. A., \& Sasson, I. (2015). Trends and group differences in the association between educational attainment and US adult mortality: Implications for understanding education's causal influence. Social Science \& Medicine, 127, 8-18. doi: 10.1016/j.socscimed.2014.11.024

Heritier, S. R., Gebski, V. J., \& Keech, A. C. (2003). Inclusion of patients in clinical trial analysis: the intention-to-treat principle. Medical Journal of Australia, 179(8), 438-440.

Herrnstein, R. J. (1970). On the law of effect. Journal of the Experimental Analysis of Behavior, 13, 243 - 266. doi: 10.1901/jeab.1970.13-243 
Hodgson, J. W. (1981). Cognitive versus behavioral-interpersonal approaches to the group treatment of depressed college students. Journal of Counseling Psychology, 28, 243-249. doi: $10.1037 / 0022-0167.28 .3 .243$

Hofmann, S. G., Sawyer, A. T., Witt, A. A., \& Oh, D. (2010). The effect of mindfulness-based therapy on anxiety and depression: A meta-analytic review. Journal of Consulting and Clinical Psychology, 78, 169-183. doi: 10.1037/a0018555

Hogg, J. A. \& Deffenbacker, J. L. (1988). A comparison of cognitive and interpersonalJournal of Counseling Psychology, 35, 304-310. doi: 10.1037/0022-0167.35.3.304

Hollon, S. D., Shelton, R. C., \& Loosen, P. T. (1991). Cognitive therapy and pharmacotherapy for depression. Journal of Consulting and Clinical Psychology, 59, 88-99. doi: 10.1037/0022006X.59.1.88

Hopko, D. R., Armento, M. E., Robertson, S., Ryba, M. M., Carvalho, J. P., Colman, L. K., ... \& Lejuez, C. W. (2011). Brief behavioral activation and problem-solving therapy for depressed breast cancer patients: randomized trial. Journal of Consulting and Clinical Psychology, 79, 834-849. doi: 10.1037/a0025450

Hopko, D. R., Bell, J. L., Armento, M. E. A., Hunt, M. K., \& Lejuez, C.W. (2005). Behavior therapy for depressed cancer patients in primary care. Psychotherapy: Theory, Research, Practice, Training, 42, 236-243.

Hopko, D. R., Bell, J. L., Armento, M. E. A., Robertson, S. M. C., Mullane, C., Wolf, N., et al. (2008). Cognitive-behavior therapy for depressed cancer patients in a medical care setting. Behavior Therapy, 39, 126-136.

Hopko, D. R., Funderburk, J. S., Shorey, R. C., McIndoo, C. C., Ryba, M. M., File, A. A., ... \& Vitulano, M. (2013). Behavioral Activation and Problem-Solving Therapy for Depressed 
Breast Cancer Patients: Preliminary Support for Decreased Suicidal Ideation. Behavior Modification, 42, 236-243. doi:10.0145445513501512.

Hopko, D., Lejuez, C., LePage, J., Hopko, S., \& McNeil, D. (2003). A brief behavioral activation treatment for depression: A randomized pilot trial within an inpatient psychiatric hospital. Behavior Modification, 27, 458-469. doi:10.1177/0145445503255489

Hopko, D. R., Robertson, S. M., \& Carvalho, J. P. (2009). Sudden gains in depressed cancer patients treated with behavioral activation therapy. Behavior Therapy, 40, 346-356. doi:10.1016/j.beth.2008.09.001

Hysenbegasi, A., Hass, S. L., \& Rowland, C. R. (2005). The impact of depression on the academic productivity of university students. Journal of Mental Health Policy and Economics, 8, 145-158.

Ibrahim, A. K., Kelly, S. J., Adams, C. E., \& Glazebrook, C. (2013). A systematic review of studies of depression prevalence in university students. Journal of Psychiatric Research, 47, 391-400. doi:10.1016/j.jpsychires.2012.11.015

Ilardi, S. S., \& Craighead, W. E. (1994). The role of nonspecific factors in cognitive-behavior therapy for depression. Clinical Psychology: Science and Practice, 1, 138-155. doi:10.1111/j.1468-2850.1994.tb00016.x

Iverson, K. M., Follette, V. M., Pistorello, J., \& Fruzzetti, A. E. (2012). An investigation of experiential avoidance, emotion dysregulation, and distress tolerance in young adult outpatients with borderline personality disorder symptoms. Personality Disorders: Theory, Research, and Treatment, 3, 415-422. doi:10.1037/a0023703 
Jacobson, N. S., Dobson, K. S., Truax, P. A., Addis, M. E., Koerner, K., Gollan, J. K., et al. (1996). A component analysis of cognitive-behavioral treatment for depression. Journal of Consulting and Clinical Psychology, 64, 295-304. doi: 10.1037/0022-006X.64.2.295

Jarrett, R. B., \& Nelson, R. O. (1987). Mechanisms of change in cognitive therapy of depression. Behavior Therapy, 18, 227-241. doi:10.1016/S0005-7894(87)80017-5

James, W. (1948). Essays in pragmatism. New York: Hafner. (Original work published 1907).

Kabat-Zinn, J. (2003). Mindfulness-based interventions in context: Past, present, and future. Clinical Psychology: Science and Practice, 10, 144-156. doi:10.1093/clipsy.bpg016

Kanter, J. W., Busch, A. M., Weeks, C. E., \& Landes, S. J. (2008). The nature of clinical depression: Symptoms, syndromes, and behavior analysis. The Behavior Analyst, 31, 121.

Kanter, J. W., Puspitasari, A. J., Santos, M. M., \& Nagy, G. A. (2012). Behavioural activation: history, evidence and promise. The British Journal of Psychiatry, 200, 361363. doi: 10.1192/bjp.bp.111.103390

Kashdan, T. B., \& Kane, J. Q. (2011). Post-traumatic distress and the presence of posttraumatic growth and meaning in life: Experiential avoidance as a moderator. Personality and Individual Differences, 50, 84-89. doi: 10.1016/j.paid.2010.08.028

Keitner, G. I., Ryan, C. E., Miller, I. W., \& Norman, W. H. (1992). Recovery and major depression: factors associated with twelve-month outcome. The American Journal of Psychiatry, 149(1), 93-99.

Kiken, L. G., \& Shook, N. J. (2011). Looking up: Mindfulness increases positive judgments and reduces negativity bias. Social Psychological and Personality Science, 2, 425-431. doi: $10.1177 / 1948550610396585$ 
Kiken, L. G., \& Shook, N. J. (2012). Mindfulness and emotional distress: The role of negatively biased cognition. Personality and Individual Differences,52, 329-333. doi: 10.1016/j.paid.2011.10.031

Klerman, G. L., Weissman, M. M., Rounsaville, B. J., \& Chevron, E. S. (1984). Interpersonal psychotherapy of depression. Basic Books. New York.

Kovacs, M., Rush, A. J., Beck, A. T., \& Hollon, S. D. (1981). Depressed outpatients treated with cognitive therapy or pharmacotherapy: A one-year follow-up. Archives of General Psychiatry, 38, 33-39. doi: 10.1001/archpsyc.1981.01780260035003

Kazdin, A. E. (2007). Mediators and mechanisms of change in psychotherapy research. Annual. Review of Clinical Psychology, 3, 1-27. doi:10.1146/annurev.clinpsy.3.022806.091432

Lee, C. L. (2005). Evidenced-based treatment of depression in the college population. Journal of College Student Psychotherapy, 20, 23-31. doi: 10.1300/J035v20n01_03

Levin, M. E., Lillis, J., Seeley, J., Hayes, S. C., Pistorello, J., \& Biglan, A. (2012). Exploring the relationship between experiential avoidance, alcohol use disorders, and alcoholrelated problems among first-year college students. Journal of American College Health, 60, 443-448. doi: 10.1080/07448481.2012.673522

Lejuez, C. W., Hopko, D. R., Acierno, R., Daughters, S. B., \& Pagoto, S. L. (2011). Ten year revision of the brief behavioral activation treatment for depression: revised treatment manual. Behavior Modification, 35, 111-161.

Lejuez, C. W., Hopko, D. R., \& Hopko, S. D. (2001). A brief behavioral activation treatment for depression: Treatment manual. Behavior Modification, 25, 255-286. doi: $10.1177 / 0145445501252005$ 
Hopko, D. R., Lejuez, C. W., Lepage, J. P., Hopko, S. D., \& McNeil, D. W. (2003). A brief behavioral activation treatment for depression: A randomized pilot trial within an inpatient psychiatric hospital. Behavior Modification, 27(4), 458-469.

Lewinsohn, P. M., Biglan, A., \& Zeiss, A. M. (1976). Behavioral treatment for depression. In P. O. Davidson (Ed.), Behavioral management of anxiety, depression and pain (pp. 91-146). New York: Brunner/Mazel.

Lewinsohn, P. M. (1974). A behavioral approach to depression. In R. J. Friedman \& M. M. Katz (Eds.), Psychology of depression: Contemporary theory and research (pp. 157-178). Oxford, England: John Wiley \& Sons.

MacPherson, L., Tull, M. T., Matusiewicz, A., Rodman, S., Strong, D. R., Kahler, C. W., .. . Lejuez, C. W. (2010). Randomized controlled trial of behavioral activation smoking cessation treatment for smokers with elevated depressive symptoms. Journal of Consulting and Clinical Psychology, 78, 55-71.

doi:10.1037/a0017939

Maier, W., \& Falkai, P. (1999). The epidemiology of comorbidity between depression, anxiety disorders and somatic diseases. International Clinical Psychopharmacology, 14, 1-6.

Martell, C. R., Addis, M. E., \& Jacobson, N. S. (2001). Depression in context: Strategies for guided action. WW Norton \& Co. New York.

Mathers, C., Fat, D. M., \& Boerma, J. T. (2008). The Global burden of disease: 2004 update. World Health Organization. Retrieved from http://www.who.int/healthinfo/global_burden_disease/2004_report_update/en/ 
Mathews, A., \& MacLeod, C. (2005). Cognitive vulnerability to emotional disorders. Annual Review of Clinical Psychology, 1, 167-195. doi:10.1146/annurev.clinpsy.1.102803.143916

Matthews, G., \& Wells, A. Rumination, Depression, and Metacognition: the S-REF Model. Depressive Rumination: Nature, Theory and Treatment, 125-151.

MacLeod, C., Mathews, A., \& Tata, P. (1986). Attentional bias in emotional disorders. Journal of Abnormal Psychology, 95(1), 15 - 26.

McDermut, J. F., Haaga, D. A., \& Bilek, L. A. (1997). Cognitive bias and irrational beliefs in major depression and dysphoria. Cognitive Therapy and Research, 21, 459-476. doi:/10.1023/A:1021936427625

Mills, N., \& Allen, J. (2000). Mindfulness of movement as a coping strategy in multiple sclerosis: A pilot study. General Hospital Psychiatry, 22, 425-431.

Moulds, M. L., Kandris, E., Starr, S., \& Wong, A. C. (2007). The relationship between rumination, avoidance and depression in a non-clinical sample. Behaviour Research and Therapy, 4, 251-261.

doi:10.1016/j.brat.2006.03.003

National Alliance on Mental Illness. (2012) College students speak: A survey report on mental health. Retrieved from https://www.nami.org/getattachment/About-NAMI/PublicationsReports/Survey-Reports/College-Students-Speak_A-Survey-Report-on-Mental-HealthNAMI-2012.pdf

National Center for Health Statistics. Health (2012). United States, 2011: With Special Feature on Socioeconomic Status and Health. Hyattsville, MD. 
National Institutes of Mental Health. (2015). Signs and Symptoms of Depression. Retrieved from http://www.nimh.nih.gov/health/topics/depression/men-and-depression/signs-andsymptoms-of-depression/index.shtml

National Institutes of Mental Health. (1999). Depression and Heart Disease. Retrieved from http://www.nimh.nih.gov/health/publications/depression-and-heartdisease/index.shtml

Nederhof, A. J. (1985). Methods of coping with social desirability bias: A review. European Journal of Social Psychology, 15(3), 263-280.

Nolen-Hoeksema, S. (2000). The role of rumination in depressive disorders and mixed anxiety/depressive symptoms. Journal of Abnormal Psychology, 109(3), 504-511. doi:10.1037/0021-843X.109.3.504

Nolen-Hoeksema, S., Parker, L. E., \& Larson, J. (1994). Ruminative Coping with Depressed Mood Following Loss. Journal of Personality and Social Psychology, 67(1), 92-104. doi:10.1037/0022-3514.67.1.92

Pace, T. M. \& Dixon, D. N. (1993). Changes in depressive self-schemata and depressive symptoms following cognitive therapy. Journal of Counseling Psychology, 40, 288-294. doi:10.1037/0022-0167.40.3.288

Paul, N. A., Stanton, S. J., Greeson, J. M., Smoski, M. J., \& Wang, L. (2012). Psychological and neural mechanisms of trait mindfulness in reducing depression vulnerability. Social Cognitive and Affective Neuroscience, 8(1), 56-64.

Porter, K. (2002). The Value of a College Degree. ERIC Digest. Retrieved from http://www.ericdigests.org/2003-3/value.htm 
Pratt, L. A. \& Brody, D. J. (2008). Depression in the United States Household Population, 20052006. NCHS Data Brief Number 7. National Center for Health Statistics. Centers for Disease Control and Prevention. Retrieved from http://www.cdc.gov/nchs/data/databriefs/db07.pdf

Raisman, N (2013). The Cost of College Attrition at Four-Year Colleges \& Universities. Education Policy Institute. Retrieved from http://www.educationalpolicy.org/pdf/ 1302_PolicyPerspectives.pdf

Reynolds, E. K., MacPherson, L., Tull, M. T., Baruch, D. E., \& Lejuez, C. W. (2011). Integration of the brief behavioral activation treatment for depression (BATD) into a college orientation program: depression and alcohol outcomes. Journal of Counseling Psychology, 58, 555-571.

doi:10.1037/a0024634

Rinck, M., \& Becker, E. S. (2005). A comparison of attentional biases and memory biases in women with social phobia and major depression. Journal of Abnormal Psychology, 114, $62-74$

doi:10.1037/0021-843X.114.1.62

Roberts, R. E., Stevenson, J. M., \& Breslow, L. (1981). Symptoms of depression among blacks and whites in an urban community. The Journal of Nervous and Mental Disease, 169, 774-779.

Rowley, L.L., \& Hurtado, S. (2002). The Non-Monetary Benefits of an Undergraduate Education. University of Michigan: Center for the Study of Higher and Postsecondary Education. Ann Arbor. 
Ryba, M. M., Lejuez, C. W., \& Hopko, D. R. (2014). Behavioral activation for depressed breast cancer patients: The impact of therapeutic compliance and quantity of activities completed on symptom reduction. Journal of Consulting and Clinical Psychology, 82, 325-335. doi: $10.1037 / \mathrm{a} 0035363$

Shaw, B. F. (1977). Comparison of cognitive therapy and behavior therapy in the treatment of depression. Journal of Consulting and Clinical Psychology,45, 543-551. doi:10.1037/0022-006X.45.4.543

Shelov, D. V., Suchday, S., \& Friedberg, J. P. (2009). A pilot study measuring the impact of yoga on the trait of mindfulness. Behavioural and Cognitive Psychotherapy, 37, 595.

Shook, N. J., Fazio, R. H., \& Vasey, M. W. (2007). Negativity bias in attitude learning: A possible indicator of vulnerability to emotional disorders?. Journal of Behavior Therapy and Experimental Psychiatry, 38, 144-155.

doi:10.1016/j.jbtep.2006.10.005

Simons, A. D., Levine, J. L., Lustman, P. J., \& Murphy, G. E. (1984). Patient attrition in a comparative outcome study of depression. A follow-up report. Journal of Affective Disorders, 6, 163-173.

Smith, G. W., \& Bloom, I. ( 1985 ). A study of the personal meaning of suicide in the context of Baechler's typology. Suicide and Life Threatening Behavior, 15, 3-13.

Snarski, M., Scogin, F., DiNapoli, E., Presnell, A., McAlpine, J., \& Marcinak, J. (2011). The effects of behavioral activation therapy with inpatient geriatric psychiatry patients. Behavior Therapy, 42, 100-108. doi: 10.1016/j.beth.2010.05.001 
Society of Clinical Psychology (2015a). Depression: Cognitive Therapy for Depression.

Retrieved from https://www.div12.org/psychologicaltreatments/disorders/depression/cognitive-therapy-for-depression/

Society of Clinical Psychology (2015b). Depression: Interpersonal Psychotherapy for

Depression. Retrieved from http://www.div12.org/psychologicaltreatments/disorders/depression/interpersonal-therapy-for-depression/

Soetens, B., Braet, C., Dejonckheere, P., \& Roets, A. (2006). 'When Suppression Backfires’ The Ironic Effects of Suppressing Eating-related Thoughts. Journal of Health Psychology, 11, $655-668$.

Stansfeld, S. A., \& Marmot, M. G. (1992). Social class and minor psychiatric disorder in British Civil Servants: a validated screening survey using the General Health Questionnaire. Psychological Medicine, 22(03), 739-749.

doi:10.1017/S0033291700038186

Symonds, W. C., Schwartz R., \& Ferguson, R. F. (2011). Pathways to prosperity: Meeting the challenge of preparing young Americans for the 21st century. Cambridge, MA: Pathways to Prosperity Project, Harvard University Graduate School of Education.

Retrieved from

http://www.gse.harvard.edu/news_events/features/2011/Pathways_to_Prosperity_Feb201 1.pd

Taylor, F. G., \& Marshall, W. L. (1977). Experimental analysis of a cognitive-behavioral therapy for depression. Cognitive Therapy and Research, 1, 59-72.

doi:10.1007/BF01173505

Thera, N. (1962). The heart of Buddhist meditation. New York: Weiser. 
Teasdale, J. D., Segal, Z. V., Williams, J. M. G., Ridgeway, V. A., Soulsby, J. M., \& Lau, M. A. (2000). Prevention of relapse/recurrence in major depression by mindfulness-based cognitive therapy. Journal of Consulting and Clinical Psychology, 68(4), 615-623.

Trousselard, M., Steiler, D., Raphel, C., Cian, C., Duymedjian, R., Claverie, D., \& Canini, F. (2010). Validation of a French version of the Freiburg Mindfulness Inventory-short version: relationships between mindfulness and stress in an adult population. BioPsychoSocial medicine, 4, 1-11.

United States Census Bureau (2014). Poverty. Current Population Survey (CPS), Retrieved from https://www.census.gov/hhes/www/poverty/data/incpovhlth/2014/highlights.html.

Voelker, R. (2003). Mounting student depression taxing campus mental health services. Journal of the American Medical Association, 289, 2055-2056.

doi:10.1001/jama.289.16.2055

Watts, A. (2001). Education and the common good: Social benefits of higher education in Kentucky. Frankfort, KY: Kentucky Long-Term Policy Research Center.

Wegner, D. M., Schneider, D. J., Carter, S. R., \& White, T. L. (1987). Paradoxical effects of thought suppression. Journal of Personality and Social Psychology, 53, 5-13. doi: $10.1037 / 0022-3514.53 .1 .5$

Wegner, D. M. \& Zanakos, S. (1994). Chronic thought suppression. Journal of Personality, 62, 615-640. doi:10.1111/j.1467-6494.1994.tb00311.x

Weissman, M. M., Klerman, G. L., Paykel, E. S., Prusoff, B., \& Hanson, B. (1974). Treatment effects on the social adjustment of depressed patients. Archives of General Psychiatry, 30(6), 771-778. doi:10.1001/archpsyc.1974.01760120033006 
Wells, A., \& Matthews, G. (1996). Modelling cognition in emotional disorder: the S-REF model. Behaviour Research and Therapy, 34, 881-888. doi:10.1016/S0005-7967(96)00050-2

Williams, J. M. G., Mathews, A., \& MacLeod, C. (1996). Emotional Stroop task and psychopathology. Psychological Bulletin, 120, 3-24.

doi:10.1037/0033-2909.120.1.3

Young, E. A., \& Nolen-Hoeksema, S. (2001). Effect of ruminations on the saliva cortisol response to a social stressor. Psychoneuroendocrinology, 26, 319-329. doi:10.1016/S0306-4530(00)00059-7

Young, J. E., Rygh, J. L., Weinberger, A. D., \& Beck, A. T. (2008). Cognitive therapy for depression. In D. H. Barlow (Ed.), Clinical handbook of psychological disorders: A step-by-step treatment manual (4th ed., pp. 250-305). New York: Guilford Press 


\section{Appendix A.}

\section{DAS-SF1}

\section{Beevers, Strong, Meyer, Pilkonis, \& Miller, 2007}

The sentences below describe people's attitudes. Circle the number which best describes how much each sentence describes your attitude. Your answer should describe the way you think most of the time.

$\begin{array}{llll}\text { Totally Agree } & \text { Agree } & 3^{\text {Disagree }} & \text { Totally Disagree } \\ 1 & & \end{array}$

1. If I don't set the highest standards for myself, I am likely to end up a second-rate person.

2. My value as a person depends greatly on what others think of me.

3. People will probably think less of me if I make a mistake.

4. I am nothing if a person I love doesn't love me.

5. If other people know what you are really like, they will think less of you.

6. If I fail at my work, then I am a failure as a person.

7. My happiness depends more on other people than it does me.

8. I cannot be happy unless most people I know admire me.

9. It is best to give up your own interests in order to please other people. 


\section{Mindful Attention Awareness Scale \\ (Brown and Ryan, 2003)}

Instructions: Below is a collection of statements about your everyday experience. Using the 1-6 scale below, please indicate how frequently or infrequently you currently have each experience. Please answer according to what really reflects your experience rather than what you think your experience should be. Please treat each item separately from every other item.

$\begin{array}{cccccc}1 & 2 & 3 & 4 & 5 & 6 \\ \text { Almost } & \text { Very } & \text { Somewhat } & \text { Somewhat } & \text { Very } & \text { Almost } \\ \text { Always } & \text { Frequently } & \text { Frequently } & \text { Infrequently } & \text { Infrequently } & \text { Never }\end{array}$

I could be experiencing some emotion and not be conscious of it until some time later.

$\begin{array}{llllll}1 & 2 & 3 & 4 & 5 & 6\end{array}$

I break or spill things because of carelessness, not paying attention, or thinking of something else.

$\begin{array}{llllll}1 & 2 & 3 & 4 & 5 & 6\end{array}$

I find it difficult to stay focused on what's happening in the present.

$\begin{array}{llllll}1 & 2 & 3 & 4 & 5 & 6\end{array}$

I tend to walk quickly to get where I'm going without paying attention to what I experience along the way.

$\begin{array}{llllll}1 & 2 & 3 & 4 & 5 & 6\end{array}$

I tend not to notice feelings of physical tension or discomfort until they really grab my attention.

$\begin{array}{llllll}1 & 2 & 3 & 4 & 5 & 6\end{array}$

I forget a person's name almost as soon as I've been told it for the first time.

$\begin{array}{llllll}1 & 2 & 3 & 4 & 5 & 6\end{array}$

It seems I am "running on automatic," without much awareness of what I'm doing.

$\begin{array}{llllll}1 & 2 & 3 & 4 & 5 & 6\end{array}$

I rush through activities without being really attentive to them. $\begin{array}{llllllll}1 & 2 & 3 & 4 & 5 & 6\end{array}$

I get so focused on the goal I want to achieve that I lose touch with what I'm doing right now to get there.

$\begin{array}{llllll}1 & 2 & 3 & 4 & 5 & 6\end{array}$

I do jobs or tasks automatically, without being aware of what I'm doing.

$\begin{array}{llllll}1 & 2 & 3 & 4 & 5 & 6\end{array}$

I find myself listening to someone with one ear, doing something else at the same time.

$\begin{array}{llllll}1 & 2 & 3 & 4 & 5 & 6\end{array}$


I drive places on "automatic pilot" and then wonder why I went there.

I find myself preoccupied with the future or the past.

I find myself doing things without paying attention.

I snack without being aware that I'm eating. $\begin{array}{llllll}1 & 2 & 3 & 4 & 5 & 6\end{array}$

$\begin{array}{llllll}1 & 2 & 3 & 4 & 5 & 6\end{array}$

$\begin{array}{llllll}1 & 2 & 3 & 4 & 5 & 6\end{array}$

$\begin{array}{llllll}1 & 2 & 3 & 4 & 5 & 6\end{array}$ 


\section{Acceptance and Action Questionnaire-II \\ (Bond et al., 2011)}

Below you will find a list of statements. Please rate how true each statement is for you by circling a number next to it. Use the scale below to make your choice.

1. My painful experiences and memories make it difficult for me to live a life that I would value.

$\begin{array}{lllllll}1 & 2 & 3 & 4 & 5 & 6 & 7\end{array}$

2. I'm afraid of my feelings.

$\begin{array}{lllllll}1 & 2 & 3 & 4 & 5 & 6 & 7\end{array}$

3. I worry about not being able to control my worries and feelings.

$\begin{array}{lllllll}1 & 2 & 3 & 4 & 5 & 6 & 7\end{array}$

4. My painful memories prevent me from having a fulfilling life.

$\begin{array}{lllllll}1 & 2 & 3 & 4 & 5 & 6 & 7\end{array}$

5. Emotions cause problems in my life.

$\begin{array}{lllllll}1 & 2 & 3 & 4 & 5 & 6 & 7\end{array}$

6. It seems like most people are handling their lives better than I am.

$\begin{array}{lllllll}1 & 2 & 3 & 4 & 5 & 6 & 7\end{array}$

7. Worries get in the way of my success.

$\begin{array}{lllllll}1 & 2 & 3 & 4 & 5 & 6 & 7\end{array}$




\section{Multidimensional Experiential Avoidance Questionnaire (Gamez, Chmielewski, Kotov, Ruggero, \& Watson, 2011)}

Please indicate the extent to which you agree or disagree with each of the following statements

$1=$ Strongly Disagree

$2=$ Moderately Disagree

$3=$ Slightly Disagree

4 = Slightly Agree

$5=$ Moderately Agree

$6=$ Strongly Agree

1. I won't do something if I think it will make me uncomfortable

$\begin{array}{llllll}1 & 2 & 3 & 4 & 5 & 6\end{array}$

2. If I could magically remove all of my painful memories, I would

$\begin{array}{llllll}1 & 2 & 3 & 4 & 5 & 6\end{array}$

3. When something upsetting comes up, I try very hard to stop thinking about it
1
2
34

4. I sometimes have difficulty identifying how I feel

$\begin{array}{lllllll}1 & 2 & 3 & 4 & 5 & 6\end{array}$

5. I tend to put off unpleasant things that need to get done

6. People should face their fears

$\begin{array}{llllll}1 & 2 & 3 & 4 & 5 & 6\end{array}$

7. Happiness means never feeling any pain or disappointment
1
23
$\begin{array}{lll}4 & 5 & 6\end{array}$

8. I avoid activities if there is even a small possibility of getting hurt

$\begin{array}{llllll}1 & 2 & 3 & 4 & 5 & 6\end{array}$

9. When negative thoughts come up, I try to fill my head with something else

$\begin{array}{lllllll}1 & 2 & 3 & 4 & 5 & 6\end{array}$

10. At times, people have told me I'm in denial

$\begin{array}{llllll}1 & 2 & 3 & 4 & 5 & 6\end{array}$

11. I sometimes procrastinate to avoid facing challenges

$\begin{array}{llllll}1 & 2 & 3 & 4 & 5 & 6\end{array}$

12. Even when I feel uncomfortable, I don't give up working toward things I value

$\begin{array}{llllll}1 & 2 & 3 & 4 & 5 & 6\end{array}$

13. When I am hurting, I would do anything to feel better
$\begin{array}{llllll}1 & 2 & 3 & 4 & 5 & 6\end{array}$

14. I rarely do something if there is a chance that it will upset me
1

2

15. I usually try to distract myself when I feel
1

23
$4 \quad 5$
56

3

16. I am able to "turn off" my emotions when I don't want to feel
1
23
4
5
6

17. When I have something important to do I find myself doing a lot of other things instead
1
2
3
4
5
6

18. I am willing to put up with pain and discomfort to get what I want
1
23
4
5
6

19. Happiness involves getting rid of negative thoughts 


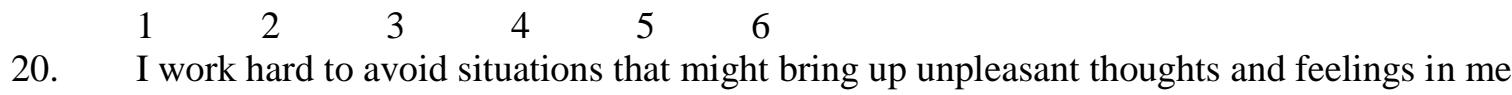

$\begin{array}{llllll}1 & 2 & 3 & 4 & 5 & 6\end{array}$

21. I don't realize I'm anxious until other people tell me
$\begin{array}{llllll}1 & 2 & 3 & 4 & 5 & 6\end{array}$

22. When upsetting memories come up, I try to focus on other things

23. $\quad$ I am in touch with my emotions

$\begin{array}{llllll}1 & 2 & 3 & 4 & 5 & 6\end{array}$

24. I am willing to suffer for the things that matter to me

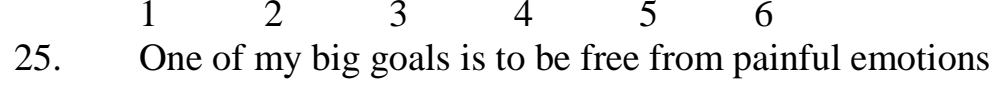

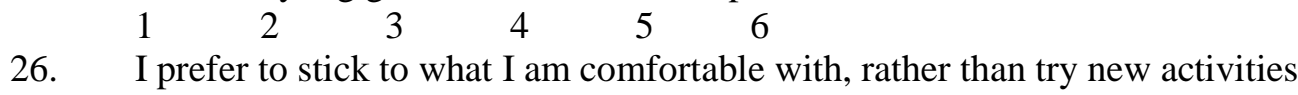

$\begin{array}{lllllll}1 & 2 & 3 & 4 & 5 & 6\end{array}$

27. I work hard to keep out upsetting feelings

28. People have said that I don't own up to my problems

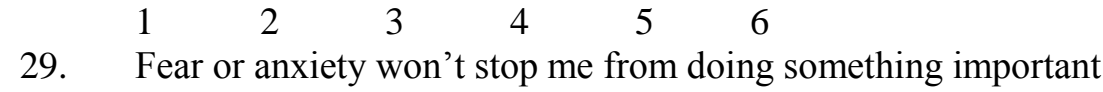

$\begin{array}{lllllll}1 & 2 & 3 & 4 & 5 & 6\end{array}$

30. I try to deal with problems right away

$\begin{array}{llllll}1 & 2 & 3 & 4 & 5 & 6\end{array}$

31. I'd do anything to feel less stressed
$\begin{array}{llllll}1 & 2 & 3 & 4 & 5 & 6\end{array}$

32. If I have any doubts about doing something, I just won't do it

33. When unpleasant memories come to me, I try to put them out of my mind

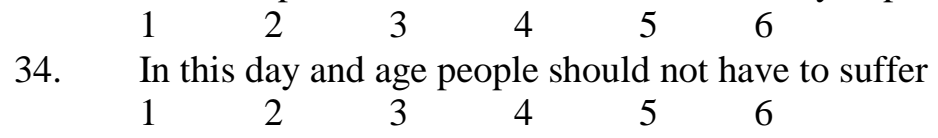
1
2
3
6

35. Others have told me that I suppress my feelings

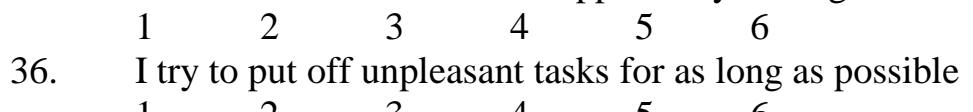
$\begin{array}{llllll}1 & 2 & 3 & 4 & 5 & 6\end{array}$
37. When I am hurting, I still do what needs to be done

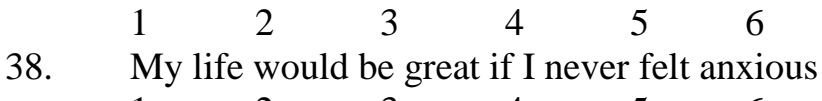

$\begin{array}{llllll}1 & 2 & 3 & 4 & 5 & 6\end{array}$

39. If I am starting to feel trapped, I leave the situation immediately

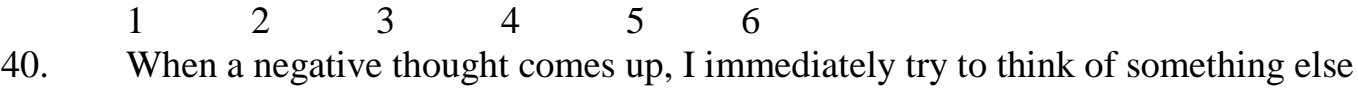

$\begin{array}{llllll}1 & 2 & 3 & 4 & 5 & 6\end{array}$

41. It's hard for me to know what I'm feeling

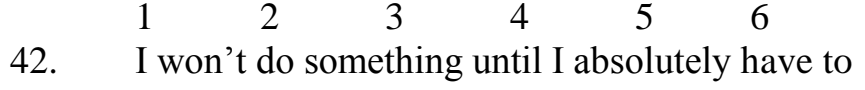

$\begin{array}{llllll}1 & 2 & 3 & 4 & 5 & 6\end{array}$

43. I don't let pain and discomfort stop me from getting what I want

$\begin{array}{llllll}1 & 2 & 3 & 4 & 5 & 6\end{array}$

44. I would give up a lot not to feel bad 
$\begin{array}{llllll}1 & 2 & 3 & 4 & 5 & 6\end{array}$

45. I go out of my way to avoid uncomfortable situations

$\begin{array}{llllll}1 & 2 & 3 & 4 & 5 & 6\end{array}$

46. I can numb my feelings when they are too intense

$\begin{array}{llllll}1 & 2 & 3 & 4 & 5 & 6\end{array}$

47. Why do today what you can put off until tomorrow
$\begin{array}{llllll}1 & 2 & 3 & 4 & 5 & 6\end{array}$

48. I am willing to put up with sadness to get what I want
$\begin{array}{llllll}1 & 2 & 3 & 4 & 5 & 6\end{array}$

49. Some people have told me that I "hide my head in the sand"

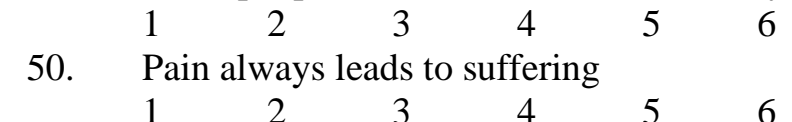

51. If I am in a slightly uncomfortable situation, I try to leave right away

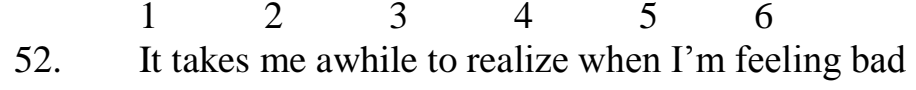

53. $\quad \begin{array}{lllll}\text { I continue } & \text { working toward my goals even if I have doubts }\end{array}$

$\begin{array}{lllllll}1 & 2 & 3 & 4 & 5 & 6\end{array}$

54. I wish I could get rid of all of my negative emotions

55. $\quad \begin{array}{lllll}\text { I avoid situations if there is a chance that I'll feel nervous } \\ \text { S }\end{array}$

56. $\quad \begin{array}{lllll}\text { I feel disconnected from my emotions } & 6\end{array}$

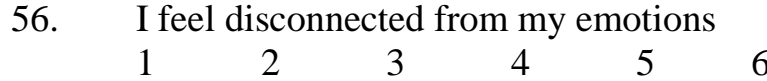

57. I don't let gloomy thoughts stop me from doing what I want

58. The key to a good life is never feeling any pain

59. I'm quick to leave any situation that makes me feel uneasy

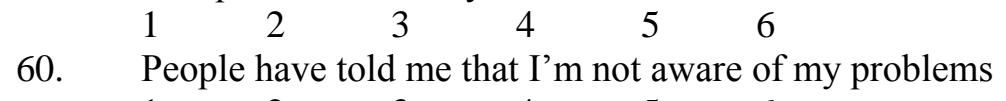

$\begin{array}{llllll}1 & 2 & 3 & 4 & 5 & 6\end{array}$

61. I hope to live without any sadness and disappointment
$\begin{array}{llllll}1 & 2 & 3 & 4 & 5 & 6\end{array}$

62. When working on something important, I won't quit even if things get difficult
1

23

$4 \begin{array}{lll}4 & 6\end{array}$ 


\section{Demographics Questions}

Gender: $\quad$ Male $\quad$ Female

Age:

Year in College:

Freshman

Sophomore

Junior

Senior

Other:

Sexual orientation:

Straight/Heterosexual

Lesbian/Homosexual Female

Gay/Homosexual Male

Bi-sexual

Transgendered

Other

Political orientation:

Very conservative

Conservative

Moderate

Liberal

Very liberal

What political party best represents your beliefs?

_Democrat __ Republican___Libertarian ___ Independent ___ Other

Marital Status:

Single
Married
Separated
Divorced
Widowed

Ethnicity:

White/Caucasian

Hispanic/Latino(a)

African-American/Black

Asian

Native American

Other - Please list 
What is your religious affiliation:

Christian - Protestant
Christian - Catholic
Hindu
Buddhist
Not religious

Muslim

Jewish

Atheist

Agnostic

Other - Please list:

What is your family income?

Less than $\$ 10,000$

$\$ 10,000$ to $\$ 19,999$

$\$ 20,000$ to $\$ 29,999$

$\$ 30,000$ to $\$ 39,999$

$\$ 40,000$ to $\$ 49,999$

$\$ 50,000$ to $\$ 59,999$

$\$ 60,000$ to $\$ 69,999$

$\$ 70,000$ to $\$ 79,999$

$\$ 80,000$ to $\$ 89,999$

$\$ 90,000$ to $\$ 99,999$

$\$ 100,000$ to $\$ 149,999$

$\$ 150,000$ or more

How would you characterize your hometown?

rural (unincorporated)

small town (village or town)

suburban (metropolitan area of a large city)

small city (population $<30,000$ )

medium-sized city (population 30,000 - 100,000)

large city (population > 100,000)

Please list all psychology courses that you have taken.

Have you ever:

Practiced meditation regularly $\mathrm{Y} / \mathrm{N}$

Practiced yoga regularly $\mathrm{Y} / \mathrm{N}$

Practiced Tai Chi regularly. Y/N

Practiced martial arts regularly $\mathrm{Y} / \mathrm{N}$

Have you ever sought mental health services before? Y/N

Are you 18 years or older? Y/N

Do you have a history of psychosis? Y/N

Do you have a history of bipolar disorder? Y/N

Do you have a history of substance abuse? Y/N

Do you have a history of suicidal thoughts? Y/N

Are you feeling depressed? Y/N 
Have you been taking an antidepressant medication for less than 8 weeks? Y/N

Are you currently seeking treatment for depression or any other psychological disorder? Y/N Are you a student in Morgantown? Y/N 
Appendix B

\title{
BATD-R Modified Protocol for BATD treatment of Moderately Depressed College Students
}

\author{
Michael J. Gawrysiak \& Derek Hopko \\ BATD-R Modifications by D. Lee McCluskey, Natalie J. Shook, \& \\ Daniel W. McNeil.
}

Manual Developed by Modifications to the 2001 "A Brief Behavioral Activation Treatment for Depression”, Treatment Manual:

By C.W. Lejuez, Derek R. Hopko, \& Sandra D. Hopko

Originally Published in Behavior Modification, Vol. 25 No. 2, April 2001, Pages 255-286

\section{Clinical Examiner: \\ Participant ID Number: \\ Date of First Session: \\ Date of Second Session: \\ Date of Third Session: \\ Length of First Session:}

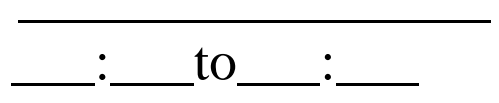




\section{Table of Contents:}

1. Session 1- Study Script and Instructions...................... 3

2. Intervention section............................................. 5

a. Unit 1- Introduction.............................. 5

b. Unit 2- Recognizing Depression..................... 6

c. Unit 3- The Rationale for BATD................... 7

d. Unit 4- Life Areas Assessment..................... 8

3. Session 2: 2-Week Follow-Up ...............................24

4. Session 3: 1-Month Follow-up and Study Conclusion ...... 26

5. Appendix A- Symptoms of Depression.................... 29

6. Appendix B- Intervention Checklist......................... 30 


\title{
Session 1- Study Script and Instructions:
}

\section{Everything in quotations should be read word for word}

\author{
Clinical Group Session I (study script)
}

\author{
Prep: In QCC, use Shook laptop to administer Assessment 1 \\ Username: shooklab \\ Password: Na2jSh0
}

Set up therapy room computers to record session.

Username: Shook Team

Password: Na2jSh0

(Click on Logitech Webcam icon on desktop. Click on 'Quick Capture.' Make sure that the webcam is in 'Video' mode, not 'Photo.' Under 'Controls' make sure that 'Follow my Face' is unchecked, 'Resolution' is small, and the microphone is not muted. Adjust the position of the webcam if necessary.)

Forms: Clinical Group consent form (2 copies), mental health services list, consent for videotaping/audiotaping, BeanFest instructions ( 2 copies), Behavioral Checkout Sheets (14 copies), Values inventory forms, included in manual.

Meet participant by 1st floor elevators (may need to check basement and 2nd floor). Ask if participant needs a parking permit and provide as necessary. Escort to experimental room.

Introduce yourself. Thank participant for his/her time. Ask that all cell phones, ipods, etc. be turned off and put away. Provide participant with Clinical Group consent form and the Videotaping/audiotaping consent form.

"The purpose of this study is to test the effectiveness of a one session intervention for individuals with depressive symptoms. This study will entail three sessions. During the session today, you will be asked to complete a computer task, called BeanFest, which requires learning whether stimuli are good or bad in order to maximize your outcomes in an imaginary world. You will then complete several questionnaires that assess mental health issues, life experiences, and general attitudes. We will then conduct the intervention session. The intervention will involve keeping a record of your daily activities, identifying important life areas, values. The intervention is entirely behavioral, no medication is involved, and its aim is that you begin to engage in more enjoyable activities. Today's session should take no longer than 2.5 hours. The individuals providing the intervention for you are all students in the clinical psychology doctoral program at WVU. Two weeks after completing the intervention and again two weeks later, you will complete the BeanFest task and questionnaires again. All information that you provide during the study is completely confidential and anonymous. That is, no one other than study personnel will have access to your data, and your data will not be connected to any personal identifiers (e.g., name, social security number). You have a participant ID, which is how we are 
able to distinguish between participants' data. Your participation in this study is completely voluntary. At any point, you can end the study without penalty. Also, if there are any questions that you do not want to answer, you may skip them. Do you have any questions?" [answer questions]

Have the participant read, sign, and date the consent form, as well as initial and date the bottom of each page.

\section{Begin Assessment}

Open MediaLab and run experiment c:lusers\shooklabldesktop\Lee Dissertation\LMDISS_S1.exp Enter participant ID (see Session 1 note sheet for ID)

**IMPORTANT** Be very careful when entering ID into MediaLab. Always double check Participant ID entry. This is the only way we will be able to match participants' data across the sessions.

"Now, I am going to go over the instructions for BeanFest with you. Please read over the instructions while I read them out loud." [read instructions, answer any questions, start experiment]

Quietly observe participant and take notes about anything unusual that occurs during the session. Be prepared to answer questions. If participant seems to be rushing or not paying attention, stop him/her and ask participant to follow directions properly/pay attention/read questions.

When participant is done, answer any questions he/she may have. **Check the BDI suicide question (Item 9). If participant reports suicidal thoughts, immediately contact Dan (304-2931712 or $304-692-5537)$.**

\section{Complete intervention (see below)}

Ask participant if he/she will allow the session to be recorded. Have participant sign the videotaping / audiotaping consent form. Wait until assessment is complete to begin video recording 
- Intervention comprised of UNITS 1 through 4.

- Start the webcam recorder (Click on the camera button underneath the webcam picture). Turn off the computer monitor.

\section{- Unit 1- Introduction}

- "You may not presently feel as though you are able to get much done or that you are always tired and lack motivation. You also may be waiting to feel better or think more positively before you become more active and start participating in activities that once brought you pleasure. As you know, however, getting yourself to feel better is not an easy thing to do. Therefore, we'd like you to try something different. The idea of the treatment we are about to begin is that your thoughts and feelings are affected by your interactions with others and your overall quality of life. So, we believe that for you to have more positive thoughts and feelings and to feel better, you must first become more active and put yourself into more positive situations. Although this may be difficult right now, it will become easier as more and more positive experiences occur. The treatment requires you to work hard, and I understand that you may be questioning your ability to make changes at this time in your life, but I will help you throughout this process, and we will work at a pace at which you feel comfortable." 


\section{- Unit 2 - Recognizing Depression}

- Provide a copy of appendix 1 and explain/instruct participants on the following:

- "You may or may not have experienced symptoms of depression that include:

$\circ$ Poor Appetite or Over Eating

- Not getting enough sleep, or sleeping too much, or tiredness

- Low energy or Fatigue

○ Low self-Esteem

- Poor Concentration or Difficulty making decisions

- Feelings of Hopelessness

- An unrealistic sense of guilt or worthlessness

- Frequently thinking about failings in the past

- Thoughts about death

- Decreased desire to engage in activities that you once found rewarding"

"Do you think any of these symptoms apply to you?"

\section{- READ ALOUD TO PARTICIPANT:}

- "Symptoms of depression may produce significant impairment in your life such as an inability to take classes, hang out with your friends, work, cook, exercise, and so forth. You may also have decreased optimism/motivation, low selfesteem, difficulties concentrating, fatigue and possibly extreme behaviors such as self-injury and or suicidal thoughts. Medical consequences may include heart disease, inability to fight off illness, abusing drugs or alcohol, and poor eating habits." 
- Unit 3-The Rationale for BATD

- Explain/instruct participants on the following:

- When depressive symptoms are recognized, a number of treatment alternatives are available. The treatment you will be provided with is a modified form of another treatment that has already been supported as being effective in treating people with depression. This treatment is environmental/behavioral in nature, which means that it targets changes in your environment and behavior as a method for improving your thoughts, mood, and overall quality of life. Although we are focusing on behavior change, we are not ignoring thoughts and feelings. Instead we suggest that negative thoughts and feelings often will change only after positive events and consequences are experienced more frequently. Said more simply, it is difficult to feel depressed and have low selfesteem if you are regularly engaging in activities that bring you a sense of pleasure and/or accomplishment. 


\section{- Unit 4-Life Areas Assessment}

- Explain/instruct participants on the following:

\section{LIFE AREAS ASSESSMENT:}

\section{- Identifying potential activities:}

- As a first step in this protocol, you must determine some activities you would like to target. In determining these activities, you might want to consider activities related to your values and goals as they relate to certain life areas:

The participant and investigator then collaboratively establish structured goals by completing the following "Life Areas Assessment." Using the Life Goal assessment and using some of these questions as prompts, discuss each of the life areas and write down what the patient would like to accomplish in each of the areas.

1. Family Relationships (e.g., What type of brother/ sister, son/ daughter, father/mother do you want to be? What are your strengths? Weaknesses? Which relationships would you like to improve? What qualities are important in close family relationships? What might you be able to do to make the relationships better?)

2. Social Relationships (e.g., What would an ideal friendship be like to you? Are certain relationships poor at the moment? What areas could be improved in your relationships with your friends? Do you have enough friends?)

3. Intimate Relationships (e.g., What would your role be in an intimate relationship? Are you currently involved in this type of relationship, or would you like to be?)

4. Education/ Training/Learning (e.g., How are your classes currently going? Do you need to have more study time? Scheduled study time? What would you like to learn more about?)

5. Hobbies/ Recreation/Leisure (e.g., Are there any special interests you would like to pursue, or new activities you would like to experience?)

6. Physical/ Health Issues (e.g., Do you wish to improve your diet, sleep, exercise, should you lose some weight?)

7. Spirituality (e.g., What, if anything, does spirituality mean to you? Are you satisfied with this area of your life? Would you like to become more spiritual?) 
8. Psychological/ Anxiety/ Avoidance Issues (e.g., Are there other issues besides depression that you would like to explore in this treatment? Do you avoid certain situations because of fear or anxiety? Would you like to face these situations? Do you need to relax more?). 


\section{Life Goal Assessment}

Instructions: Describe goals that you would like to accomplish in these areas.

1. Family Relationships

2. Social Relationships

3. Intimate Relationships

4. Education/Training

5. Hobbies/ Recreation

6. Physical/ Health Issues 
7. Spirituality

8. Psychological/ Anxiety/ Avoidance Issues 


\section{Introduce Values Based Activities}

Values. Once we have considered these different life areas, we move to identifying your values in each of these areas. A value is an ideal, quality, or strong belief in certain way of living.

In other words, thinking about what you have identified as important to you about each of these life areas? What are you striving to be in each life area? What are the qualities of that life area that are important to you? A value is something that is important to you, in your heart, about that life area. Be sure that the values you identify are very personal to you, and not necessarily the values of other people in your life or society in general.

Activities. A primary goal of this session is to identify key values from each life area and translate them into activities. Life areas are the important parts of your life, values are how you want to live your life in each of those areas, and activities are things you can do to actually live according to the values. Become more aware of your values and using them as a guide to selecting your activities is key to this treatment. However, without the activities that help you live according to your values, the values are just words and ideas, and not a reality.

The Life Areas assessment allows you to turn your values across key areas of your life into reality. For each life area, you have space for both values and activities (you can add extra blank sheets for each life area to add additional values and activities). Each activity should be something that you might do to live consistently with the value that you identified. For example, if "being a good husband/wife" is something you value, list some activities that you think are consistent with being a good husband/wife. Possible activities might include planning a date with your husband/wife once a week or helping your husband/wife with a household chore she/he dislikes. When selecting activities it is important to remember that the activity must have two specific characteristics: they should be both observable by others and measurable. Therefore, "feeling better" is not what we mean by activity, but "eating dinner with my mother twice a week" would be appropriate. This latter activity could be observable and measurable in the sense that you could meet with her twice per week. The activity should also be broken into its smallest piece. For example, if an activity is going for a bike ride, consider that a number of intermediate steps are required before one can do this. Such steps might include, bringing the bike up from the basement, checking the air in the tires, finding a tire pump, pumping the tires, etc. So the first step in the activity of going for a bike ride might just include checking that the bike is in good shape, with later weeks including the actual ride. Activities are far easier to accomplish if they are broken 
into the smallest pieces possible. Thus, if these three conditions (observable, measureable, smallest piece possible) are met, you have identified an acceptable activity.

Sometimes it is tempting to select very difficult activities for which the benefits are in the future and not a guarantee. For example, getting a college degree is a longterm goal that may take some time to achieve. It's important to have these types of goals, but it's even more important to be clear about the rewarding activities that are a part of achieving that long-term goal. This might include activities that get you to the goal but are important and/or enjoyable on a daily basis such as studying a topic you enjoy or having a discussion about something you learned in a class. Therefore, you should select activities across a range of difficulty, with only a few being smaller steps toward more difficult long-term projects. To improve the likelihood of initial success and to help you start this program, some of the activities you choose should be activities you already are doing regularly but would like to increase in frequency or duration (see your Behavioral Checkout Sheets for assistance). We will now add activities to your Behavioral Checkout Sheets together and you will continue adding to them and editing them for homework.

By now, you will have identified many activities for each of the values in your life areas. Today, we will schedule activities for you to engage in over the next two weeks. As you select an activity, add it to the corresponding Behavioral

Checkout Sheet. Go ahead add your activities to each of these 14 Behavioral Checkout Sheets.

1. Family Relationships 
Value:

- Activity 1:

- Activity 2:

- Activity 3:

- Activity 4:

- Activity 5:

Value:

- Activity 1:

- Activity 2:

- Activity 3:

- Activity 4:

- Activity 5:

\section{Value:}

- Activity 1:

- Activity 2:

- Activity 3:

- Activity 4:

- Activity 5: 
2. Social Relationships

\begin{tabular}{|l|}
\hline Value: \\
\hline$\bullet \quad \underline{\text { Activity 1: }}$ \\
\hline$\bullet \underline{\text { Activity 2: }}$ \\
\hline$\bullet \underline{\text { Activity 3: }}$ \\
\hline$\bullet \underline{\text { Activity 4: }}$ \\
\hline$\bullet \underline{\text { Activity 5: }}$ \\
\hline
\end{tabular}

\begin{tabular}{|l|}
\hline Value: \\
\hline$\bullet \quad \underline{\text { Activity 1: }}$ \\
\hline$\bullet \quad \underline{\text { Activity 2: }}$ \\
\hline$\bullet \quad \underline{\text { Activity 3: }}$ \\
\hline$\bullet \underline{\text { Activity 4: }}$ \\
\hline$-\underline{\text { Activity 5: }}$ \\
\hline
\end{tabular}

\begin{tabular}{|l|}
\hline Value: \\
\hline$\bullet \quad \underline{\text { Activity 1: }}$ \\
\hline$\bullet \underline{\text { Activity 2: }}$ \\
\hline$\bullet \underline{\text { Activity 3: }}$ \\
\hline$\bullet \underline{\text { Activity 4: }}$ \\
\hline$\bullet \underline{\text { Activity 5: }}$ \\
\hline
\end{tabular}




\section{Intimate Relationships}

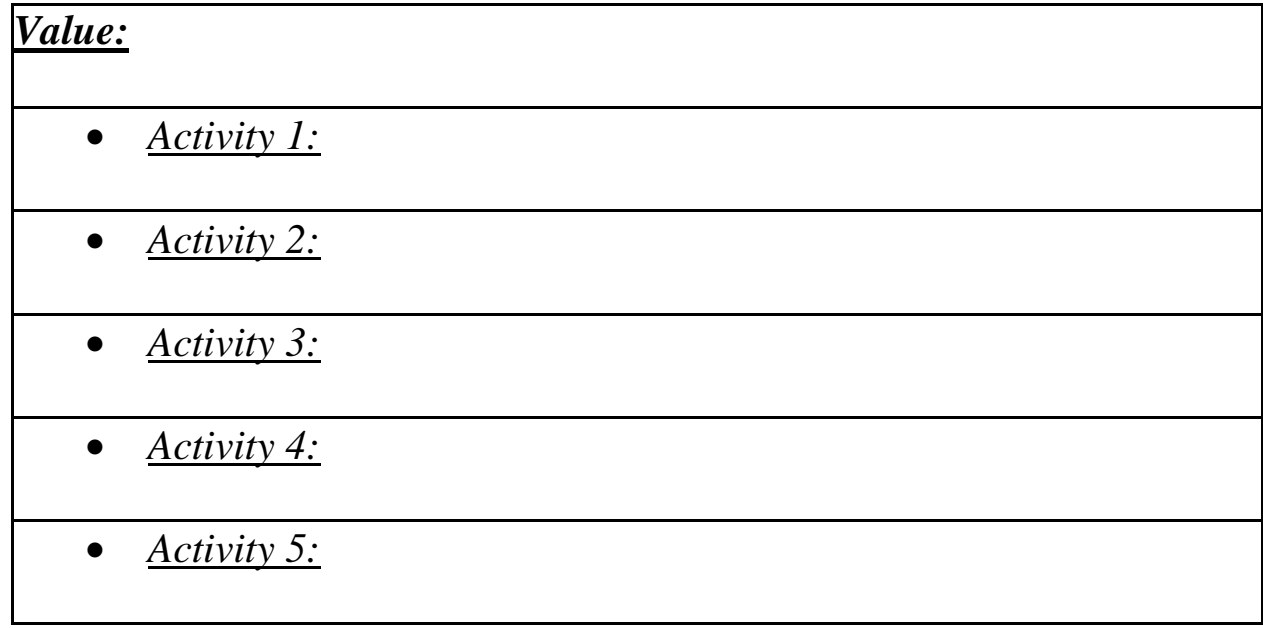

\begin{tabular}{|l|l|}
\hline \multicolumn{1}{|l|}{ Value: } \\
\hline$\bullet$ & $\underline{\text { Activity 1: }}$ \\
\hline$\bullet$ & Activity 2: \\
\hline & $\underline{\text { Activity 3: }}$ \\
\hline & $\underline{\text { Activity 4: }}$ \\
\hline & $\underline{\text { Activity 5: }}$ \\
\hline
\end{tabular}

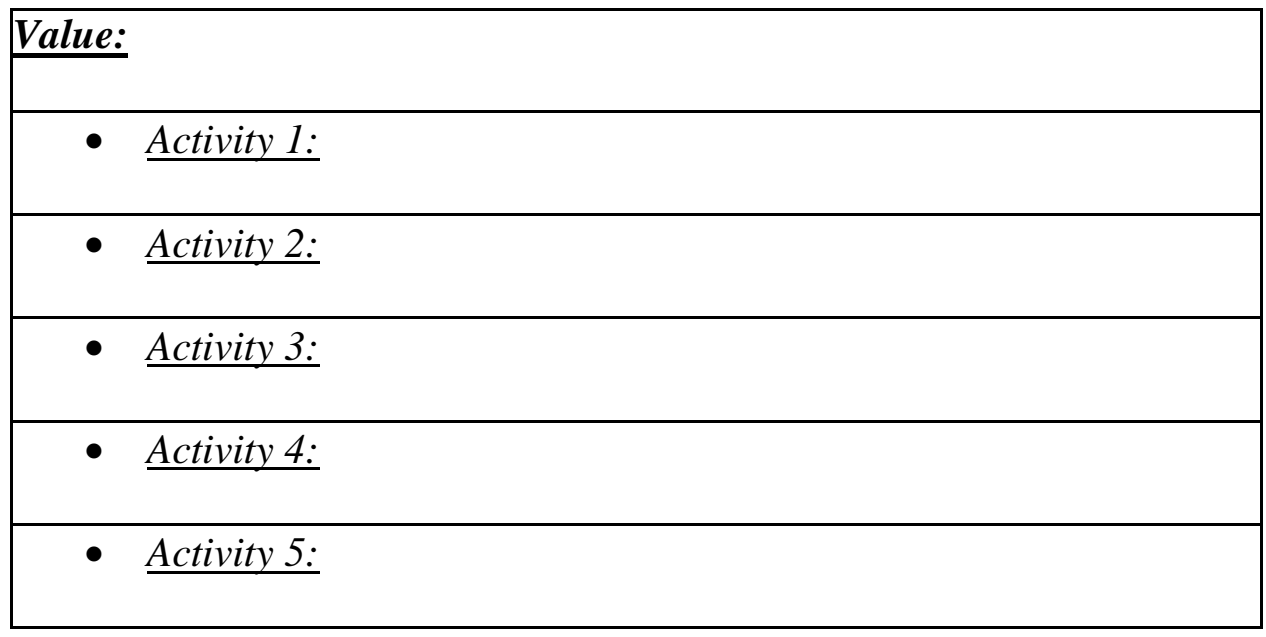




\section{Education/Training}

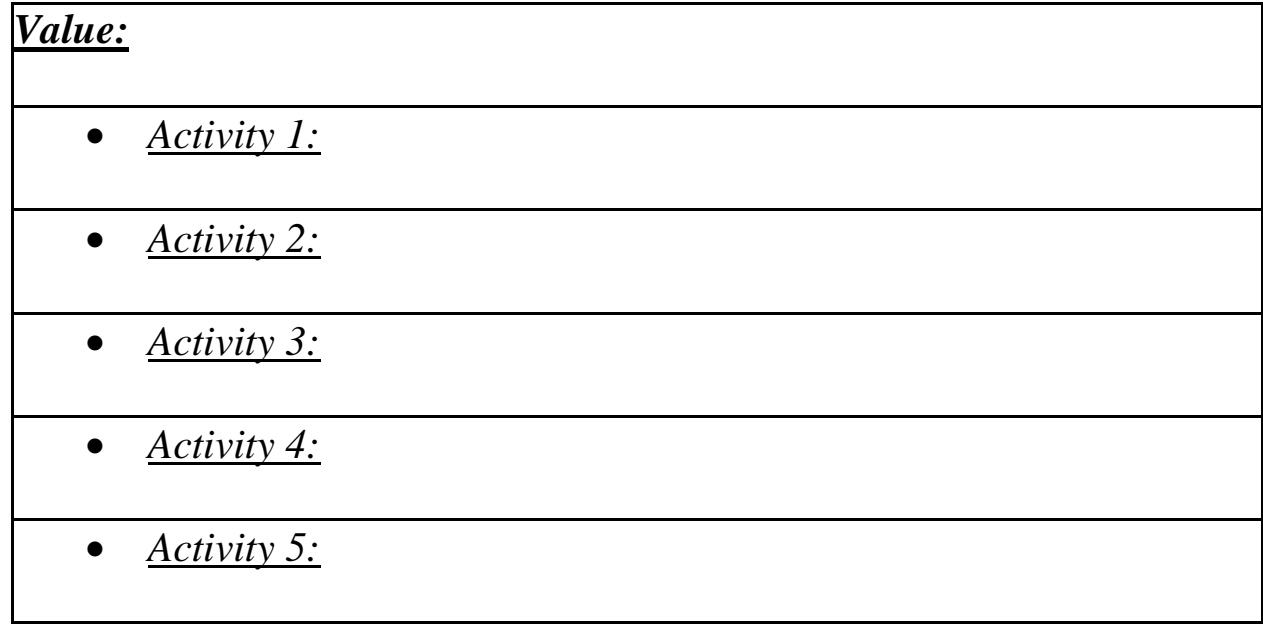

\begin{tabular}{|l|l|}
\hline \multicolumn{1}{|l|}{ Value: } \\
\hline$\bullet$ & $\underline{\text { Activity 1: }}$ \\
\hline$\bullet$ & Activity 2: \\
\hline & $\underline{\text { Activity 3: }}$ \\
\hline & $\underline{\text { Activity 4: }}$ \\
\hline & $\underline{\text { Activity 5: }}$ \\
\hline
\end{tabular}

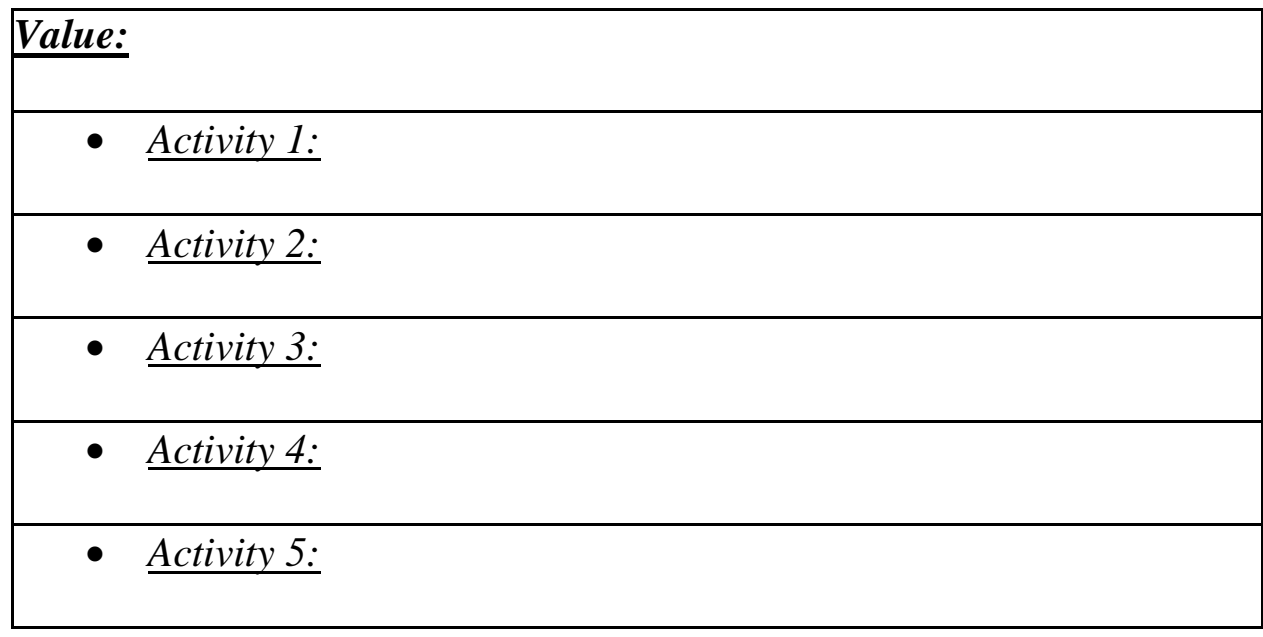




\section{Hobbies/ Recreation}

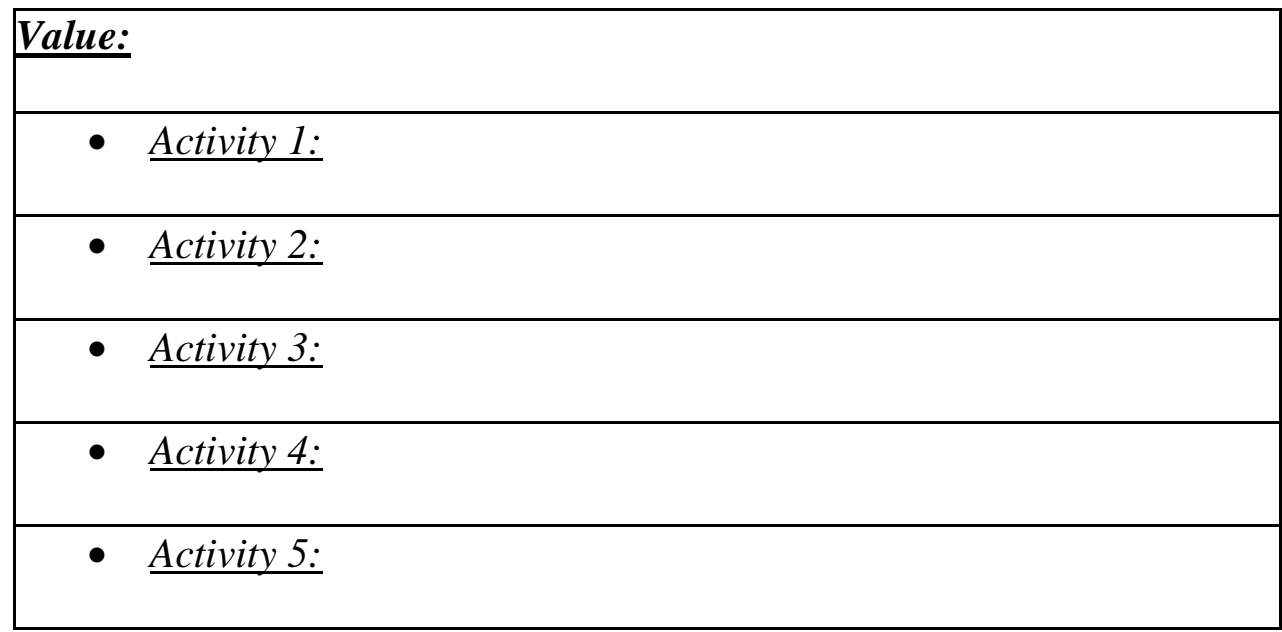

\begin{tabular}{|l|}
\hline Value: \\
\hline$\bullet \quad \underline{\text { Activity 1: }}$ \\
\hline$\bullet \quad \underline{\text { Activity 2: }}$ \\
\hline$\bullet \underline{\text { Activity 3: }}$ \\
\hline$-\underline{\text { Activity 4: }}$ \\
\hline$\bullet \quad$ Activity 5: \\
\hline
\end{tabular}

\begin{tabular}{|l|}
\hline Value: \\
\hline$\bullet \quad \underline{\text { Activity 1: }}$ \\
\hline$\bullet \underline{\text { Activity 2: }}$ \\
\hline$\bullet \underline{\text { Activity 3: }}$ \\
\hline Activity 4: \\
\hline$\bullet \underline{\text { Activity 5: }}$ \\
\hline
\end{tabular}




\section{Physical/ Health Issues}

\begin{tabular}{|l|}
\hline Value: \\
\hline$\bullet \quad \underline{\text { Activity 1: }}$ \\
\hline$\bullet \underline{\text { Activity 2: }}$ \\
\hline$\bullet \underline{\text { Activity 3: }}$ \\
\hline$\bullet \underline{\text { Activity 4: }}$ \\
\hline$\bullet \underline{\text { Activity 5: }}$ \\
\hline
\end{tabular}

\begin{tabular}{|l|}
\hline Value: \\
\hline$\bullet \quad \underline{\text { Activity 1: }}$ \\
\hline$\bullet \quad \underline{\text { Activity 2: }}$ \\
\hline$\bullet \quad \underline{\text { Activity 3: }}$ \\
\hline$\bullet \underline{\text { Activity 4: }}$ \\
\hline$\bullet \quad$ Activity 5: \\
\hline
\end{tabular}

\begin{tabular}{|l|}
\hline Value: \\
\hline$\bullet \quad \underline{\text { Activity 1: }}$ \\
\hline$\bullet \underline{\text { Activity 2: }}$ \\
\hline$\bullet \underline{\text { Activity 3: }}$ \\
\hline$-\underline{\text { Activity 4: }}$ \\
\hline$\bullet \quad$ Activity 5: \\
\hline
\end{tabular}




\section{Spirituality}

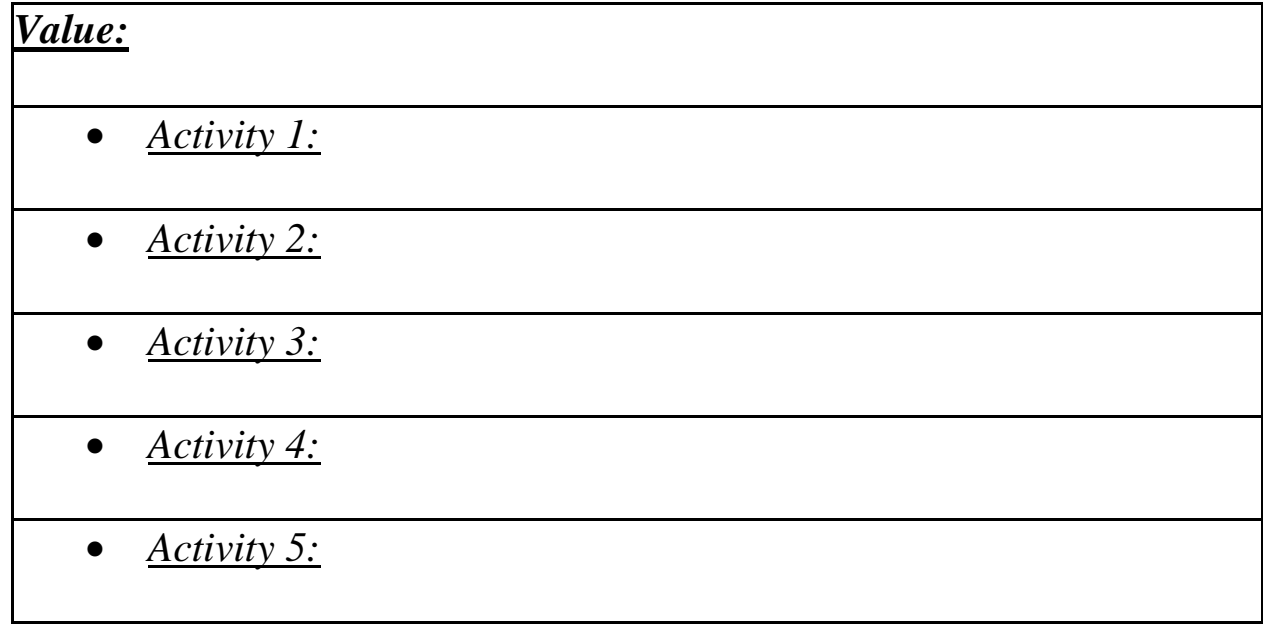

\begin{tabular}{|l|l|}
\hline \multicolumn{1}{|l|}{ Value: } \\
\hline$\bullet$ & $\underline{\text { Activity 1: }}$ \\
\hline$\bullet$ & Activity 2: \\
\hline & $\underline{\text { Activity 3: }}$ \\
\hline & $\underline{\text { Activity 4: }}$ \\
\hline & $\underline{\text { Activity 5: }}$ \\
\hline
\end{tabular}

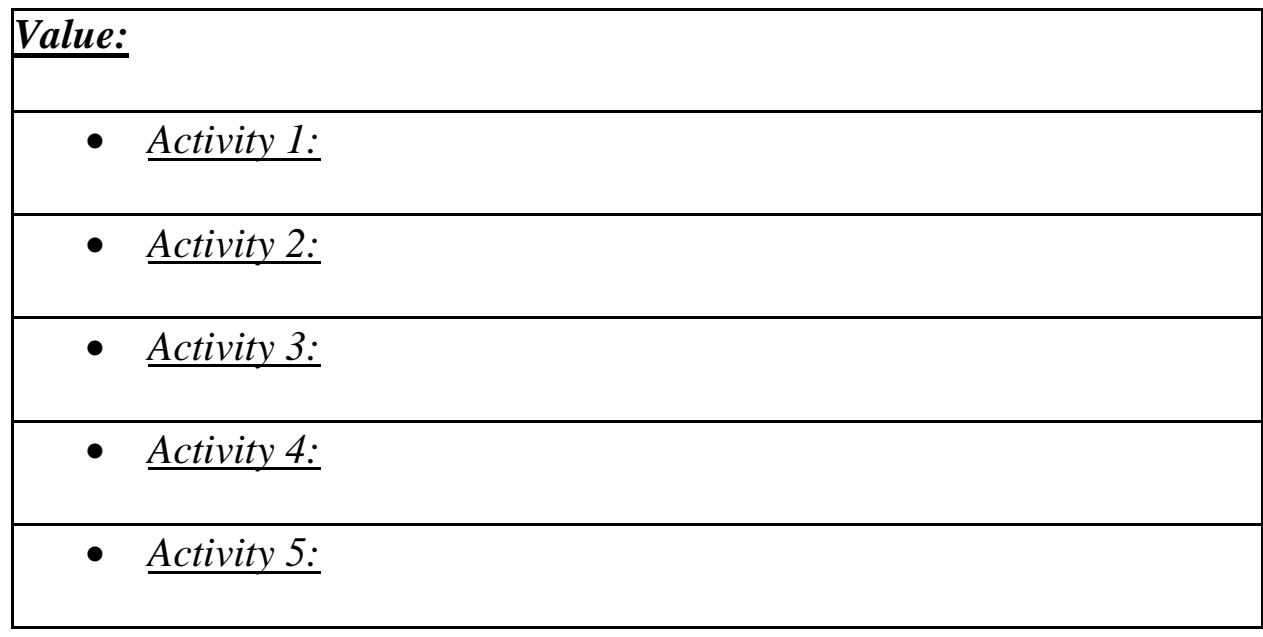




\section{$\underline{\text { 8. Psychological/Anxiety/Avoidance Issues }}$}

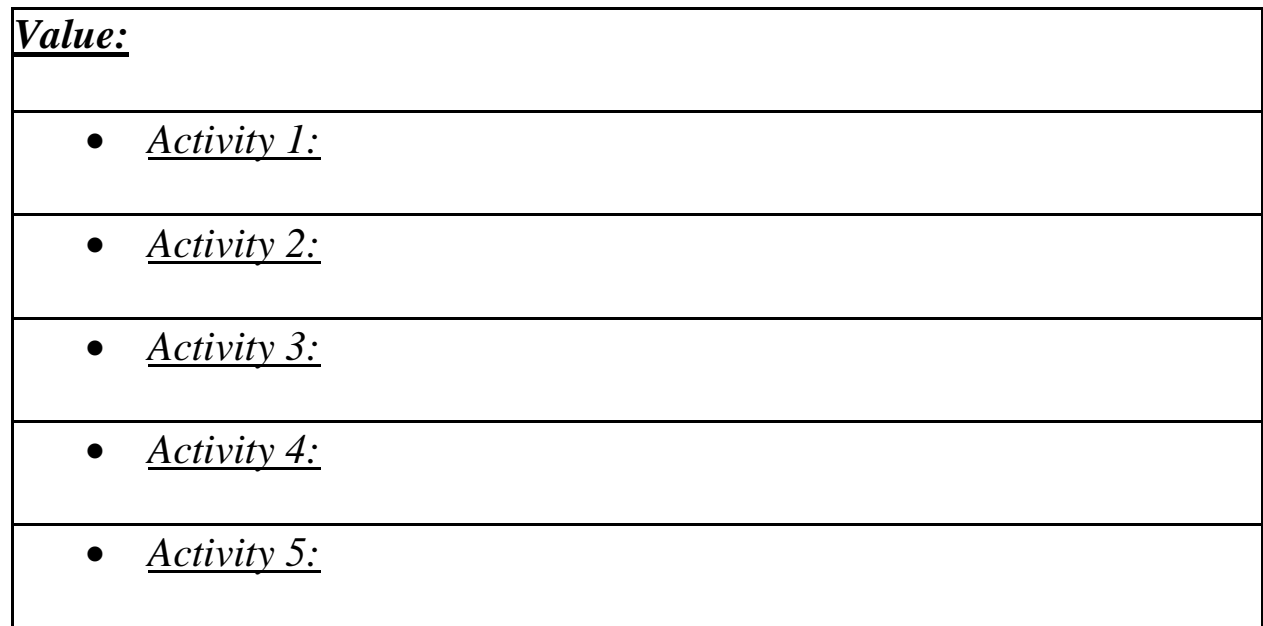

Value:

- Activity 1:

- Activity 2:

- Activity 3:

- Activity 4:

- Activity 5:

Value:

- Activity 1:

- Activity 2:

- Activity 3:

- Activity 4:

- Activity 5: 


\section{Behavioral Checkout Sheets:}

- Based on the Life Areas assessment, identify 8-10 values based activities from the Life Areas Assessment that the student will monitor over the next two weeks and enter them into the Behavioral Checkout Sheets across the next two weeks.

- In general, if you believe that completing a particular activity would bring a sense of pleasure and/or accomplishment, then it probably would be good to include it. When selecting activities, they should be both observable by others and measurable.

- Now that you have identified the 8-10 target activities, you will need a plan for how you will assess your progress.

- The Behavioral Checkout Sheets are a useful way of tracking your progress on a weekly basis. In the first column, we will list your activities. In the second and third columns you will rate how enjoyable and important each event was to you.

- Give rationale for activity tracking (see below)

\section{Rationale for activity tracking:}

Because the main focus of this intervention is increasing your healthy behavior, it is important to become aware of what you do each day. Although you probably have an idea of how you spend your time, we really need exact information about what you are doing each day. To that end, we would like you to spend the next week writing down all of your activities. This is useful for several reasons. First, it will help us to identify the pattern of your depressed behaviors and moods. Every person is different, so it is important for us both to see how depression is affecting your daily activities. Being aware of your patterns might motivate you to increase your healthy activity level. Second, this will provide us a measure of your activity level which we will then be able to compare with your activity level in treatment, after you have been using the treatment strategies. Finally, a close look at your daily routine might lead you to develop some ideas about where you might consider adding some healthy activities to each day following treatment to prevent further symptoms of depression. To monitor your current activities, you keep a detailed log (hour by hour) of all activities that you do, including those that seem insignificant, such as sleeping or watching television. You will use the Daily 
Monitoring Form to record your activities both scheduled and unscheduled throughout the study. You will need to complete one form for each day.

\section{- BEHAVIOR CHECKOUT}

- "Now you are ready to record your activity and progress on a daily basis using the daily behavior checkout sheets. Let's write down your behaviors as well as the level of enjoyment and importance of said activity in the appropriate columns for each activity."

- "You are to track all daily activities (See above)"

- "You have 14 behavior checkout sheets. Seven for Week 1 and Seven for Week 2."

- "Each day you circle a scheduled activity if you completed the activity and write an $N$ beside it if you did not."

- "To ensure that you maintain accurate records, it is best if you allocate a specific time of the day to complete this task (e.g., before bedtime)."

- "Remember - It is essential that you bring ALL 14 behavioral checkout sheets back with you to your second meeting with me".

- See next page for form 


\section{Behavioral Checkout Sheet}

\begin{tabular}{|c|c|c|c|}
\hline Time & Activity & $\begin{array}{c}\text { Enjoyment } \\
(0-10)\end{array}$ & $\begin{array}{c}\text { Importance } \\
(0-10)\end{array}$ \\
\hline $5-6 \mathrm{am}$ & & & \\
\hline 6-7 am & & & \\
\hline 7-8 am & & & \\
\hline 8-9 am & & & \\
\hline $9-10 \mathrm{am}$ & & & \\
\hline $10-11 \mathrm{am}$ & & & \\
\hline $11-12 \mathrm{am}$ & & & \\
\hline $12-1 \mathrm{pm}$ & & & \\
\hline $1-2 \mathrm{pm}$ & & & \\
\hline $2-3 \mathrm{pm}$ & & & \\
\hline 3-4 pm & & & \\
\hline $4-5 \mathrm{pm}$ & & & \\
\hline $5-6 \mathrm{pm}$ & & & \\
\hline 6-7 pm & & & \\
\hline 7-8 pm & & & \\
\hline $8-9 \mathrm{pm}$ & & & \\
\hline 9-10 pm & & & \\
\hline $10-11 \mathrm{pm}$ & & & \\
\hline $11-12 \mathrm{pm}$ & & & \\
\hline $12-1 \mathrm{am}$ & & & \\
\hline 1-2 am & & & \\
\hline $2 \rightarrow 5 \mathrm{am}$ & & & \\
\hline
\end{tabular}


Overall Mood for the day (0-10) 


\section{Session 1 Conclusion}

- Remind the participant to practice the intervention over the next two weeks.

- If they want cash, have participant complete the tax form (FORM MUST BE COMPLETELY FILLED OUT). After fully completing the form, pay participant $\mathbf{\$ 1 0}$.

- Schedule Session II with participant at least two weeks from Session I. Present participant with appointment card for Session 2. Email the day and time to Rebecca so that she can send a reminder the day before session 2 .

(Date)

(If not able to schedule, ask the participant for days and times that he/she is available in two weeks. Email Rebecca this information so that she can schedule the appointment along with your availability, Rebecca will send the participant an email with a day and time for the next assessment session.)

- Confirm participant knows what they are to do - have them explain in his/her own words what they will be doing

- Remind participant that he/she can email Rebecca regarding any questions they may have over the course of the intervention.

- Provide participant with mental health services list and explain why being given list

- Thank participant for his/her time.

- Inform Rebecca whether participant needs to receive CREDIT FOR PARTICIPATION in session two or if they were given $\$ 10$ from the lock box 


\section{Session 2: 2-Week Follow-Up:}

- CONFIRMATION - Completion of all Materials

- Master Activity Log

- Behavioral Checkout Sheets Y/N

- Use Script Below to Guide Session

Session 2 (clinical)

Assessment Prep: Use Shook laptop in QCC

Username: shooklab

Password: Na2jSh0

Open MediaLab and run experiment

c:lusers\shooklabldesktop\Lee Dissertation\LMDISS_S2.exp

Enter participant ID (see Session 1 note sheet for ID)

Forms: Participant ID/Name record, Session 2 note sheet, BeanFest instructions (2 copies), tax form, mental health services list

Meet participant by 1st floor elevators (may need to check basement and 2nd floor). Ask if participant needs a parking permit and provide as necessary. Escort to experimental room.

Thank participant for his/her time. Ask that all cell phones, ipods, etc. be turned off and put away.

"Thank you for coming back to the lab for the second assessment session. Did you remember to bring your Behavioral Checkout Sheets? (if not, ask that they bring them to Session 3) This session will be just like the first session. Before we begin the second assessment; I'd like to hear a little about what this experience has been like for you, how the tracking went, and what did you learn about yourself? You have spent two weeks scheduling and tracking your activities; what has that been like for you?" (Therapist should look through log if available while doing this; limit discussion to 5 min)

"Today you will complete the BeanFest task, which requires learning whether stimuli are good or bad in order to maximize your outcomes in an imaginary world. You will also be asked to complete several questionnaires that assess mental health issues, life experiences, and general attitudes. The session should take no more than one hour. All information that you provide during the study is completely confidential and anonymous. That is, no one other than study personnel will have access to your data, and your data will not be connected to any personal identifiers (e.g., name, social security number). You have a participant ID, which is how we are able to distinguish between participants' data. Your participation in this study is completely voluntary. At any point, you can end the study without penalty. Also, if there are any questions that you do not want to answer, you may skip them. Do you have any questions?" [answer questions]

"Now, I am going to go over the instructions for BeanFest with you. Please read over the instructions while I read them out loud." [read instructions, answer any questions, start experiment] 
Quietly observe participant and take notes about anything unusual that occurs during the session. Be prepared to answer questions. If participant seems to be rushing or not paying attention, stop him/her and ask participant to follow directions properly/pay attention/read questions.

When participant is done, answer any questions he/she may have. **Check the BDI suicide question (Item 9). If participant reports suicidal thoughts, Contact Dan (304-293-1712 or 304-692-5537).**

If they want cash, have participant complete the tax form (FORM MUST BE COMPLETELY FILLED OUT). After fully completing the form, pay participant \$10. Remind the participant the next session will be in 2 weeks. Schedule Session 3. Present participant with appointment card for session 3.

Thank and dismiss.

$$
* * \text { IMPORTANT** }
$$

If participant chooses to receive cash, be sure to have them fill out tax form, ensure them that their information will be securely kept.

Be very careful when entering ID into MediaLab. Always double check Participant ID entry. This is the only way we will be able to match participants' data across the sessions.

Be very careful when handling the lockbox and money. DO NOT leave the lockbox unlocked or unattended. DO NOT leave money lying out in the QCC.

- CONFIRMATION -

○ Completion of BeanFest and measures

- Schedule Session 3 with participant for at least two weeks from today. Present participant with appointment card for Session 3.

- *If participant did not bring Behavioral Checkout Sheets, remind them to bring sheets to the next session.

- Thank and dismiss.

- Inform Rebecca whether participant needs to receive CREDIT FOR PARTICIPATION in session two or if they were given $\$ 10$ from the lock box 


\title{
Session 3: 1-Month Follow-up and Study Conclusion:
}

- CONFIRMATION - Completion of all Materials

- Master Activity Log

- Behavioral Checkout Sheets (if Not at session 2)

- Use Script Below to Guide Session

\author{
Session 3 (clinical)
}

Prep: Use Shook laptop in QCC

Username: shooklab

Password: Na2jSh0

Open MediaLab and run experiment

c:lusers|shooklabldesktop\Lee Dissertation|LMDISS_S3.exp

Enter participant ID (see Session 1 note sheet for ID)

Forms: Participant ID/Name record, Session 3 note sheet, BeanFest instructions ( 2 copies), tax form, mental health services list

Meet participant by 1st floor elevators (may need to check basement and 2nd floor). Ask if participant needs a parking permit and provide as necessary. Escort to experimental room.

Thank participant for his/her time. Ask that all cell phones, ipods, etc. be turned off and put away.

"Thank you for coming back to the lab for the third assessment session. (**Did you remember to bring your Behavioral Checkout Sheets?) Before we begin the third assessment; I'd like to hear a little about what this experience has been like for you, how has your mood been, and what have you learned about yourself? You spent the previous two weeks scheduling and tracking your activities then spent two weeks between Session 2 and Session 3; what has that been like for you? (limit discussion to $5 \mathrm{~min}$ )

This session will be just like the first two sessions. You will complete the BeanFest task, which requires learning whether stimuli are good or bad in order to maximize your outcomes in an imaginary world. You will also be asked to complete several questionnaires that assess mental health issues, life experiences, and general attitudes. The session should take no more than one hour. All information that you provide during the study is completely confidential and anonymous. That is, no one other than study personnel will have access to your data, and your data will not be connected to any personal identifiers (e.g., name, social security number). You have a participant ID, which is how we are able to distinguish between participants' data. Your participation in this study is completely voluntary. At any point, you can end the study without penalty. Also, if there are any questions that you do not want to answer, you may skip them. Do you have any questions?" [answer questions]

"Now, I am going to go over the instructions for BeanFest with you. Please read over the instructions while I read them out loud." [read instructions, answer any questions, start experiment] 
Quietly observe participant and take notes about anything unusual that occurs during the session. Be prepared to answer questions. If participant seems to be rushing or not paying attention, stop him/her and ask participant to follow directions properly/pay attention/read questions.

When participant is done, answer any questions he/she may have. **Check the BDI suicide question (Item 9). If participant reports have suicidal thoughts contact Dan (304-293-1712 or 304-692-5537).**

Have participant complete the tax form (FORM MUST BE COMPLETELY FILLED OUT). After fully completing the form, pay participant $\mathbf{\$ 1 5}$. Thank and dismiss.

**IMPORTANT**

If participant chooses to receive cash, be sure to have them fill out tax form, ensure them that their information will be securely kept.

Be very careful when entering ID into MediaLab. Always double check Participant ID entry. This is the only way we will be able to match participants' data across the sessions.

Be very careful when handling the lockbox and money. DO NOT leave the lockbox unlocked or unattended. DO NOT leave money lying out in the QCC.

- CONFIRMATION -

○ Completion of BeanFest and measures

- Inform Rebecca whether the participant needs to receive CREDIT FOR PARTICIPATION in session three or if they were given $\$ 15$ from the lock box 


\section{Appendix A:}

- You may or may not have experienced symptoms of depression that include:

- Poor Appetite or Over Eating

- Not getting enough sleep, or sleeping too much, or tiredness

- Low energy or Fatigue

- Low self-Esteem

- Poor Concentration or Difficulty making decisions

- Feelings of Hopelessness

- An unrealistic sense of guilt or worthlessness

- Frequently thinking about failings in the past

- Thoughts about death

- Decreased desire to engage in activities that you once found rewarding 


\section{$\underline{\text { Appendix B }}$}

Intervention Checklist

\begin{tabular}{|l|l|}
\hline & Introduction \\
\hline & Recognizing Depression \\
\hline & The Rationale for BATD \\
\hline & Life Areas Assessment \\
\hline Rationale for Tracking \\
\hline Schedule activities on Behavioral Checkout Sheets \\
\hline Schedule 2 week follow-up appointment \\
\hline Remind Participant to bring Behavioral Checkout Sheets to \\
follow-up
\end{tabular}


Table 1.

Demographic Percentages and Chi-square Statistics Comparing Individuals Invited to Participate in the Study to the Final Sample

\begin{tabular}{|c|c|c|c|c|}
\hline Variables & & $\begin{array}{r}\text { Invited \% } \\
(n=311)\end{array}$ & $\begin{array}{c}\text { Sample \% } \\
(n=39)\end{array}$ & $X^{2}$ \\
\hline \multirow[t]{2}{*}{ Gender } & Male & 17.3 & 18.9 & .063 \\
\hline & Female & 82.7 & 81.1 & \\
\hline \multirow[t]{5}{*}{ Ethnicity } & Black & 3.3 & 10.8 & 4.90 \\
\hline & White & 89.6 & 81.1 & \\
\hline & Hispanic & 2.3 & 2.7 & \\
\hline & Asian & 4.3 & 5.5 & \\
\hline & Other & .3 & 0 & \\
\hline \multirow[t]{2}{*}{ Yoga } & Yes & 14.3 & 18.9 & .550 \\
\hline & No & 85.7 & 81.1 & \\
\hline \multirow[t]{2}{*}{ Meditate } & Yes & 13.4 & 8.1 & .815 \\
\hline & No & 86.6 & 91.9 & \\
\hline \multirow[t]{2}{*}{ Martial Arts } & Yes & 5.5 & 10.8 & .308 \\
\hline & No & 94.5 & 89.2 & \\
\hline
\end{tabular}


Table 2.

Means, Standard Deviations, and Comparisons for All Prescreening Measures for Those Invited to Participate $(n=311)$ and the Final Sample $(n=39)$

\begin{tabular}{llccccc}
\hline Measure & Group & $M$ & $S D$ & $t$ & $d f$ & $p$ \\
\hline \multirow{2}{*}{ BDI-II } & Invited & 20.15 & 6.90 & -1.29 & 347 & .20 \\
& Sample & 18.67 & 3.01 & & & \\
DAS-SF1 & Invited & 21.39 & 4.29 & 1.29 & 344 & .20 \\
& Sample & 22.43 & 5.16 & & & \\
MEAQ & Invited & 217.00 & 30.07 & .03 & 347 & .98 \\
& Sample & 217.15 & 24.84 & & & \\
MAAS & Invited & 49.22 & 11.23 & -.84 & 347 & .40 \\
& Sample & 47.53 & 12.75 & & & \\
ATSPPH-SF & Invited & 26.81 & 5.47 & -.75 & 343 & .46 \\
& Sample & 26.08 & 6.45 & & & \\
MSPSS & Invited & 63.27 & 12.56 & .37 & 344 & .72 \\
& Sample & 64.05 & 9.64 & & & \\
\hline
\end{tabular}

Note. BDI-II = Beck Depression Inventory-II; DAS-SF1-Dysfunctional Attitudes Scale - Short Form 1; MEAQ-Multidimensional Experiential Avoidance Questionnaire; MAAS-Mindful Attention Awareness Scale ATSPPH-SF Attitudes Toward Seeking Professional Psychological Help- Short Form; MSPSS = Multidimensional Scale of Perceived Social Support 
Table 3.

Means, Standard Deviations, and Comparisons for Session 1 Variables for Clinical and Control Group Participants

\begin{tabular}{llllllll}
\hline Measure & Condition & $n$ & $M$ & $S D$ & $t$ & $d f$ & $p$ \\
\hline \multirow{2}{*}{ Age } & Clinical & 20 & 19.60 & 1.273 & -.03 & 37 & .98 \\
& Control & 18 & 19.61 & 1.461 & & & \\
BDI-II & Clinical & 20 & 18.75 & 8.08 & -.07 & 37 & .95 \\
& Control & 18 & 21.56 & 7.13 & & & \\
DAS-SF1 & Clinical & 20 & 21.95 & 6.05 & .35 & 37 & .73 \\
& Control & 18 & 21.22 & 7.06 & & & \\
MEAQ & Clinical & 20 & 211.38 & 43.31 & -.93 & 37 & .36 \\
\multirow{2}{*}{ MAAS } & Control & 18 & 222.22 & 26.26 & & & \\
& Clinical & 20 & 50.29 & 14.69 & 1.11 & 37 & .27 \\
\multirow{2}{*}{ ATSPPH-SF } & Control & 18 & 45.50 & 11.79 & & & \\
& Clinical & 20 & 27.25 & 6.08 & -1.21 & 37 & .23 \\
MSPSS & Control & 18 & 27.39 & 6.70 & & & \\
& Clinical & 20 & 55.75 & 16.61 & -.62 & 37 & .54 \\
& Control & 18 & 61.67 & 12.99 & & & \\
\hline
\end{tabular}

Note. BDI-II = Beck Depression Inventory-II; DAS-SF1-Dysfunctional Attitudes Scale - Short Form 1; MEAQ-Multidimensional Experiential Avoidance Questionnaire; MAAS-Mindful Attention Awareness Scale ATSPPH-SF Attitudes Toward Seeking Professional Psychological Help- Short Form; MSPSS = Multidimensional Scale of Perceived Social Support 
Table 4.

Demographic Percentages and Chi-square Statistics Comparing Clinical and Control Groups

\begin{tabular}{|c|c|c|c|c|}
\hline Variables & & $\begin{array}{c}\text { Clinical \% } \\
(n=21)\end{array}$ & $\begin{array}{c}\text { Control \% } \\
(n=18)\end{array}$ & $X^{2}$ \\
\hline \multirow[t]{2}{*}{ Gender } & Male & 23.8 & 16.7 & .30 \\
\hline & Female & 76.2 & 83.3 & \\
\hline \multirow[t]{5}{*}{ Ethnicity } & Black & 5.0 & 11.1 & 1.7 \\
\hline & White & 90.0 & 77.8 & \\
\hline & Hispanic & 0 & 5.6 & \\
\hline & Asian & 5.0 & 5.6 & \\
\hline & Other & .3 & 0 & \\
\hline \multirow[t]{2}{*}{ Yoga } & Yes & 57.1 & 50.0 & .19 \\
\hline & No & 42.9 & 50.0 & \\
\hline \multirow[t]{2}{*}{ Meditate } & Yes & 28.6 & 16.7 & .77 \\
\hline & No & 71.4 & 83.3 & \\
\hline \multirow[t]{2}{*}{ Pray Daily } & Yes & 9.5 & 22.2 & 1.20 \\
\hline & No & 90.5 & 77.8 & \\
\hline
\end{tabular}


Table 5

Means, Standard Deviations, Cronbach's Alphas, and Bivariate Correlations for All Measures at Session $1(n=39)$.

\begin{tabular}{|c|c|c|c|c|c|c|c|c|c|c|}
\hline Measure & 1 & 2 & 3 & 4 & 5 & 6 & 7 & $M$ & $S D$ & $\alpha$ \\
\hline 1. BDI-II & & $.47 * *$ & $.50 * *$ & $-.65 * *$ & $.58^{* *}$ & .01 & .18 & 19.56 & 8.23 & .77 \\
\hline 2. BAI & & & $.25^{* *}$ & $-.25 * *$ & $.34 *$ & -.05 & .21 & 13.05 & 8.40 & .88 \\
\hline 3. DAS-SF1 & & & & $-.53 * *$ & $.42 * *$ & .24 & $-.42 * *$ & 21.62 & 6.46 & .91 \\
\hline 4. MAAS & & & & & $-.68 * *$ & $-.44 * *$ & .10 & 48.08 & 13.48 & .89 \\
\hline 5. MEAQ & & & & & & $.36^{*}$ & -.03 & 216.38 & 36.41 & .91 \\
\hline 6. MSPSS & & & & & & & .21 & 58.28 & 15.00 & .93 \\
\hline 7. ATSPPH-SF & & & & & & & & 27.41 & 6.24 & .84 \\
\hline
\end{tabular}

Note. BDI-II = Beck Depression Inventory-II, BAI = Beck Anxiety Inventory-II, DAS-SF $=$ Dysfunctional Attitudes Scale - Short Form, MAAS = Mindful Attention Awareness Scale, MEAQ- Multidemensional Experiential Avoidance Scale ATSPPH-SF Attitudes Toward Seeking Professional Psychological Help- Short Form; MSPSS = Multidimensional Scale of Perceived Social Support $* * p<.01, * p<.05$. 
Table 6

Means, Standard Deviations, Cronbach's Alphas, and Bivariate Correlations for All Measures at Session $2(n=33)$.

\begin{tabular}{|c|c|c|c|c|c|c|c|c|c|c|}
\hline Measure & 1 & 2 & 3 & 4 & 5 & 6 & 7 & $M$ & $S D$ & $\alpha$ \\
\hline 1. BDI-II & & $.520 * *$. & .300 & -.477 & .470 & -.213 & -.154 & 5.26 & 4.58 & .544 \\
\hline 2. BAI & & & .310 & $-.469 * *$ & $.519 * *$ & .064 & .007 & 10.69 & 7.53 & .863 \\
\hline 3. DAS-SF & & & & $-.614 * *$ & $.460 * *$ & .039 & -.425 & 20.82 & 6.69 & .911 \\
\hline 4. MAAS & & & & & $-.551 * *$ & -.032 & .251 & 50.15 & 14.01 & .903 \\
\hline 5. MEAQ & & & & & & .145 & -.151 & 210.33 & 38.10 & .930 \\
\hline 6. MSPSS & & & & & & & .075 & 58.79 & 16.42 & .943 \\
\hline 7. ATSPPH-SF & & & & & & & & 27.67 & 6.23 & .837 \\
\hline
\end{tabular}

Note . BDI-II = Beck Depression Inventory-II, BAI = Beck Anxiety Inventory-II, DAS-SF $=$ Dysfunctional Attitudes Scale - Short Form, MAAS = Mindful Attention Awareness Scale, MEAQ- Multidemensional Experiential Avoidance Scale ATSPPH-SF Attitudes Toward Seeking Professional Psychological Help- Short Form; MSPSS = Multidimensional Scale of Perceived Social Support

$* * p<.01, * p<.05$. 
Table 7

Means, Standard Deviations, Cronbach's Alphas, and Bivariate Correlations for All Measures at Session $3(n=23)$.

\begin{tabular}{|c|c|c|c|c|c|c|c|c|c|c|}
\hline Measure & 1 & 2 & 3 & 4 & 5 & 6 & 7 & $M$ & $S D$ & $\alpha$ \\
\hline 1. BDI-II & & $.564 * *$ & $.396^{*}$ & $-.487 * *$ & $.332 *$ & -.052 & -.258 & 11.92 & 9.09 & .861 \\
\hline 2. BAI & & & $.370^{*}$ & $-.549 * *$ & $.396^{*}$ & .005 & -.163 & 9.64 & 6.91 & .840 \\
\hline 3. DAS-SF & & & & -.632 & $.351 *$ & .033 & -.477 & 20.46 & 7.02 & .926 \\
\hline 4. MAAS & & & & & $-.505^{* *}$ & -.084 & .295 & 50.33 & 14.85 & .919 \\
\hline 5. MEAQ & & & & & & $.329 *$ & -.107 & 208.77 & 37.90 & .931 \\
\hline 6. MSPSS & & & & & & & $.367^{*}$ & 59.44 & 14.73 & .915 \\
\hline 7. ATSPPH-SF & & & & & & & & 27.64 & 6.30 & .845 \\
\hline
\end{tabular}

Note. BDI-II = Beck Depression Inventory-II, BAI = Beck Anxiety Inventory-II, DAS-SF $=$ Dysfunctional Attitudes Scale - Short Form, MAAS = Mindful Attention Awareness Scale, MEAQ- Multidemensional Experiential Avoidance Scale ATSPPH-SF Attitudes Toward Seeking Professional Psychological Help- Short Form; MSPSS = Multidimensional Scale of Perceived Social Support

$* * p<.01, * p<.05$. 
Table 8 .

Means, Standard Deviations, and Comparisons of MAAS Scores for Individuals with and without a History of Mindfulness-related Practices.

\begin{tabular}{llcccccc}
\hline Practice & History & $n$ & $M$ & $S D$ & $t$ & $d f$ & $p$ \\
\hline Yoga & Yes & 21 & 47.86 & 14.44 & -.109 & 37 & .91 \\
& No & 18 & 48.33 & 12.68 & & & \\
Meditation & Yes & 9 & 49.22 & 12.82 & .287 & 37 & .78 \\
& No & 30 & 47.73 & 13.86 & & & \\
Pray daily & Yes & 6 & 47.17 & 11.09 & -.178 & 37 & .86 \\
& No & 33 & 48.24 & 14.01 & & & \\
\hline
\end{tabular}


Table 9.

Demographic Percentages and Chi-square Statistics Comparing Study Completers and NonCompleters at Prescreening.

\begin{tabular}{llccc}
\hline Variables & & $\begin{array}{c}\text { Completer } \% \\
(n=24)\end{array}$ & $\begin{array}{c}\text { Non-Completer } \% \\
(n=15)\end{array}$ & $X^{2}$ \\
\hline \multirow{2}{*}{ Gender } & Male & 12.5 & 33.3 & 2.5 \\
& Female & 87.5 & 66.7 & \\
& Black & 8.7 & 6.7 & .81 \\
& White & 82.6 & 86.7 & \\
& Hispanic & 4.3 & 0.0 & \\
& Asian & 4.3 & 6.7 & \\
& Other & 0.0 & 0.0 & .003 \\
Yoga & Yes & 54.2 & 53.3 & .18 \\
& No & 45.8 & 46.7 & \\
Meditate & Yes & 20.8 & 26.7 & 1.4 \\
& No & 79.2 & 73.3 & \\
\hline \multirow{7}{*}{ Pray Daily } & Yes & 20.8 & 6.7 & \\
& No & 79.2 & 93.3 & \\
\hline
\end{tabular}


Table 10.

Means, Standard Deviations, and Comparisons for Prescreening Variables for Study Completers $(n=24)$ and Non-Completers $(n=15)$.

\begin{tabular}{lllllll}
\hline Measure & Condition & $M$ & $S D$ & $t$ & $d f$ & $p$ \\
\hline \multirow{2}{*}{ BDI-II } & Completer & 18.54 & 2.90 & -.39 & 37 & .70 \\
& Non-Completer & 18.93 & 3.17 & & & \\
\multirow{2}{*}{ DAS-SF1 } & Completer & 23.14 & 4.43 & 1.26 & 32 & .22 \\
& Non-Completer & 20.92 & 5.82 & & & \\
MEAQ & Completer & 220.57 & 21.91 & 1.43 & 32 & .16 \\
& Non-Completer & 208.15 & 28.39 & & & \\
MAAS & Completer & 48.69 & 13.28 & .62 & 36 & .54 \\
& Non-Completer & 46.13 & 11.24 & & & \\
ATSPPH-SF & Completer & 25.41 & 6.32 & -.35 & 37 & .72 \\
& Non-Completer & 26.20 & 7.06 & & & \\
MSPSS & Completer & 63.50 & 8.95 & .30 & 37 & .97 \\
& Non-Completer & 63.40 & 11.87 & & & \\
\hline
\end{tabular}

Note. BDI-II = Beck Depression Inventory-II; DAS-SF1-Dysfunctional Attitudes Scale - Short Form 1; MEAQ-Multidimensional Experiential Avoidance Questionnaire; MAAS-Mindful Attention Awareness Scale ATSPPH-SF Attitudes Toward Seeking Professional Psychological Help- Short Form; MSPSS = Multidimensional Scale of Perceived Social Support 


\section{CONSORT Flow Diagram}

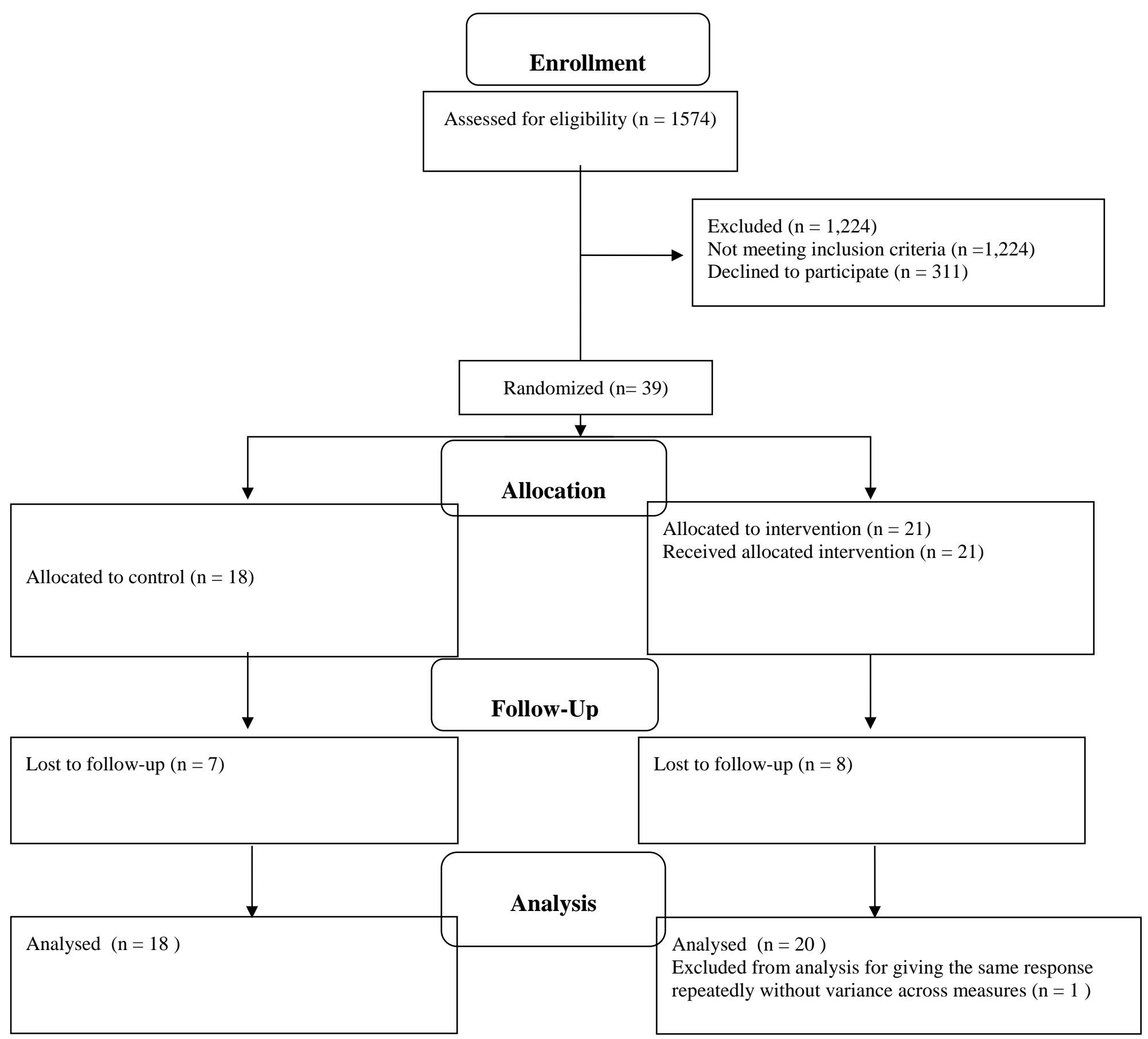

Figure 1. Flow diagram of the study's randomization and attrition process. 


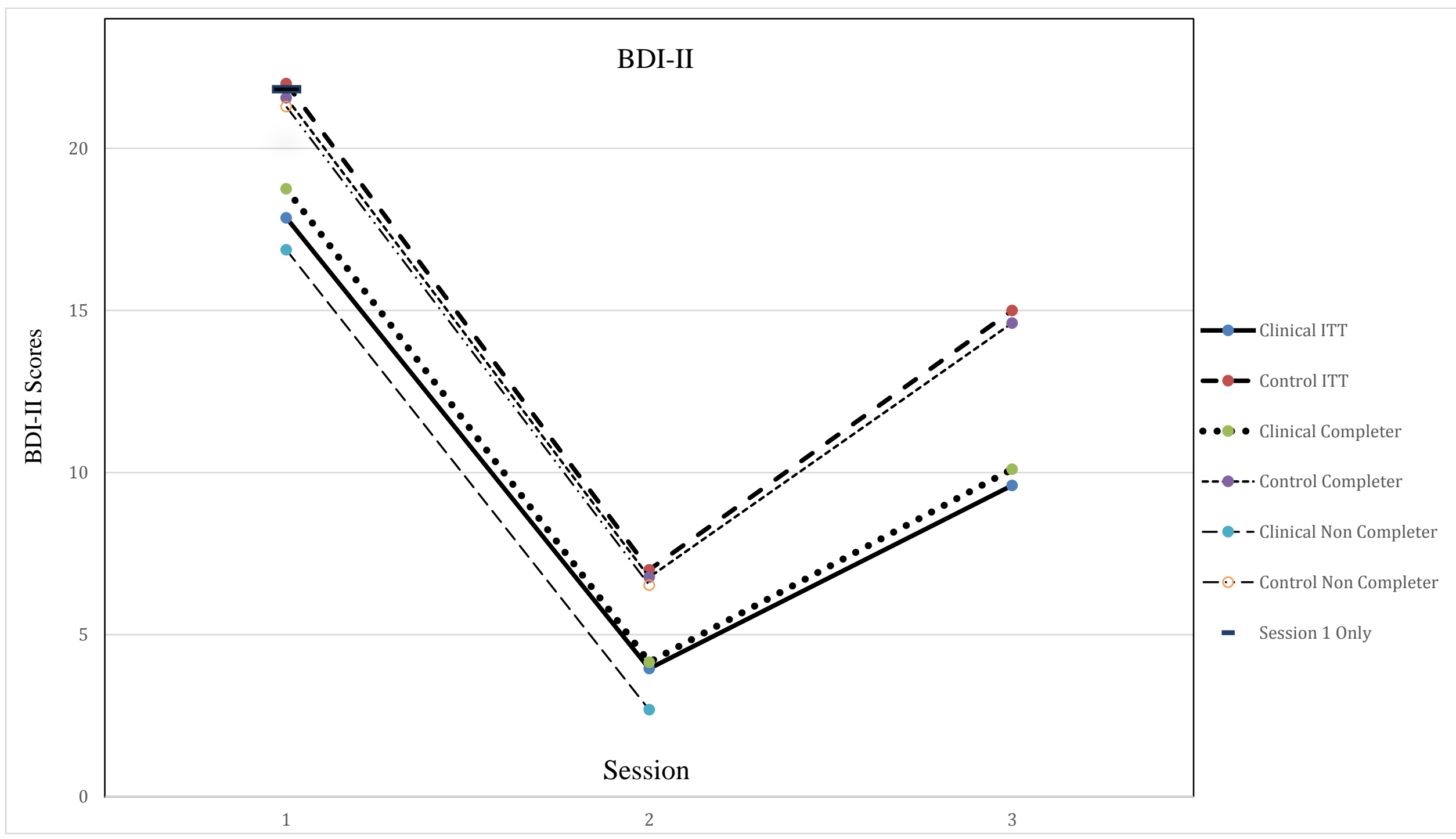

Figure 2. Attrition and BDI-II scores across sessions for clinical and control participants who completed Sessions 1, 2, or 3. 


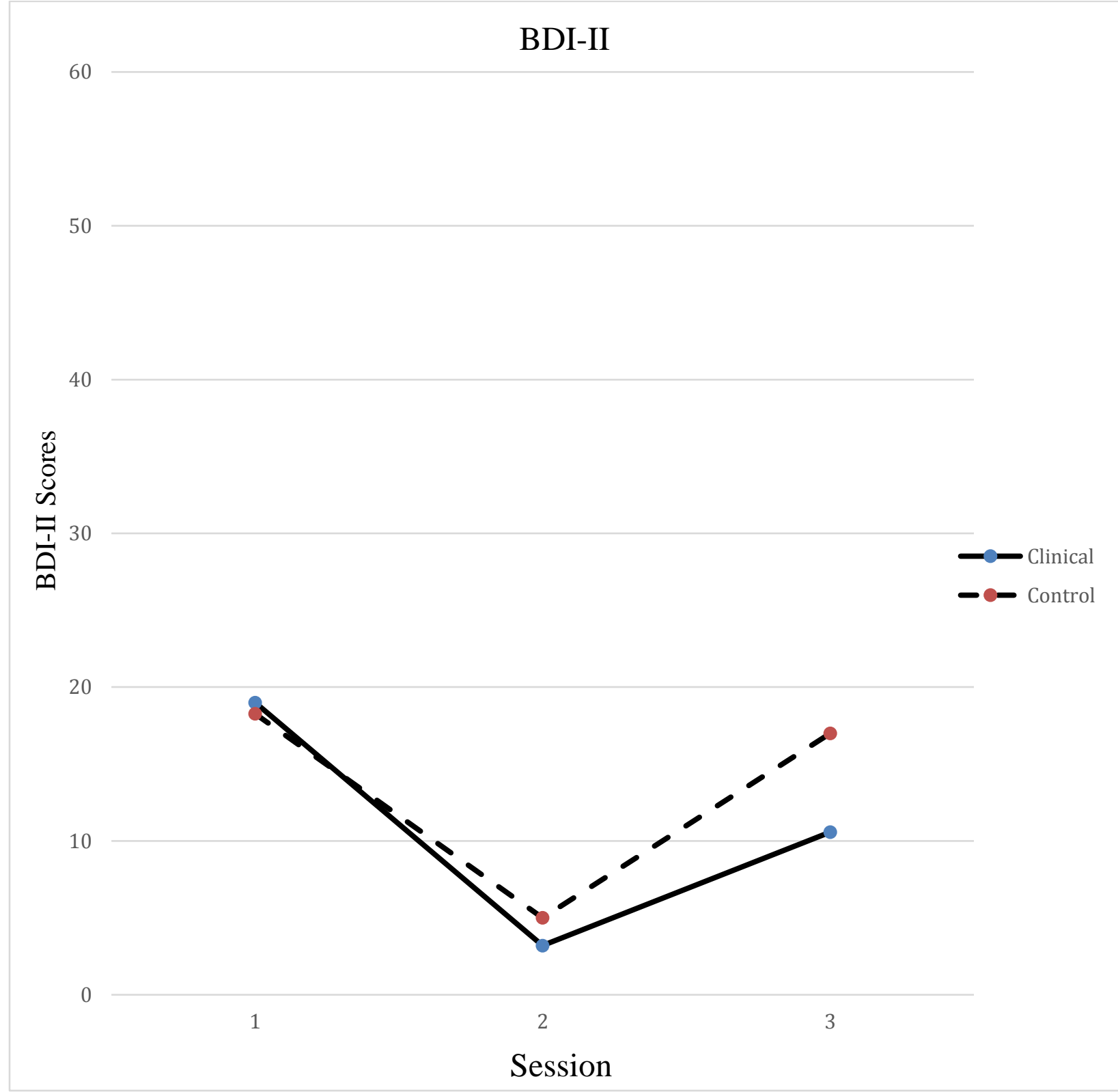

Figure 3. Changes in BDI-II scores across sessions for clinical and control groups. 